\title{
BWR Spent Nuclear Fuel Integrity Research and Development Survey for UKABWR Spent Fuel Interim Storage
}

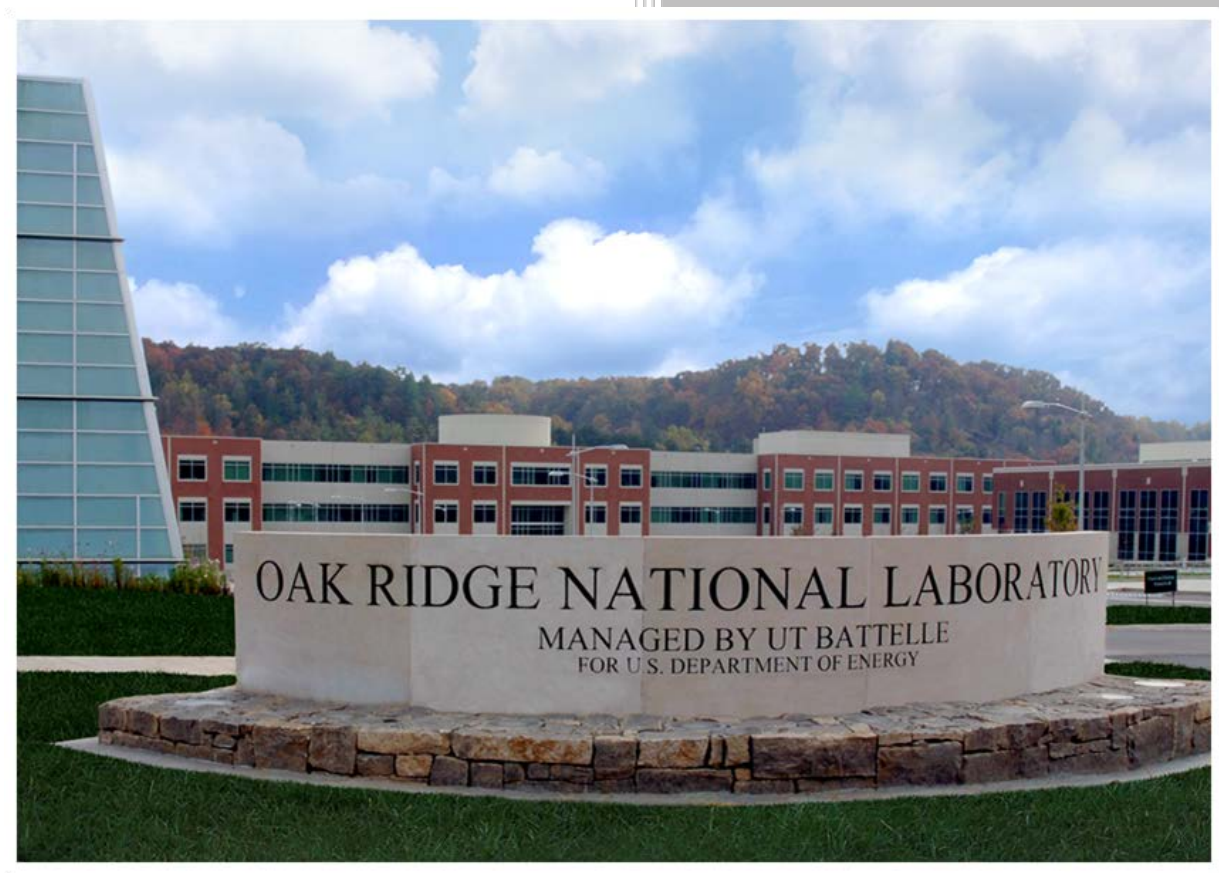

B. B. Bevard U. Mertyurek R. J. Belles J. M. Scaglione October 2015 


\title{
DOCUMENT AVAILABILITY
}

Reports produced after January 1, 1996, are generally available free via US Department of Energy (DOE) SciTech Connect.

\section{Website http://www.osti.gov/scitech/}

Reports produced before January 1, 1996, may be purchased by members of the public from the following source:

\author{
National Technical Information Service \\ 5285 Port Royal Road \\ Springfield, VA 22161 \\ Telephone 703-605-6000 (1-800-553-6847) \\ TDD 703-487-4639 \\ Fax 703-605-6900 \\ E-mail info@ntis.gov \\ Website http://www.ntis.gov/help/ordermethods.aspx
}

Reports are available to DOE employees, DOE contractors, Energy Technology Data Exchange representatives, and International Nuclear Information System representatives from the following source:

Office of Scientific and Technical Information

PO Box 62

Oak Ridge, TN 37831

Telephone 865-576-8401

Fax 865-576-5728

E-mail reports@osti.gov

Website http://www.osti.gov/contact.html

This report was prepared as an account of work sponsored by an agency of the United States Government. Neither the United States Government nor any agency thereof, nor any of their employees, makes any warranty, express or implied, or assumes any legal liability or responsibility for the accuracy, completeness, or usefulness of any information, apparatus, product, or process disclosed, or represents that its use would not infringe privately owned rights. Reference herein to any specific commercial product, process, or service by trade name, trademark, manufacturer, or otherwise, does not necessarily constitute or imply its endorsement, recommendation, or favoring by the United States Government or any agency thereof. The views and opinions of authors expressed herein do not necessarily state or reflect those of the United States Government or any agency thereof. 
Reactor and Nuclear Systems Division

\title{
BWR SPENT NUCLEAR FUEL INTEGRITY RESEARCH AND DEVELOPMENT SURVEY FOR UKABWR SPENT FUEL INTERIM STORAGE
}

\author{
B. B. Bevard \\ U. Mertyurek \\ R. J. Belles \\ J. M. Scaglione
}

Date Published: October 2015

Prepared by OAK RIDGE NATIONAL LABORATORY

Oak Ridge, TN 37831-6283

managed by

UT-BATTELLE, LLC

for the

US DEPARTMENT OF ENERGY

under contract DE-AC05-00OR22725 



\section{CONTENTS}

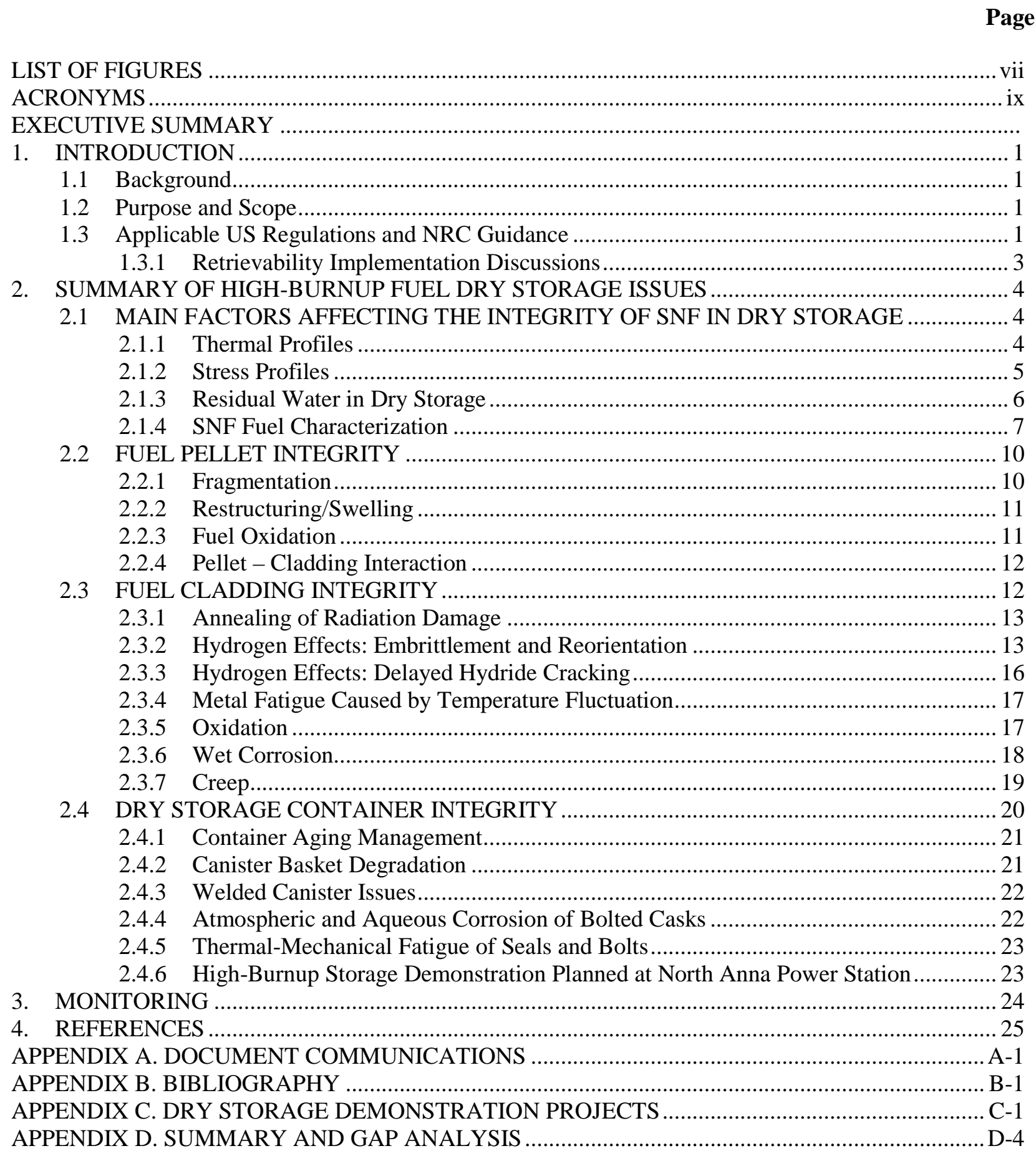




\section{LIST OF FIGURES}

Figure $\quad$ Page

Fig. 1. Nevada Test Site Demonstration Project (Patrick WC 1986).......................................................

Fig. 2. REA 2023 BWR cask. (McKinnon ME and VA Deloach 1993) ....................................................

Fig. 3. NUHOMS Demonstration System (EPRI 1990) …..................................................................... C-3 



\section{ACRONYMS}

\begin{tabular}{|c|c|}
\hline AMPs & aging management programs \\
\hline BUC & burnup credit \\
\hline BWR & boiling water reactor \\
\hline CNWRA & Center for Nuclear Waste Regulatory Analyses \\
\hline $\mathrm{CoC}$ & Certificate of Compliance \\
\hline CFR & Code of Federal Regulations \\
\hline CIRFT & Cyclic Integrated Reversible-bending Fatigue Tester \\
\hline CWSR & cold-worked and stress relief annealed \\
\hline DBTT & ductile to brittle transition temperature \\
\hline DCSCP & Dry Cask Storage Characterization Project \\
\hline DCSS & dry cask storage system \\
\hline DHC & delayed hydride cracking \\
\hline DOE & US Department of Energy \\
\hline DSS & dry storage system \\
\hline EPRI & Electric Power Research Institute \\
\hline ES & extended storage \\
\hline GWd & gigawatt day \\
\hline GTCC & greater than class c \\
\hline HBS & high-burnup structure \\
\hline HDRP & High Burnup Dry Storage Research Project \\
\hline HLW & high-level radioactive waste \\
\hline HRT & hydride reorientation treatment \\
\hline INEL & Idaho National Engineering Laboratory \\
\hline INL & Idaho National Laboratory \\
\hline ISFSI & independent spent fuel storage installation \\
\hline MTU & metric ton uranium \\
\hline $\mathrm{NE}$ & (DOE) Office Of Nuclear Energy \\
\hline NRC & US Nuclear Regulatory Commission \\
\hline ORNL & Oak Ridge National Laboratory \\
\hline PCI & pellet-clad interaction \\
\hline PCSR & pre-construction safety report \\
\hline
\end{tabular}




$\begin{array}{ll}\text { PNNL } & \text { Pacific Northwest National Laboratory } \\ \text { PWR } & \text { pressurized water reactor } \\ \text { R\&D } & \text { research and development } \\ \text { RCT } & \text { ring compression testing } \\ \text { RHT } & \text { radial hydride treatment } \\ \text { SCC } & \text { stress corrosion cracking } \\ \text { SFIS } & \text { spent fuel interim storage } \\ \text { SSC } & \text { systems, structures, and components } \\ \text { SME } & \text { subject matter experts } \\ \text { SNF } & \text { spent nuclear fuel } \\ \text { SPP } & \text { second-phase precipitate } \\ \text { TLAA } & \text { time-limited aging analyses } \\ \text { UFDC } & \text { Used Fuel Disposition Campaign } \\ \text { UKABWR } & \text { United Kingdom Advanced Boiling Water Reactor }\end{array}$




\section{EXECUTIVE SUMMARY}

This report identifies issues and support documentation and identifies and details existing research on spent fuel dry storage; provides information to support potential research and development for the UKABWR (United Kingdom Advanced Boiling Water Reactor) Spent Fuel Interim Storage PreConstruction Safety Report; and supports development of answers to questions developed by the regulator. Where there are gaps or insufficient data, Oak Ridge National Laboratory (ORNL) has summarized the research planned to provide the necessary data along with the schedule for the research, if known.

Spent nuclear fuel (SNF) from nuclear power plants has historically been stored on site (wet) in pools pending ultimate disposition. Nuclear power users (countries, utilities, vendors) are developing a suite of options and set of supporting analyses that will enable future informed choices about how best to manage these materials. As part of that effort, they are beginning to lay the groundwork for implementing longerterm interim storage of the SNF and the Greater Than Class C waste (dry). Deploying dry storage will require a number of technical issues to be addressed.

To ensure the safety of the SNF under normal conditions of wet and subsequent dry storage, intact fuel must be shown to

1. maintain fuel cladding integrity;

2. maintain its geometry for cooling, shielding, and subcriticality; and

3. maintain retrievability.

Where pressurized water reactor information is used or referenced, justification has been provided as to why the data can be used for boiling water reactor fuel. 



\section{INTRODUCTION}

The quantity of spent nuclear fuel (SNF) continues to increase worldwide. It is, therefore, in the national interest of all countries that use nuclear power as an energy source to develop a long-term SNF storage and disposal plan. Such a plan will necessarily include provisions for dry storage of SNF. The United States began using dry storage in 1986. Commercial SNF in the United States is expected to remain in storage for considerably longer than was originally intended (e.g., $<40$ years). Extended storage time and irradiation of nuclear fuel to high-burnup values $(>45 \mathrm{GWd} / \mathrm{t}$ ) result in increased uncertainties related to aging management of the structures, systems, and components important to safety during normal, offnormal, and accident conditions during extended storage and subsequent transportation. Hence, a great deal of research and development $(R \& D)$ has been undertaken to reach future storage limits, and significant R\&D is ongoing.

Dual-purpose storage systems for SNF have been developed by the nuclear industry and licensed by the US Nuclear Regulatory Commission (NRC). Dual-purpose systems allow for both storage and transport without the need to rehandle individual SNF assemblies before shipment off site. The majority of independent spent fuel storage installation (ISFSI) facilities in the US commissioned since 2000 have loaded SNF into dual-purpose storage technologies. Many companies that began ISFSI operation in the 1980s and 1990s also have transitioned from storage-only technologies to dual-purpose storage technologies (EPRI 2014).

\subsection{BACKGROUND}

SNF and high-level radioactive waste from nuclear power plants has historically been stored underwater in onsite spent fuel pools, pending ultimate disposition. Nuclear power users (countries, utilities, vendors) are developing a suite of options and a set of supporting analyses that will enable informed choices in the future regarding how best to manage these materials. As part of that effort, they are beginning to lay the groundwork for implementing longer-term interim storage of SNF and greater than class C (GTCC) waste using dry technology. Deploying dry storage will require a number of technical issues to be addressed.

\subsection{PURPOSE AND SCOPE}

This report provides a publicly available summary of existing research related to spent fuel dry storage as it might relate to the United Kingdom Advanced Boiling Water Reactor (UKABWR). The documentation will (1) provide an indication of the $R \& D$ necessary to prepare the UKABWR spent fuel interim storage pre-construction safety report and (2) support interaction with the regulator.

\subsection{APPLICABLE US REGULATIONS AND NRC GUIDANCE}

Regulations issued by the US Nuclear Regulatory Commission (NRC) govern the transportation and storage of SNF to protect the public health and safety. In addition, NRC provides extensive guidance on these topics.

Requirements for packaging, preparation for shipment, and transportation of licensed material are contained in Title 10 of the Code of Federal Regulations (10 CFR) under Part 71 (10 CFR 71), "Packaging and Transportation of Radioactive Material.” This regulation applies to license holders determined to transport licensed material, including SNF, outside the confines of the authorized place of use. The NRC issues a Certificate of Compliance (CoC) approving the design of a package for the transportation of radioactive material. This regulation is intended to protect the health and safety of the public and transportation workers while licensed material is in transit. 
The requirements, procedures, and criteria for the issuance of licenses to receive, transfer, and possess power reactor spent fuel, power reactor-related GTCC waste, and other radioactive materials associated with spent fuel storage in an ISFSI, and the terms and conditions under which NRC will issue these licenses, are contained in 10 CFR 72, "Licensing Requirements for the Independent Storage of Spent Nuclear Fuel, High-Level Radioactive Waste, and Reactor-Related Greater than Class C Waste.” The regulations in this part also establish requirements, procedures, and criteria for the issuance of CoCs approving spent fuel storage cask designs. Storage systems must be designed to allow ready retrieval of spent fuel for further processing or disposal. This regulation is intended to protect the health and safety of the public when SNF and GTCC waste are stored away from the reactor, typically in dry storage, after cooling for at least 1 year in a spent fuel pool.

Aging management programs (AMPs) are required by 10 CFR 72 to manage those issues associated with aging that could adversely affect ISFSI structures, systems, and components important to safety. A defined AMP is a prerequisite for the issuance of an ISFSI license renewal. This requirement ensures the continued health and safety of the public as related to the operation of an ISFSI.

NUREG-1536, Revision 1, Standard Review Plan for Spent Fuel Dry Storage Systems at a General License Facility, provides guidance for reviewing an application for a spent fuel dry storage system (DSS) for a facility storing spent fuel under the general license authorized by 10 CFR 72.210. A general license authorizes a nuclear power plant licensee to store SNF in NRC-approved casks at a site that is licensed to operate a power reactor under 10 CFR Part 50. Any aspect of the DSS design or procedures that the NRC determines should not be changed, by either the certificate holder or the general licensee, without prior NRC approval, must be placed in the CoC conditions or in the attached technical specifications to ensure adequate protection of public health and safety. (NRC 2010)

NUREG-1567, Standard Review Plan for Spent Fuel Dry Storage Facilities, provides guidance for reviewing a site-specific application for an ISFSI. This process is similar to the design reviews conducted for ISFSI casks certified under 10 CFR Part 72, Subpart L, and conducted according to the guidance of NUREG-1536. NUREG-1567 builds on the guidance in NUREG-1536, and the chapters related to criteria and design evaluation often reference specific sections of NUREG-1536. The evaluation of proposed programs that support protection of worker and public health and safety (e.g., radiation protection, conduct of operations, quality assurance) is a review area for specific licenses rather than the CoCs under NUREG-1536. (NRC 2000)

NUREG-1927, Standard Review Plan for Renewal of Spent Fuel Dry Storage System Licenses and Certificates of Compliance, provides guidance for the safety review of license (specific or general) and CoC renewal applications submitted by licensees and holders of CoCs for dry cask storage systems DCSSs). The NRC-approved DSSs listed in 10 CFR 72.214, "List of Approved Spent Fuel Storage Casks,” may be used by any 10 CFR Part 72 general licensee in accordance with 10 CFR 72.212, “Conditions of General License Issued Under 10 CFR 72.210.” If the CoC holder chooses not to apply for the renewal of a particular CoC or is no longer in business, a DSS user or user's representative may apply for renewal of the CoC in place of the CoC holder. (NRC 2011) Draft revision 1 to NUREG-1927 (NRC 2015) notes that both the specific license and the CoC renewal applications must contain revised technical requirements and operating conditions (fuel storage, surveillance and maintenance, and other requirements) for the ISFSI or DSS that address aging mechanisms and aging effects that could affect structures, systems, and components relied upon for the safe storage of spent fuel.

The NRC Division of Spent Fuel Storage and Transportation has issued interim staff guidance (ISG-8, Revision 3) on "Burnup Credit in the Criticality Safety Analyses of PWR Spent Fuel in Transportation and Storage Casks.” ISG-8 notes that

Unirradiated reactor fuel has a well-specified nuclide composition that provides a straightforward and bounding approach to the criticality safety analysis of transportation and storage systems. As the fuel is irradiated in the reactor, the nuclide composition 
changes and, ignoring the presence of burnable poisons, this composition change will cause the reactivity of the fuel to decrease. Allowance in the criticality safety analysis for the decrease in fuel reactivity resulting from irradiation is termed burnup credit.

Extensive investigations have been performed both within the United States and by other countries in an effort to understand and document the technical issues related to the use of burnup credit. (NRC 2012a)

Though ISG-8 strictly addresses pressurized water reactor (PWR) fuel, ongoing research is in progress on boiling water reactor (BWR) burnup credit (BUC). A discussion of this research and some of the research gaps is in Section 2.1.4 of this report.

The NRC codified this requirement in its regulations, including 10 CFR 72.122(l), which states

Storage systems must be designed to allow ready retrieval of spent fuel, high level radioactive waste, and reactor-related GTCC waste for further processing or disposal.

Retrievability is also required by the dry storage requirements on confinement barriers and systems, which are governed by 10 CFR 72.122(h)(1) which states

The spent fuel cladding must be protected during storage against degradation that leads to gross ruptures or the fuel must be otherwise confined such that degradation of the fuel during storage will not pose operational safety problems with respect to its removal from storage. This may be accomplished by canning of consolidated fuel rods or unconsolidated assemblies or other means as appropriate.

Finally, the specific requirements for spent fuel storage cask approval and fabrication are governed by 10 CFR 72.236(m) which states

To the extent practicable in the design of spent fuel storage casks, consideration should be given to compatibility with removal of the stored spent fuel from a reactor site, transportation, and ultimate disposition by the Department of Energy.

\subsubsection{Retrievability Implementation Discussions}

As stated in a recent NRC memo (Haney 2015) and presentation (Wong 2015), the NRC is currently discussing the implementation of retrievability requirements with industry. As the duration of spent fuel storage at an ISFSI increases, the practical impact of the application of the first part of ready retrievalthe ability of the fuel assembly to be removed from the canister or cask by normal means-has led the NRC to take a closer look at retrievability. To ensure that the application of the first part of "ready retrieval" is met in the renewal period(s), periodic monitoring or inspection may be needed to verify the condition of the fuel and the internal components of the DSS and possible remediation (Haney 2015). Because of the difficulties in accessing the fuel and the interior components, inspection, monitoring, and potential remediation may involve opening the system to verify the condition of the fuel and internal components. However, opening the DSS would expose workers to additional dose and, particularly for welded canisters, degrade or eliminate the confinement boundary.

NRC has been exploring alternatives to the guidance on the application of ready retrieval. Discussions have centered on eliminating the first part of the guidance on ready retrieval- the ability to remove the fuel assemblies from a canister or cask by normal means, but maintaining the second part- the ability to remove the canister or cask from the storage location. If the first part of the guidance were eliminatedthe ability to remove the individual spent fuel assemblies or canned assemblies by normal means-the DCSS could still be retrieved safely and be readied for transportation consistent with the regulations. This way, the spent fuel dry storage confinement continues to be maintained without the potential negative impacts associated with unnecessarily removing the individual fuel assemblies. 


\section{SUMMARY OF HIGH-BURNUP FUEL DRY STORAGE ISSUES}

As the burnup of fuel increases, a number of changes occur that may affect the performance of the fuel, cladding, and assembly hardware in storage and transportation. These changes include increased cladding corrosion layer thickness, increased cladding hydrogen content, increased cladding creep strains, increased fission gas release, and the formation of the high burnup structure (HBS) at the surface of the fuel pellets (Hanson et al. 2012). Over the last several decades, the discharge burnup of fuel has increased steadily beyond $45 \mathrm{GWd} / \mathrm{MTU}$. The current maximum rod-averaged burnup is limited by NRC to $62 \mathrm{GWd} / \mathrm{MTU}$ because of these changes and because of the lack of data at higher burnups, especially under design-basis-accident conditions.

Issues associated with increased fuel burnup include the formation of a high-burnup structure (HBS) at the surfaces of the fuel pellets; increased levels of oxidation and hydriding of the cladding; higher fuel rod internal pressures due to higher fission gas release from the fuel pellets; and, consequently, higher hoop stresses in the cladding. Increased fission gas release increases the pressure differential across the cladding during dry storage. Increased oxidation decreases the effective load-bearing metal thickness of the cladding. Both phenomena contribute to higher stresses.

The combination of sufficiently high hoop stresses and high temperatures can lead to deformation and rupture of the cladding, a change in the morphology of the hydrides upon cooling, and degradation of the cladding mechanical properties. Mechanical properties of specific interest include creep, ductility under impact loading conditions (accidents), and fracture toughness. These properties determine the ability of the cladding to maintain the fuel in the configuration that is, or will be, used for licensing analysesspecifically in the criticality, shielding, and retrievability evaluations. Therefore, as discharge burnup levels continue to increase, additional experimental data are needed to confirm and support the licensing of DSSs and confirm their effects on the mechanical properties of interest for resolving issues associated with the transportation, handling, and disposal operations. (McKinnon 2003)

\subsection{MAIN FACTORS AFFECTING THE INTEGRITY OF SNF IN DRY STORAGE}

There are several phenomena that can affect fuel and clad integrity in a DSS. However, every failure mechanism depends on a range of conditions occurring, and these conditions are set by thermal profiles, stress profiles, residual water in dry storage and SNF characteristics.

\subsubsection{Thermal Profiles}

Most degradation mechanisms are temperature dependent and, as a general rule, occur faster at higher temperatures. Initial temperatures in a DCSS are a direct function of the decay heat load in the cask or canister when it is first placed in dry storage. From the standpoint of thermal analysis, fuel burnup is significant mainly because it affects the initial heat load of the fuel when it is first placed in the fuel pool and, consequently, the length of time the assembly must remain in the pool before it is cool enough to be a candidate for dry storage. The minimum cooling time is thus a function of burnup. Burnup also affects the temperature as a function of time in dry storage.

After fuel is discharged from the reactor, its temperature decays exponentially, with a relatively rapid rate of decrease shortly after discharge that slows as time progresses. Thus, it is often assumed and stated that the period of concern for materials degradation is the first 20 years, when the decay heat and temperatures 
are the highest (EPRI 1998). Similarly, the regulations and guidance (SFST-ISG-11 (NRC 2003) with respect to temperature specify that the maximum calculated fuel cladding temperature should not exceed $400^{\circ} \mathrm{C}$ for normal conditions of storage and short-term loading operations. Under all conditions, the maximum cladding temperature should not exceed $570^{\circ} \mathrm{C}$. Because the regulations deal with maximum temperatures, utilities routinely use conservative assumptions when calculating temperature profiles. These conservatisms are used to ensure that peak cladding temperatures, especially of high-burnup fuel during drying/transfer operations, are within regulations.

Recent data have shown (Burtseva 2010, Daum 2006, Aomi M 2008), however, that high-burnup ZIRLO, Zyr-4, and Zyr-2 claddings can become brittle at lower temperatures. Similarly, recent models developed to describe delayed hydride cracking (Holston 2010) suggest this mechanism may become more prolific at lower temperatures for Ziry-4 and Ziry-2 claddings.

Finally, although it may be conservative to calculate corrosion or degradation rates based on conservatively high temperatures, doing so may significantly shorten calculated material lifetimes and result in unnecessary repackaging.

There is a need to develop realistic or even lower-bound temperature profiles as part of a modeling and analysis task. Plans are to accomplish this using codes such as COBRA-SFS (Michener et al. 1995) for vertical casks and STAR-CD (2004) for horizontal casks. COBRA-SFS was validated for low-burnup fuels against the data obtained from the thermal testing at the Idaho National Engineering Laboratory (INEL) (McKinnon and Deloach 1993). However, instead of simply assuming conservative values for properties such as clad emissivity or the contact area between fuel assemblies and the canister (which affect heat transfer via conduction), more realistic values or ranges of values should be developed and used in the analysis. Both axial and radial temperature profiles within the DCSS will be calculated and used to calculate potential degradation rates of the various materials.

More rigorous modeling of thermal profiles is not considered a requirement in Japan, mainly because of the much lower peak cladding temperature limit there $\left(275^{\circ} \mathrm{C}\right)$ than the $400^{\circ} \mathrm{C}$ peak cladding temperature in the United States. (PNNL 2012)

\subsubsection{Stress Profiles}

There is a gap in stress profiles with respect to the experimental data and detailed calculations needed to determine the types of stresses (e.g., magnitude, frequency, duration) imparted to various systems, structures, and components (SSCs) under various conditions. These conditions include normal cask handling, cask drop, seismic events, cask tip over, and normal transportation. Accurate inputs and quantification of the primary stresses (from pressure and thermal loading), secondary stresses (from residual stresses from fabrication), and external loadings (from vacuum drying, handling, and vibratory loads during transportation) are important for evaluating the material and structural response of an SSC subjected to extended storage and transportation conditions.

The structural analyses performed for the storage facility license applications typically use bounding approximations to demonstrate that the SSCs maintain their safety functions through design-basis storage events and normal transportation. However, these analyses do not use degraded material properties, so it is difficult to determine how much degradation can occur before the SSCs can no longer perform their safety functions. R\&D to close the stress profiles gap will provide this information and thus provide inputs to, and outputs from, the research to close gaps on the effect of the degradation mechanisms on the structural properties of SSCs.

In Japan, integrity of concrete cask storage technology has been verified by Central Research Institute of Electric Power Industry through several research programs on demonstrative testing for the interim storage of spent fuel (Saegusa 2010). It is found that tipping-over of the scale model cask was not observed even if the acceleration level exceeded the ultimate input level (Shirai 2003). Currently, Japan 
does not consider stress profiles a gap; however, research continues in the United States for more accurate modeling of stress profiles, mainly to predict stress profile during transportation of DCSSs.

\subsubsection{Residual Water in Dry Storage}

Some degradation mechanisms are dependent on or accelerated by the presence of water. Because the DCSS is loaded with fuel while in the pool, both for shielding and temperature control, it is important to remove as much water as possible during the drying process.

If the efficacy of the drying process can be verified, a number of degradation processes for fuel, cladding, assembly hardware, and canister/cask internals can be ruled out. This was shown by the examination of the CASTOR V/21 cask (which was loaded in air) after approximately 15 years of storage. In it, the internals and fuel assemblies appeared the same as they did when the cask was loaded dry (INEL DCSS), so that these mechanisms were not possible (EPRI 2002).

There are no specific regulations for the process of fuel drying, and each cask vendor develops procedures specific to its cask/canister design. However, NUREG-1536 Section 9.4.1 states "The operating procedure descriptions should facilitate reducing the amount of water vapor and oxidizing material within the confinement casks to an acceptable level to protect the SNF cladding against degradation that might otherwise lead to gross ruptures.”

NUREG-1536 Section 9.5.1 states that an accepted method is to drain the cask of as much water as practicable and then to evacuate to less than or equal to $4.0 \times 10^{-4} \mathrm{MPa}$. SFST-ISG-11 also limits the peak cladding temperature during the drying process to help reduce the potential for radial hydride formation that could cause embrittlement and loss of ductility.

ASTM C1553-08 (2008), Standard Guide for Drying Behavior of Spent Nuclear Fuel, details methods and criteria that may be used to dry SNF that has been stored underwater. It also provides methods and criteria that may be used to confirm adequate dryness of SNF in a container following the drying process. ASTM C1553-08 states that cask drying procedures can remove most of the water from the cask, but it is not physically possible to remove all water in this way. There will always be some amount of free water remaining in the cask. Estimates using equilibrium assumption ignore potential mechanical holdup due to the tortuous path water may follow, as well as the contribution from physisorbed and chemisorbed water that may not be removed under these conditions

In addition, even under vacuum and applied heat, waterlogged rods can continue to outgas water, even through relatively large breaches, for about 1,000 hours at $325^{\circ} \mathrm{C}$ (Kohli et al. 1985)

However, as verified by measurements obtained as part of the initial temperature validation tests performed at INL, the amount of water in a DCSS is expected to be small. For the REA-2023 cask (also known as MSF IV) that was loaded in water and went through a vacuum drying process, the concentration of water vapor in the gas sample was no higher than that in other casks loaded in air (Knoll and Gilbert 1987), such as the CASTOR V/21.

In addition to interaction with the cladding, water, water vapor, or its decomposition products produced by radiolysis can interact with the fuel, assembly hardware, baskets, neutron poisons, and canister materials; or it can result in the generation of hydrogen that could result in flammability concerns. This possibility has led some regulators, such as in France, to require monitoring of packages for hydrogen.

A study performed under the Center for Nuclear Waste Regulatory Analyses (CNWRA) by Jung et al. (Jung 2013) examined potential impacts of residual water remaining inside a dry storage cask for SNF after the drying process. The study concluded that degradation of cladding, fuels, and other internal components is not expected to be significant over the analyzed period, up to 300 years of storage time. With no significant degradation of cladding, fuel, and internal components, criticality safety is not affected. At the higher end of the analyzed range of residual water ( 0.1 to $1 \mathrm{~L}$ ), and for relatively low 
initial temperature and backfill pressure, the canister environment could meet the condition of flammability in terms of the amount of hydrogen and available oxygen present, given a source of ignition.

In a recent study (Wittman 2013), radiolysis outside storage canister walls and within the canister fill gas over a possible 300-year lifetime was analyzed. A detailed analysis including coupled kinetics for 111 reactions for 40 gas species to account for radiolytic-induced chemistry concluded that a much greater amount of residual water $(20 \mathrm{~L})$ would be required to reach the $4 \% \mathrm{H}_{2}$ flammability limit in 16 years and between 3 and $4 \mathrm{~L}$ of water would be required to reach the $4 \% \mathrm{H}_{2}$ flammability limit in 300 years.

There have been no experimental tests to measure the quantity of residual water that may remain in the canister following vacuum drying. A recent report by CNWRA (Miller 2013a) reviewed potential methods to measure residual water in a dry cask, and a test plan to determine the residual water and best practices for effective drying of PWR and BWR assemblies were proposed (Miller 2013b).

\subsubsection{SNF Fuel Characterization}

The characteristics of SNF that are the most significant for long-term storage considerations are the spent fuel isotopic compositions, and the radiation and thermal source terms. However, accurate prediction of isotopic compositions is important for criticality safety, as well as accurate prediction of the radiation and thermal source terms.

Unirradiated reactor fuel has a well-specified nuclide composition of uranium and oxygen that provides a straightforward and bounding approach to the criticality safety analysis of storage and transport casks. The nuclide composition of the fuel changes as the fuel is irradiated in the reactor through depletion of

${ }^{235} \mathrm{U}$, generation of fission products, breeding of higher actinides, and radioactive decay. This composition change causes the reactivity of the fuel to decrease. An allowance in the criticality safety analysis for the decrease in fuel reactivity resulting from irradiation is termed "burnup credit." The level of burnup credit depends on the isotopes modeled in the criticality analysis. Actinide-only burnup credit generally refers to calculations employing only actinides with the highest reactivity worth, including uranium ${ }^{(234} \mathrm{U},{ }^{235} \mathrm{U}$, ${ }^{236} \mathrm{U}$, and $\left.{ }^{238} \mathrm{U}\right)$, plutonium, and americium $\left({ }^{241} \mathrm{Am}\right)$ isotopes. "Full” burnup credit refers to a combination of the uranium and plutonium isotopes evaluated in actinide-only burnup credit, plus a number of fission products and minor actinides. Thus far, the number of isotopes included in any burnup credit application for storage, transportation, and disposal has been a subset of 16 fission product isotopes. The fission product isotopes with the highest reactivity worth after extended storage are ${ }^{149} \mathrm{Sm},{ }^{103} \mathrm{Rh},{ }^{143} \mathrm{Nd},{ }^{151} \mathrm{Sm}$, ${ }^{155} \mathrm{Gd}$, and ${ }^{133} \mathrm{Cs}$.

Extensive investigations for PWR fuel have been performed domestically and internationally in an effort to evaluate and license the technical bases related to burnup credit (Radulescu et al. 2012, Scaglione et al. 2012), which include predictions of isotopic concentrations as a function of in-reactor irradiation parameters, evaluation of fission product and actinide cross sections for use in the depletion analysis (Leal et al. 2007), and criticality modeling assignment of burnup values for discharged SNF based on reactor records and/or measurements as required by ISG-8.

These extensive efforts are reflected in the update of ISG-8 (NRC 2012), which includes

1. Optional credit for fission product and minor actinide neutron-absorbing isotopes in the SNF composition.

2. Misload analyses and additional administrative procedures in lieu of a burnup measurement at the time of loading. This Interim Staff Guidance revision also includes an increase in the maximum assembly average burnup recommended for burnup credit.

Although ISG-8 closes many gaps in PWR SNF burnup credit, currently NRC does not allow any burnup credit for BWR SNF. ISG-8 states 
Boiling Water Reactor (BWR) burnup credit has not typically been sought by dry storage and transportation applicants due to the complexity of the fuel and irradiation parameters, the lack of code validation data to support burnup credit, and a general lack of need for such credit in existing designs. Although the ISG does not provide explicit guidance on BWR burnup credit, criticality analyses which include such credit should be reviewed on a case-by-case basis.

There have not been significant efforts toward allowing BWR SNF burnup credit until recent years. The validation of codes used in modeling and simulation of BWR SNF against measured data for biases and uncertainties in k-effective is challenging.

There are large gaps in BWR BUC due to lack of operating data and proprietary design data, in addition to the increased complexity in BWR SNF simulations resulting from

- heavy use of gadolinium burnable absorbers

- axially and radially changing enrichment zones

- $\quad$ significant change in axial profile of the coolant density

- power shaping and power control with control blades

- multiple moderator zones due to fuel channel surrounding assembly

An ORNL report (Mueller et al. 2013) proposes and documents a computational benchmark for the estimation of the additional reactivity margin available in BWR SNF from fission products and minor actinides in a burnup credit storage/transport environment. The report provides estimations of the additional reactivity margin to be used in ISG-8 as a function of initial enrichment, burnup, and cooling time.

SNF loaded cask systems tend to have excess and uncredited margins (i.e., the difference between the licensing basis and the as-loaded calculations). This is because the final safety analysis report for a particular SNF cask system documents the bounding models and calculations used to demonstrate that a system meets the regulatory requirements. The cask systems from seven sites (six PWR, one BWR) were explicitly modeled and analyzed (Banerjee et al. 2015) for 206 fuel assemblies using the SNFST\&DARDS tool. The paper demonstrated that most of the as-loaded casks have substantial uncredited safety margins (0.05 to almost $0.30 \Delta \mathrm{keff}$ ), considering that Marshall et al. (Marshall 2012) showed that the maximum increases in keff for the PWR and BWR cask systems are nearly $4 \%$ and $2.4 \%$, respectively. The savings in the calculated margins could potentially be used to offset postulated safetyrelated performance losses and uncertainties as systems age and to accommodate potential reactivity increases from fuel failure during extended storage.

Note also that because of a lack of data, bounding modeling approximations (e.g., uniform axial void profile) were used in simulating BWR SNF in Banerjee's study. The effect of this conservative approach can be an increase in keff of as much as 1 to 2\% (Casado, Sabater, \& Serrano, 2009). A more detailed review of BWR operation and design uncertainties with regard to the calculated keff can be found in recent ORNL reports on BWR burnup credit (Mueller 2013b, Marshall 2015).

A recent ORNL report (Marshall 2015) reviewed the most commonly used peak reactivity methods in single-point-failure analyses for BWR SNF to provide the technical background for potential applications to storage and transportation casks. It includes (1) an examination of the fuel assembly lattice design and operating parameters that affect the burnup and reactivity of the peak reactivity in storage and transportation configurations, (2) validation of these reactivity calculations, and (3) validation of the depleted isotopic inventories in BWR SNF at burnups associated with peak reactivity. Each of these three areas is investigated in detail in the report. The Marshall report is focused on peak reactivity, so it applies to fuel assemblies with average burnups of approximately $20 \mathrm{GWd} / \mathrm{MTU}$ or less. The same group plans to 
address burnup credit for BWR fuel assemblies with typical discharge burnups in future reports over the next few years.

\subsubsection{UNF-ST\&DARDS}

The need for detailed operating and design data is clear for PWR and BWR SNF. Criticality safety crosscuts all areas of the back end of the nuclear fuel cycle, including storage, transportation, recycling/reprocessing, and disposal; and the data needs are applicable to each area. The Used Nuclear Fuel-Storage, Transportation \& Disposal Analysis Resource and Data System (UNF-ST\&DARDS) (Scaglione 2014) provides a unified domestic SNF system database and key analysis capabilities to support numerous DOE waste management and fuel cycle-related objectives, and it provides the foundation for tracking SNF from reactor power production through ultimate disposition. UNFST\&DARDS allows users to perform a large volume of as-loaded SNF safety analyses to assess the actual characteristics of loaded casks during long-term storage and subsequent transportation in a variety of DSSs. The CURIE (Centralized Used Fuel Resource for Information Exchange) website provides access to UNF-ST\&DARDS for industry, vendor, federal, and laboratory partners for usable, collaborative document and data access

\subsubsection{Subcriticality under hypothetical fuel geometry changes}

Although transportation of dry casks is not a focus in this report, a transportation accident condition analyzed by Scaglione et al. (2015) is included to show the consequences of a worst-case scenario for clad failure and pellet dislocation.

For criticality, it was postulated that the cask/package was fully flooded under normal and accident conditions, although that is very unlikely. In NUREG-2125, NRC indicates that if an accident during transportation should occur, there is about a one-in-a-billion chance that the accident would result in loss of containment, which is a prerequisite for flooding of cask internals. The actual probability of flooding is even lower when one factors in the probability of such an accident in the presence of a sufficient depth of water to enable full flooding of the cask internals.

Scaglione analyzed potential changes in system characteristics with respect to criticality, shielding, containment/confinement, and thermal safety parameters under a wide range of fuel reconfiguration scenarios, such as cladding failure, rod/assembly deformation without cladding failure, or changes to assembly axial alignment without cladding failure. Based on the thirty-two 17×17 PWR and sixty-eight $10 \times 10$ BWR fuel assemblies investigated, the results showed that most of the evaluated PWR and channeled BWR fuel reconfigurations resulted in increases in system reactivity (keff) of less than $4 \%$ $\Delta$ keff when the reconfigured fuel remained inside the neutron absorber panel envelope.

For reconfigurations with fuel materials beyond the neutron absorber panel envelope, and others involving unchanneled BWR fuel, the system reactivity varied widely, ranging from decreases to increases of greater than $5 \% \Delta \mathrm{keff}$, depending on the water-to-fuel ratio and the length of the fuel outside the absorber envelope.

However, the results depend on the modeling assumptions and canister characteristics, particularly the available volume above and below the neutron absorber panel envelope for the fuel rods and failed fuel fragments to accumulate. This indicates that using axial spacers to limit axial movement of fuel is an effective measure to maintain criticality safety under such conditions. 


\subsection{FUEL PELLET INTEGRITY}

Typical $\mathrm{UO}_{2}$ fuels undergo significant changes during reactor operations. The fission process generates a myriad of fission products, many of which are soluble in the $\mathrm{UO}_{2}$ matrix. Those elements that are not soluble in the matrix tend either to diffuse out of the grains to the grain boundaries, and eventually out of the fuel pellet to the fuel-clad gap, or to form separate metallic or oxide phases within the fuel.

Initial densification of the fuel pellet, followed by swelling, are primarily results of a buildup of fission products and radiation damage. The thermal conductivity - which is relatively poor for $\mathrm{UO}_{2}$ and results in very large temperature gradients across the pellet diameter-decreases with increasing burnup, again as fission products and radiation damage increase and disrupt the $\mathrm{UO}_{2}$ lattice. The nonuniform heating rates and large temperature differentials lead to uneven thermal expansion that results first in cracking of the fuel pellets, followed by possible deformation. The thermal expansion and swelling of the fuel pellet combined with cladding creepdown closes the fuel-clad gap so that the fuel and cladding are in contact with each other. Local stresses on the cladding, combined with chemical reactions between the fuel pellet and cladding, can result in pellet-clad interaction (PCI) failures.

Degradation of the fuel pellets will have a direct impact on retrievability only if the degradation is sufficient to split the cladding so that fuel relocation occurs. NUREG-1536, Section 8.6 (NRC 2010), states that, other than for fine powder, a cladding crack width of at least $2-3 \mathrm{~mm}$ is required to release a fragment of the pellet. Using this reasoning, a gross breach is defined as any cladding breach greater than $1 \mathrm{~mm}$. The fuel degradation mechanisms examined either cannot occur unless the clad is already breached, or are insufficient to cause further clad cracking in the absence of an oxidizing environment (which implies an off-normal or accident condition). Therefore, fuel degradation mechanisms are considered of low importance during normal operations.

\subsubsection{Fragmentation}

The concern with fuel fragmentation is that under various accident scenarios, such as cask drop or tipover, the fuel might fragment or break into small, respirable-size particles and pose both retrievability and dose issues (Einziger and Beyer 2007). Pellets crack during reactor operation because of the large temperature gradients across the pellet diameter. These cracks reduce the distance that fission gases or volatiles need to travel before they are released to the free volume of the rod. However, the majority of fission gases and other fission products remain in the fuel matrix.

There are two postulated mechanisms for additional fuel fracture during extended storage. The first is a result of mechanical force from a cask drop or tip-over, both of which are accident conditions and are not analyzed in this report. The second is pressurization resulting from fission gases or from generation of helium from $\alpha$ decay (Rondinella 2011). The precipitation of helium bubbles on the grain boundaries could eventually result in decohesion of the grains and a reduction in the mechanical strength. However, the production of helium even by high-burnup fuels over the time frames of extended storage is minimal.

Lorenz et al. (1980) studied the release of fission products from UNF segments. Pacific Northwest National Laboratory (PNNL) conducted flow tests on segments of high-burnup fuel ( $\sim 60 \mathrm{GWd} / \mathrm{MTU}$ ) and medium burnup fuel ( $\sim 42 \mathrm{GWd} / \mathrm{MTU})$. The results showed no significant difference in either the release fraction or the particle size distribution between high-burnup and medium-burnup fuels.

The limited data to date agree with the release fractions in NUREG-1567. Release of the fine-grained high-burnup structures in high-burnup fuels could contribute to a much larger respirable fraction and complicate fuel retrievability. However, such a scenario is possible only under accident conditions. 


\subsubsection{Restructuring/Swelling}

$\mathrm{UO}_{2}$ fuel pellets initially shrink during reactor operation as the fuel matrix undergoes densification. At relatively low burnup, the fuel pellet begins to swell, largely as a result of fission product and radiation damage accumulation. In addition, the cladding tends to creep during reactor operation because of irradiation creep mechanisms that are not well understood. At higher burnups, the fuel-clad gap closes and the fuel is in direct contact with the cladding. Often, this interaction results in bonding of the fuel pellet and cladding (Lee et al. 2004). In the past, the fuel swelling and cladding creepdown often resulted in "bambooing" or "hourglassing," in which the cladding crept in more at the body of the pellets and less at the pellet-pellet interfaces so that pellets resembled bamboo (Olander 2009). Although better designs of both fuel and cladding have reduced this bambooing effect, the differences in the pellet diameter, especially at the interfaces with the chamfered edges, lead to local stresses that can result in pellet-clad mechanical interaction failures. This is especially true during power transients and in areas of the pellet that have been chipped or damaged (missing pellet surface) (Aleshin et al. 2010).

Although conditions during extended storage are obviously much less severe than during reactor power transients, it is unknown if the local areas of hoop stress caused by pellet-clad bonding can have any long-term effects on mechanisms such as clad creep or stress corrosion cracking (SCC).

As was discussed previously, when the local burnup of a fuel rod exceeds about $40 \mathrm{GWd} / \mathrm{MTU}$, the microstructure of the fuel pellet changes at the pellet surface, forming the rim or HBS. Formation of the HBS appears to be a function of both burnup and local temperature. There are disagreements in the literature regarding whether the thermal conductivity of the HBS is actually lower than that of the rest of the fuel, or how it affects mechanical properties such as hardness and fracture toughness.

Additional data to definitively show the effects of HBS on fuel properties such as thermal conductivity, hardness, and fracture toughness are desired. Modeling and simulation should be performed to calculate local hoop stresses from pellet-clad bonding and thermal expansion/contraction at the temperatures of interest for extended storage; these data are needed to determine if the stresses are large enough to cause localized creep or SCC.

However, as the formation of HBS is a function of burnup, there will be no change or additional restructuring during extended storage.

\subsubsection{Fuel Oxidation}

Oxidation of $\mathrm{UO}_{2}$ is a thermally activated process. As the temperature decreases, the rate of oxidation also decreases significantly. Oxidation of UNF has also been shown (Hanson 1998) to be a function of burnup, with higher-burnup fuels being significantly more resistant to the formation of oxides with $\mathrm{O} / \mathrm{M}$ ratios above 2.4. There has been some concern that the highly porous HBS in high-burnup fuels would oxidize rapidly, but the results in Hanson et al. (2008) have shown that is not the case.

The concern with fuel oxidation is that the grain boundaries are oxidized first, potentially releasing additional fission gases and enabling the production of fine particulate matter as grain decohesion occurs. Next, if oxidation occurs to form $\mathrm{U}_{3} \mathrm{O}_{8}$, a phase that is $36 \%$ less dense than the starting $\mathrm{UO}^{2}$, the fuel will swell; this can result in unzipping (crack propagation) in the cladding, which would allow fuel relocation. Relocation could impact retrievability, confinement, radiation protection, and subcriticality safety functions.

For fuel oxidation to occur, an oxidizing environment must be present. This could occur if the cask/canister were mistakenly backfilled with air instead of an inert gas. Depending on the size of the cask, there would still be only enough oxygen present to oxidize one or two rods (EPRI 1998). An oxidizing environment could also be present if there were a breach in the cask/canister seal, or if too 
much water were left in the cask after drying. The water could then undergo radiolysis and form hydrogen, oxygen, and highly oxidizing species like $\mathrm{H}_{2} \mathrm{O}_{2}$. There also must be a through-wall failure in the cladding to expose the fuel to the oxidizing environment.

Given that the only occurrences of fuel oxidation can be under off-normal or accident conditions, and that the decreasing temperatures for extended storage do not facilitate oxidation to the higher states, this mechanism is of low importance for fuel integrity.

\subsubsection{Pellet - Cladding Interaction}

The phenomenon of PCI is fairly well understood. It involves SCC of the cladding as a result of the combination of an aggressive environment, a tensile stress, and a susceptible material. In this case, the aggressive environment is caused by the fission products iodine, cesium, and cadmium that are known to promote SCC. PCI occurs during power ramps under normal operation (reactor startup or mid-cycle maneuvers) as a result of thermal expansion of the pellet, closure of the pellet-cladding gap, and an ensuing buildup of cladding tensile stresses. While PCI failures have occurred in both PWRs and BWRs, they have been more prevalent in BWRs; the latter use control rod movement to adjust reactor power, whereas PWRs typically use soluble boron in the reactor coolant water.

To help reduce PCI failures, the industry first reduced local cladding strains by changing the pellet design to include a chamfer at the edges and dishes at the ends of the pellets. BWR vendors then introduced liner or barrier fuels in which a thin liner (pure zirconium metal under the original General Electric design) was included on the fuel side of the cladding. This softer layer reduces the local stress. Adding iron to the zirconium liner improves the corrosion resistance, and Westinghouse now uses a $\mathrm{ZrSn}$ liner (Dag et al. 2010). Had it not been for these design changes, it is highly likely that PCI failures would have increased significantly with higher burnup, because the fission product inventory is higher, the fission gas release (and thus internal rod pressure) is higher, fuel pellet swelling is greater, and fuel-clad bonding occurs. These factors would have increased both the aggressive environment and the tensile stress.

The lower fuel temperatures in dry storage, especially at extended times, should not promote an additional release of iodine, cesium, or cadmium. As the temperatures decrease, so will the rod internal pressure, alleviating much of the tensile stress. Thus, the driving forces for PCI failure will not increase; and, in fact, the stress will decrease with extended storage.

There are only limited data for the new clad materials compared with Zircaloy-2 and Zircaloy-4. However, the newer clad materials tend to incorporate design changes, such as liners, that reduce the probability of PCI failure.

PCI failures are expected to be small flaws, such as pinhole or hairline cracks, releasing only fission gas. However, in the event of exposure to an oxidizing environment, fuel oxidation could occur.

\subsection{FUEL CLADDING INTEGRITY}

Although the NRC does not explicitly consider cladding as a confinement barrier, as evidenced by failed fuel assemblies being allowed in DCSSs as long as they are in a damaged fuel can, the state and material properties of the cladding are still important to licensing. In fact, the NRC regulations require (10 CFR 72.122[h]) that "spent fuel cladding must be protected during storage against degradation that leads to gross ruptures or the fuel must be otherwise confined such that degradation of the fuel during storage will not pose operational safety problems with respect to its removal from storage.” Gross ruptures or breaches are defined in NUREG-1536 as any cladding breach greater than 1 mm. ISG-1 (NRC 2007) also defines gross rupture as "a breach in spent fuel cladding that is larger than a pinhole leak or a hairline crack. An 
acceptable examination for a gross breach is a visual examination that has the capability to determine the fuel pellet surface may be seen through the breached portion of the cladding."

The mechanical properties of cladding are highly interrelated with numerous factors (e.g., radiation damage and annealing, hydride content and orientation, amount of creep and ductility, and oxide layer thickness) affecting cladding performance. There are limited publicly available data on properties of highburnup cladding and the associated newer cladding alloys.

\subsubsection{Annealing of Radiation Damage}

Radiation damage, typically in the form of dislocation loops that affect the strength and ductility of the cladding, is a function of the fast neutron fluence and irradiation temperature. Thermal annealing, or recovery of this radiation damage, also appears to be related to the fast neutron fluence that caused the damage, the annealing temperature, and the composition of the alloy (EPRI 2006). One important conclusion of EPRI (2006) is that low-fluence data are not relevant to the cases of high-burnup fuels with fast neutron fluences $(\mathrm{E}>1 \mathrm{MeV})$ sometimes exceeding $10^{22} \mathrm{n} / \mathrm{cm} 2$. It was also shown that niobium, used in ZIRLO and M5 cladding, affects the thermal recovery by increasing the onset temperature relative to Zry-2. Zircaloy with low oxygen content recovered at a lower temperature than normal-oxygen Zircaloy.

The overwhelming majority of annealing studies are performed for very short times (about 1-2 hours) at elevated temperatures $\left(400^{\circ} \mathrm{C}\right.$ or higher), mostly to simulate in-reactor problems like reactivity insertion accidents or loss-of-coolant accidents. The data of Ito et al. (2004) are some of the only data directly applicable to extended storage of UNF. The authors tested both SRA Zry-4 and RXA Zry-2 and reported the results of micro-Vickers hardness tests as a function of time at annealing temperature. Hardness continued to recover, albeit quite slowly, at temperatures as low as $330^{\circ} \mathrm{C}$ over 8,000 hours ( 0.9 year); and nearly $50 \%$ recovery was observed over the same time at $360^{\circ} \mathrm{C}$. Thus, over the many years of extended storage, it is very possible that thermal annealing will decrease the hardness and increase ductility. This would lessen the chance of breakage from mechanical shock but could facilitate creep. Thermal annealing also has the potential to release hydrogen trapped in dislocation loops or with the second-phase precipitates. This could ultimately affect the hydrogen-related phenomena.

The Nuclear Waste Technical Review Board (NWTRB 2010) states that annealing is not expected at temperatures below $400^{\circ} \mathrm{C}$. The Dry Cask Storage Characterization Project (DCSCP) (EPRI 2002) has proved that to be the case by showing no signs of annealing after 15 years of storage. However, Ito et al. (2004) showed nearly 50\% recovery over almost 1 year in dry storage conditions at $360^{\circ} \mathrm{C}$.

\subsubsection{Hydrogen Effects: Embrittlement and Reorientation}

During reactor operation, the cladding undergoes outer surface corrosion as the high-temperature water reacts with the cladding, producing a zirconium oxide layer. Hydrogen is released during this chemical reaction, and a fraction of this hydrogen is absorbed by the Zircaloy (hydrogen pickup). The solubility of hydrogen in zirconium is highly temperature dependent, with solubility increasing at higher temperatures. When the concentration of hydrogen exceeds the solubility limit, zirconium hydrides form. Depending on the size, distribution, and orientation, these hydrides can embrittle the cladding and reduce ductility. Furthermore, the presence of hydrides can facilitate cracking if the hydrides are aligned radially, perpendicular to the tensile stress field. Cladding hydrides are typically observed to be oriented in the circumferential direction; but they can reorient to the radial direction, depending on the stress level of the cladding when it is cooled from a higher temperature, as will occur following the drying process used in dry cask storage. Hydrides have also been shown to diffuse to colder regions of the cladding under a relatively small temperature gradient. The reorientation and diffusion of hydrides can result in cracking of the cladding. Even if a through-wall crack is not formed, the extent of cracking needs to be modeled to determine if cladding will then fail as a result of stresses caused by normal handling or transportation. 
The mechanical properties of high-burnup cladding have been studied by subjecting the materials to longitudinal (axial) tensile tests, ring-stretch tests, ring-compression tests, and biaxial tube burst tests. At temperatures relevant to extended storage, the corrosion layer and the hydride rim are brittle. The metal matrix has reduced ductility (compared with as-fabricated cladding) due to irradiation-induced hardening. Based on axial tensile tests, there is a significant decrease in both total and uniform elongation due to irradiation-induced hardening. For high-burnup Zry-2 and Zry-4, mechanical properties can be found in MATPRO (NUREG/CR-6150, Siefken et al. 2001), Garde et al. (Garde 1996), and Aomi et al. (Aomi 2008) Only limited data are available in the literature for the current PWR alloys ZIRLOTM and M5® because Westinghouse and AREVA consider such data to be proprietary. For the metal matrix below the hydride rim, the reduction in ductility is due primarily to irradiation hardening. However, the presence of brittle-corrosion and hydride-rim layers results in crack initiation at stresses lower than the ultimate strength of the metal matrix. As toughness also decreases with irradiation, the metal matrix may exhibit lower ductility due to the presence of the corrosion and hydride-rim layers (Hanson 2012, Aomi 2008).

During the drying-transfer process and during storage, high-burnup cladding is subjected to elevated temperatures ( $\leq 400^{\circ} \mathrm{C}$ based on SFST-ISG-11, Revision 3) and elevated pressures. Technical specifications limit the internal pressure for most assemblies to less than the coolant pressure during normal operation for fuel rods. For a limited number of rods, the internal pressure is limited to 1.3 times the coolant pressure: BWR (9.32 MPa, 1,350 psia) and PWR (20.2 MPa, 2,925 psia). Such internal gas pressures lead to PWR cladding hoop stresses in the range of $130 \pm 20 \mathrm{MPa}$ at $340^{\circ} \mathrm{C}$ during drying and initial storage. For modern BWR cladding, the limiting internal gas pressures lead to cladding hoop stresses in the range of $56 \pm 6 \mathrm{MPa}$ at $290^{\circ} \mathrm{C}$. At a $340^{\circ} \mathrm{C}$ average gas temperature, the BWR stresses would be about $60 \pm 7 \mathrm{MPa}$. At $400^{\circ} \mathrm{C}$, the solubility of hydrogen in Zr-based cladding alloys is about 200 wppm (Kearns 1967; Kammenzind et al. 1996). Cooling under conditions of decreasing stress with decreasing temperature may result in a fraction of the hydrogen in solution precipitating as radial hydrides, which enhances cladding embrittlement in response to hoop stresses.

After cooling to $200^{\circ} \mathrm{C}$, only about 15 wppm hydrogen remains in solution (. Thus, the hydride distribution across the cladding wall and the hydride morphology are essentially fixed after a relatively short storage time during which the cladding temperature drops below $200^{\circ} \mathrm{C}$. The length and distribution of radial hydrides at this point in storage time depends on the peak drying-storage temperature and internal pressure, the cladding alloy, and the manufacturing process. High-burnup cladding has higher decay heat, higher internal pressure, and higher hydrogen content than low-burnup cladding. Therefore, it is more susceptible to radial hydride formation. Niobium-bearing cladding alloys and RXA alloys are more susceptible to radial-hydride precipitation than tin-bearing CWSRA (cold-worked, stress-relief annealed) alloys (e.g., Zry-4; Aomi et al. 2008; Burtseva et al. 2010).

The radial-hydride embrittlement issue for high-burnup cladding is emphasized in SFST-ISG-11, Revision 3 (NRC 2003). Based on data available at that time for pre-hydrided/non-irradiated cladding materials, the following limits were imposed: $400^{\circ} \mathrm{C}$ peak cladding temperature during drying-transferstorage, fewer than 10 thermal cycles, and less than $65^{\circ} \mathrm{C}$ temperature drop during each thermal cycle. The SFST-ISG- $11400^{\circ} \mathrm{C}$ peak cladding temperature limit is based on a PNNL letter report to NRC in 2001 (PNNL 2001) that referred to findings of research conducted by Bouffioux and Legras (2000). Bouffioux and Legras performed annealing test of CWSRA Zircaloy-4 $17 \times 17$ hydrided specimens over a temperature range covering 400 to $520^{\circ} \mathrm{C}$ and hold times from 1 to 1,000 hours. The hydrides in the samples, in the form of circumferentially oriented platelets, ranged from $100 \mathrm{ppm}$ to $350 \mathrm{ppm}$ at the test temperatures. Bouffioux and Legras found that hydriding inhibits the recovery in CWSRA Zircaloy-4 by increasing the hold time, relative to the literature data, for the beginning-of-recovery temperature and the end-of-recovery time to achieve full recrystallization. Creep tests of hydrided specimens (560 ppm) conducted at $400^{\circ} \mathrm{C}$, which involved zero recovery, showed a creep rate reduction factor of five relative to the as-received specimens. However, creep tests of specimens with higher hydrogen content (720$760 \mathrm{ppm}$ ) conducted at $470^{\circ} \mathrm{C}$ for 250 hours showed only a factor of three reduction in the creep rate 
relative to the as-received specimens. This can be attributed to the partial annealing of cold work, which amounted only to $25 \%$ at $470^{\circ} \mathrm{C}$ (Kimball and Billone 2003; EPRI 2007; EPRI 2000).

However, data for high-burnup cladding were not available at that time. Since then, the data generated by Daum et al. (2002, 2006, 2008) for Zr-4, Aomi et al. (2008) for Zr-2 with Zirc lining, and Burtseva et al. (2010) for ZIRLO strongly indicate that these limits are insufficient to prevent radial-hydride formation and embrittlement at cladding temperatures $<200^{\circ} \mathrm{C}$.

Aomi et al. (2008) subjected Zry-2 and Zry-4 to a single drying cycle with peak temperatures in the range of $250-400^{\circ} \mathrm{C}$ and cooling rates of $30^{\circ} \mathrm{C} /$ hour, $3^{\circ} \mathrm{C} /$ hour, and $0.3^{\circ} \mathrm{C} /$ hour. They conducted three types of tests to assess the effects of radial-hydrides on embrittlement: ring compression tests, ring tensile tests, and longitudinal tensile tests. The results indicate that hydride reorientation to the radial direction occurred at a relatively low hydride reorientation treatment (HRT) hoop stress, e.g., less than $70 \mathrm{MPa}$. The increase in reorientation with hoop stress was not monotonic for specimens in which a part of the hydrides remained precipitated at the HRT temperature, such as the case for 50GWd/t type cladding at a $300^{\circ} \mathrm{C}$ HRT. However, the degree of reorientation under relatively moderate HRT conditions depends on the HRT solution temperature rather than on the estimated temperature at which the hydride precipitation occurs. It is suggested that reorientation behavior under relatively moderate HRT conditions - such as $300^{\circ} \mathrm{C}, 70 \mathrm{MPa}$, and $30^{\circ} \mathrm{C} /$ hour - is a complex function of several effects, including the effects of precipitated (not dissolved at the HRT temperature) hydrides and the memory effect. The memory effect is due to the straining within the $\mathrm{Zr}$-alloy lattice and between grain boundaries needed to accommodate the lower density hydrides. Reheating of the sample results in dissolution of hydrogen, but the strained lattice and grain-boundary regions remain. If cooling is performed under stress-free conditions or at stresses too low to reorient precipitation of new hydrides, hydrogen tends to precipitate at the same strained locations where hydrides were observed from the previous heating-cooling cycle. Perhaps related to the memory effect, hydrides that remain precipitated at the peak HRT temperature also act as preferential sites for hydride precipitation during cooling. With regard to locations for precipitation of dissolved hydrogen during cooling, there is competition among sites at which hydrides were present at the peak HRT, sites at which hydrides dissolved during heating, and new sites.

Most of the high-burnup BWR cladding in reactors and in pool storage is Zry-2. The data of Aomi et al. (2008) are relatively comprehensive for this alloy and show a high susceptibility to radial-hydride formation and embrittlement. However, the data set does not include the effects of temperature cycling during drying, of test temperatures higher than room temperature, and of higher displacement rates. Additional data are needed for Zry-2, as well as for newer BWR alloys developed by Global Nuclear Fuels (e.g., ZIRON).

Many factors affect conditions for hydride reorientation and the potential brittleness of the cladding. Temperature, end-of-life rod internal pressure, external stress, and cladding properties are the main factors. There are limited available data in each of these areas, and each one is an active research area.

Billone et al. (2013a) performed ring compression tests on various PWR clad types subjected to radial hyride treatment (RHT). They showed ductile-brittle transition temperature (DBTT) dependence on the clad type as well as hydrogen content and hoop stress. Their results showed the relative effect of decreasing RHT stress and decreasing hydrogen content $\left(\mathrm{CH}_{\mathrm{H}}\right.$ on the DBTT as

- $80^{\circ} \mathrm{C}$ DBTT for peak RHT stress of $140 \mathrm{MPa}$ and $\mathrm{CH}$ of $94 \mathrm{wppm}$

- $70^{\circ} \mathrm{C}$ DBTT for peak RHT stress of $110 \mathrm{MPa}$ and $\mathrm{CH}$ of $72 \mathrm{wppm}$

- $\quad<20^{\circ} \mathrm{C}$ DBTT for peak RHT stress of $90 \mathrm{MPa}$ and $\mathrm{CH}$ of 58 wppm

Based on this research, Billone states that cladding temperatures may not exceed $350^{\circ} \mathrm{C}$ during vacuum drying and storage. For cladding alloys with high hydrogen content (350 to $650 \mathrm{wppm}$ ), the dissolved hydrogen available to precipitate as radial hydrides decreases by $80 \mathrm{wppm}$ with a peak temperature 
decrease from 400 to $350^{\circ} \mathrm{C}$. Moreover, for the same amount of gas inside a fuel rod, there would be a decrease in the temperature, internal pressure, and hoop stress at which radial-hydride precipitation would initiate.

However, Billone et al. (2013b) also showed that uniformly pre-hydrided, non-irradiated cladding was not a good surrogate for high-burnup cladding because of the high density of circumferential hydrides across the wall and the high metal-matrix ductility for prehydrided cladding.

Another important initiative for investigating clad behavior under external stress is the Cyclic Integrated Reversible-bending Fatigue Tester (CIRFT) (Wang et al. 2015). CIRFT is used to determine the effects of vibration and bending on clad failure. Although CIRFT was designed to determine the ability of highburnup (>45 GWd/MTU) spent fuel to maintain its integrity under normal conditions of transportation, it is particularly important for comparing high-burnup PWR and BWR fuel cladding under the same external stress conditions. Under NRC and DOE sponsorship, ORNL performed CIRFT tests for H. B. Robinson PWR high-burnup fuel with Zircolay-4 clad, Limerick BWR high-burnup fuel with Zircaloy lined Zircolay-2 clad, North Anna Power Station PWR high-burnup fuel with M5 clad, and Catawba PWR mixed oxide fuel with M5 clad.

An important finding from the CIRFT is that despite different physical properties and operating environments (water chemistry, temperature, pressure), BWR and $\mathrm{PWR} \mathrm{UO}_{2}$ fuel rod claddings show similar performance under CIRFT evaluation. The numbers of cycles to failure versus strain and moment amplitude curves are very similar for high-burnup Zircolay-2 and Zircolay-4 clad types.

\subsubsection{Hydrogen Effects: Delayed Hydride Cracking}

Delayed hydride cracking (DHC) is a time-dependent mechanism traditionally thought of as diffusion of hydrogen to an incipient crack tip (flaw) followed by nucleation, growth, and fracture of the hydride at the crack tip. The process continues as long as a sufficient stress to promote the hydrogen diffusion occurs (Puls 2009; McRae et al. 2010). DHC has traditionally been ruled out as a possible mechanism for cladding degradation during extended storage because as the temperatures decrease, the stress decreases and becomes insufficient to promote crack propagation (BSC 2004a; EPRI 2002b; Rothman 1984). However, Rothman (1984) noted that additional data are necessary for larger crack depths ( $50 \%$ of wall thickness).

The earlier models did not account for the hysteresis in the hydrogen/zirconium solvus, which has important effects on the temperature dependence of the DHC velocity (Puls 2005). This hysteresis shows that the hydrogen concentration can be substantially higher on a cooling solvus line than for a heating solvus line (Kim 2008).

DHC is a known failure mechanism in pressure tubes of the Zry-2.5\% Nb alloy used in the CANDU and RBMK reactors (IAEA 2004) as well as in the Zry-2 tubing used in the Hanford N-reactor (Huang et al. 1991). Simpson and Ells (Simpson 1974) reported DHC failure of unirradiated Zry-2.5\% Nb specimens at room temperature over periods of from 4 to 5 weeks to up to 24 months. Huang et al. reported that cracking occurred only above a critical temperature $\left(180^{\circ} \mathrm{C}\right)$ when specimens were subjected to an overtemperature cycle. Below that temperature, DHC occurred regardless of whether specimens were heated or cooled to the test temperature (Huang et al. 1991). Chao et al. (Chao 2008) report that the location of the crack is important in determining whether or not the cladding will breach, with the greatest chance being when the crack is located on the outer side of the cladding.

Kim (2009) has proposed a new model for DHC. In this model, creep deformation, prior creep strain, higher burnup, the solvus hysteresis, and the $\gamma$ to $\delta$ hydride phase transition all play important roles in DHC. Although there is much disagreement (EPRI 2002; McRae et al. 2010) with Kim's model (Kim 2009), if Kim's hypotheses are correct, then spent fuel will be more likely to fail by DHC upon cooling below $180^{\circ} \mathrm{C}$ if there are stress raisers inside the rod, such as the end cap weld region or incipient cracks 
due to an interaction of fuel and cladding during reactor operation. This may be one factor in explaining why DHC failure was not observed in the 15 year demonstration project in which the fuel temperature in an open cask (a lower temperature than in a sealed cask) was measured as $154^{\circ} \mathrm{C}$. A second factor is that the fuel was relatively low-burnup, so the hydrogen concentration may have been too low for the mechanism proposed by Kim to occur. The proposal of Kim that prior plastic deformation of the cladding may be a preferential site for DHC needs to be examined further.

Nakatsuka et al. (2010) reported that DHC initiates in the metal at oxide cracks at the metal-oxide interface at the outer diameter of Zr-2 RXA. These DHC tests have been performed at constant temperature with the hoop stress changing with time over a period of several $(<25)$ minutes using Zry-2 RXA cladding. Oxide cracking occurred at hoop stresses between 100 and $170 \mathrm{MPa}$ with strains of $0.21 \%$. The zirconium hydrides in the metal were observed to begin cracking between 200 and $350 \mathrm{MPa}$ hoop stress with strains of $0.34 \%$. Holston et al. (2010) reported that DHC is present only at temperatures below $380^{\circ} \mathrm{C}(653 \mathrm{~K})$ in either Zry-2 or Zry-4 at constant temperature for only a few minutes. This paper noted that, for the conditions tested, several parameters had to be satisfied for DHC to be observed: (1) high hydrogen levels near the crack tip, (2) temperatures less than $380^{\circ} \mathrm{C}$, and (3) sufficient stress levels at the crack tip (above $600 \mathrm{MPa}$ ) or stress riser (hydride tip).

\subsubsection{Metal Fatigue Caused by Temperature Fluctuation}

With longer storage times, there are more summer-winter temperature fluctuations and an increased likelihood of extreme weather conditions. However, the temperature of the assembly hardware is not expected to be significantly affected by those fluctuations, given the relatively large heat capacity of storage systems and the fact that assembly hardware is an integral component of the heat-generating fuel. Although temperature fluctuations may result in changes in the material properties of the assembly hardware, they are not likely to result in a failure. Material property changes are important in evaluating assembly hardware performance during design-basis accidents and transportation hypothetical accident conditions

The NRC notes that cumulative stress cycles of sufficient magnitude can lead to a change in material properties, metal fatigue, and failure below yield strength. Metal fatigue because of temperature fluctuations of the fuel assembly hardware would likely be more operative during extended storage beyond 40 years, resulting from the increase in the accumulated number of stress/temperature cycles over time (NRC 2012a)

\subsubsection{Oxidation}

Oxidation of Zircaloy is a thermally induced process and requires an oxidant. During normal cask operations during which a DCSS is filled with inert gas (e.g., helium), oxidation cannot occur. Oxidation may occur because of a reaction with oxygen if the DCSS is mistakenly backfilled with air, because a leak allows oxygen into the DCSS, or because of oxygen production from radiolysis of residual water (including waterlogged rods).

At higher burnups, the fuel-clad gap is closed and the fuel is in direct contact with the cladding. Often, as a result of oxygen and zirconium transport, clad forms a mixture at the fuel/clad interface. Thermodynamics predicts that zirconium will take oxygen from $\mathrm{UO}_{2}$ at all temperatures of interest, thus forming an oxide layer on the fuel side of the cladding as well. Rothman (1984) examined multiple cladding oxidation conditions and predicted cladding thinning of 4 to $53 \mu \mathrm{m}$ (up to $9 \%$ of cladding thickness) after 10,000 years at $180^{\circ} \mathrm{C}$. Based on this prediction, oxidation-whether from steam, water, or air-is considered inconsequential for extended dry storage. Accelerated tests of defective fuel rod segments in closed test vessels with humid air at $175^{\circ} \mathrm{C}$ were conducted at Argonne National Laboratory (BSC 2004b) and showed extensive fuel-side corrosion of the cladding and axial splitting after 1.5 years. 
These conditions were probably initially more oxidizing than those that would be experienced by a waterlogged rod in dry storage under an inert atmosphere. The splitting was interpreted as the direct result of the fuel-side corrosion/oxidation of the cladding and associated specific volume increase of the observed monoclinic $\mathrm{ZrO}_{2}$ corrosion products. Through-wall penetration of the cladding up to $18 \%$ was observed. According to BSC 2004b,

This result indicated that regions on the fuel-side of the cladding had corroded actively under the humid ( $100 \%$ relative humidity) $175^{\circ} \mathrm{C}$ test conditions. It is likely that this corrosion was caused by the occurrence of some water vapor condensation in local regions of the fuel-cladding interface that served as an electrolyte within which the corrosion potentials exceeded the Zircaloy repassivation potential or the passive layer breakdown potential. (BSC 2004b).

It is possible that corrosion due to humid air is much more aggressive than the dry-air or saturated corrosion mechanisms that have been extensively studied. Another hypothesis is that the rapid oxidation may have been promoted by deliquescent fission product salts at those regions. Conditions under which breakdown of the Zircaloy passive layer may occur are described by Pan et al. (2001).

Oxidation of UNF has also been shown (Hanson 1998) to be a function of burnup, with higher-burnup fuels being significantly more resistant to formation of oxides with $\mathrm{O} / \mathrm{M}$ ratios above 2.4. There has been some concern that the highly porous HBS in high-burnup fuels would oxidize rapidly, but the results in Hanson et al. (2008) have shown that is not the case.

The temperature range for $\mathrm{U}_{3} \mathrm{O}_{8}$ formation in an air atmosphere is $450-600^{\circ} \mathrm{C}$. In an air atmosphere, the higher temperature is necessary to give a more rapid reaction rate. In pure oxygen, the lower temperature is sufficient. In an $\mathrm{NO}_{2}$ atmosphere, the reaction temperature is $350^{\circ} \mathrm{C}$. (Collins 2015)

Gas release depends on burnup of fuel, but all of the gaseous fission products-xenon, krypton, tritium, and iodine-are released as the ceramic $\mathrm{UO}_{2}$ pellet is converted to $\mathrm{U}_{3} \mathrm{O}_{8}$ powder (SCALE/ORIGEN calculations can provide amounts of the gaseous fission products relative to heavy metal). On heating above $600^{\circ} \mathrm{C}$, other semi-volatile fission products can be vaporized, such as technetium, molybdenum, and cesium. (Collins 2015)

\subsubsection{Wet Corrosion}

Wet corrosion can occur only when water is present within the DCSS. Residual water will always remain after even a successful drying procedure. The free water should be minimal, but there can be physisorbed and chemisorbed water present, especially in the oxide and crud layers on the cladding and in any breached rods. Cladding wet corrosion mechanisms include general corrosion, pitting corrosion, SCC, crevice corrosion, and galvanic corrosion; it also can be facilitated by waterlogged rods and radiolysis of air and water. The amount of water will determine which, if any, of the wet corrosion mechanisms are applicable. Therefore, assuming drying occurs as proposed, it is assumed that the water remaining would be insufficient to have any real effect.

Kohli et al. (1985) showed that the bulk of the water in a waterlogged rod was released not just during vacuum drying, but during vacuum drying at a temperature of $100^{\circ} \mathrm{C}$. Because of decay heat, the fuel in most DCSS drying can approach the NRC recommendation of $400^{\circ} \mathrm{C}$ peak clad temperature. It would be expected that most water would be removed during drying. However, the reactor-induced breaches in the rods tested by Kohli et al. were relatively large and could be seen by visual examination. In addition, "holes ( $3.0 \mathrm{~mm}$ in diameter) were drilled in the plenum region of each rod to release any water that may have been trapped in the plenum" (Kohli et al.). Multiple large defects allow water to be released and have less chance of icing up (sealing) during vacuum drying. Even with these multiple large defects, the rods continued to outgas for about 1,000 hours at $325^{\circ} \mathrm{C}$ (Kohli et al.). Waterlogged rods would be 
capable of producing high relative humidities at temperatures higher than $175^{\circ} \mathrm{C}$ and could result in clad unzipping, as was observed in tests conducted at Argonne National Laboratory (BSC 2004b).

Radiolysis of water can result in the production of oxygen or highly oxidizing species (e.g., $\mathrm{OH}$ or $\mathrm{H}_{2} \mathrm{O}_{2}$ ) that can then corrode fuel, cladding, or cask internals. However, the water present is limited to what may be left in a cask after vacuum drying (as free, chemisorbed, or physisorbed water) or in waterlogged rods. Radiolysis of nitrogen (from either air ingress or mistaken backfill) can result in the production of very aggressive oxidants such as nitric acid, even though concentrations may be low (Sunder and Miller 1996; Delegard et al. 2009). Water reactions could produce hydrogen that could react with the cladding, resulting in embrittlement.

\subsubsection{Creep}

The main driving force for cladding creep is the hoop stress caused by internal rod pressure, which will decrease over time as the temperature decreases and the rod volume increases. The hoop stresses are between 30 and $200 \mathrm{MPa}$ for a $17 \times 17 \mathrm{PWR}$ fuel rod and 12 to $130 \mathrm{MPa}$ for a $10 \times 10 \mathrm{BWR}$ rod at $400{ }^{\circ} \mathrm{C}$. Creep is considered self-limiting; as creep increases, the internal volume of the rod increases, which results in the pressure decreasing and reducing the hoop stress. Clad creep to failure typically results in a very small defect (pinhole or hairline crack) that will release the internal gas, including fission gases. However, of equal or more importance is whether creep, which thins the wall thickness of the cladding, is sufficient to make the rods susceptible to breaking at those thin points during handling or transportation.

Examination of UNF with burnups of up to $36 \mathrm{GWd} / \mathrm{MTU}$ stored for approximately 15 years in a CASTOR V/21 dry storage cask as part of the DCSCP showed that the maximum creep was no more than 0.1\% (EPRI 2002a). However, no rod profilometry data was available for the rods before storage, so this conclusion is based on a comparison with as-fabricated data and not a comparison with actual pre-storage experimental data. Note that the diameter of the cladding can change significantly in-reactor as a result of creepdown and fuel swelling; therefore, as-fabricated data would not be capable of revealing creep strains of $1 \%$ or smaller in these fuel rods. In addition, the low-burnup fuel in this test had fuel rod pressures that can be a factor of 2 to 7 lower than those in limiting-high burnup rods in today's aggressive operating plants.

In creep tests at temperatures from 250 to $400^{\circ} \mathrm{C}$ of Zircaloy cladding irradiated to a burnup of up to 64 GWd/MTU, no failures have been observed below 2\% strain (Goll et al. 2001; EPRI 2002b). However, all test durations were between a few days and at most 100 days (2,400 hours). In addition, those tests above $1 \%$ strain were all performed near $400^{\circ} \mathrm{C}$, where annealing improves cladding ductility. An exception is the failure observed by Tsai and Billone (2003) when a high-burnup cladding was cooled from $400^{\circ} \mathrm{C}$ at $190 \mathrm{MPa}$ hoop stress, although that failure occurred at the end caps. Examination revealed that a significant amount of hydride reorientation had occurred.

It is often stated that at temperatures below $300^{\circ} \mathrm{C}$, creep may be considered to be immeasurably slow and not a factor in extended storage under normal operation (EPRI 2002b). However, there are multiple mechanisms for cladding creep (Murty 2000). These mechanisms come into play under different temperature and stress regimes. Murty warns that

"blind extrapolations of the short-term, high stress data to low stresses and temperatures could lead to nonconservative predictions of the creep rates, creep strains, and lifetimes due to the dominance of viscous creep mechanisms, such as Nabarro-Herring, Coble, and Harper-Dorn creep at low stresses” (Murty 2000).

Chin et al. (1986) have created a deformation and fracture map that predicts creep failure mechanisms for Zircaloy cladding within the different temperature and stress regimes, but most of the data used for this mapping were from nonirradiated cladding. This deformation and fracture map was then incorporated into the DATING computer code for predicting cladding creep and rupture in UNF (Simonen and Gilbert 
1988). This creep and rupture model/code was updated later based on a much larger amount of creep and rupture data from unirradiated Zry-4 CWSRA and Zry-2 RXA cladding, and a much smaller amount of data from irradiated cladding (Gilbert et al. 2002).

Another potential source of clad strain, regardless of internal pressure, is the fuel-clad bond. Fuel pellet hourglass swelling and clad creepdown during reactor operations can lead to "bambooing," which may not be visible but creates more strain at the pellet-pellet interfaces. This strain would be present even at low temperatures and after the rod has been depressurized because of a breach. Although the strain is obviously much lower than the strain from internal gas pressure, it must be analyzed to see if it contributes to creep for some of the low-strain mechanisms discussed by Murty (2000).

Finally, the contribution of oxide and crud layers and hydride concentration and orientation to creep behavior needs to be better determined.

Although it seems clear that the traditional high-temperature, high-strain creep mechanism will be limited during extended storage, it is unclear if low-temperature, low-strain mechanisms will be operative. However, creep to failure is only a minor issue; creep such that the cladding breaks during handling or transportation is more of a concern.

\subsection{DRY STORAGE CONTAINER INTEGRITY}

Initially, casks for dry storage of spent fuel were licensed for assembly-average burnup of about $35 \mathrm{GWd}$ /MTU. Over the past several decades, the discharge burnup of fuel has increased steadily and now exceeds $45 \mathrm{GWd} / \mathrm{MTU}$. With spent fuel burnups approaching the US licensing limits (peak rod burnup of $62 \mathrm{GWd} / \mathrm{MTU}$ ) and some lead test assemblies being burned beyond this limit, the need for confirmatory dry storage demonstration programs in the US is ongoing.

Two types of confinement containers are currently in use in DSSs_-bolted metal casks and welded metal canisters. The confinement container provides a physical barrier to perform several safety functions:

- $\quad$ Prevent release of radionuclides

- Maintain an inert atmosphere for the container internals to prevent chemical degradation and enhance heat transfer

- Prevent ingress of moderator (water) to provide additional criticality protection

Welded canisters are stored or transported within a separate, air-ventilated overpack that provides both neutron shielding and physical protection. Bolted direct-load casks have integral gamma and neutron shielding with a thick metal body and polymer-resin neutron shields. The bolted direct-load casks are mechanically sealed via a combination of lids, bolts, and physical seals. A weather cover is positioned over the bolts and seals to protect them from rainwater. Numerous degradation mechanisms exist that could compromise the listed safety functions of either type of confinement container. (Hanson et al. 2012)

Degradation mechanisms considered for components of the steel and cast iron casks and stainless steel canisters include uniform corrosion, localized corrosion, thermal-mechanical degradation, and irradiation damage. The level of knowledge regarding the degradation mechanisms and the status of monitoring and inspection techniques varies. Some degradation mechanisms - such as microbiologically influenced corrosion and irradiation damage of stainless steel or steel and cast iron casks - are well understood, and the threshold for diminished canister mechanical properties is unlikely to be reached during the extended storage period. (NRC 2012b) Degradation mechanisms that could impact canister performance during the extended storage period are discussed in Section 2.4.1.

Degradation mechanisms considered for concrete components (overpacks, vaults, and pads) include cracking, spallation, rebar corrosion, chemical degradation, and radiation damage. These effects on 
concrete are fairly well understood, and inspection/repair techniques have been routinely applied at nuclear power plants. (NRC 2012b) Therefore, those concrete degradation mechanisms are not discussed further.

\subsubsection{Container Aging Management}

In the United States, when a spent fuel cask CoC comes up for renewal, an aging management process is required by 10 CFR 72.240 to ensure that the existing licensing basis remains valid. The aging management process includes time-limited aging analyses (TLAAs) to assess SSCs that are important to safety with a time-dependent operating life. An aging management review also includes an AMP to ensure that any aging effects do not result in the loss of the intended safety function SSCs within the scope of the original CoC (Chopra et al. 2014). An AMP may include prevention, mitigation, condition monitoring, and performance monitoring (NRC 2011)

In reality, the management of aging effects on DCSSs for extended long-term storage and transportation of used fuel "begins" when the used fuel assemblies are loaded into a canister (or cask) under water in the spent fuel pool. Managing aging effects on DCSSs for extended long-term storage and transportation of used fuel requires knowledge and understanding of the various aging degradation mechanisms for the materials used in the SSCs and their environmental exposure conditions for the intended period of operation (Chopra et al. 2014).

Generic container TLAAs include

- Fatigue of metal and concrete structures and components

- General corrosion analysis of metal components

- Time-dependent degradation of neutron-absorbing materials

- Time-dependent degradation of radiation-shielding materials

Generic container AMPs include

- Concrete structure monitoring program

- Monitoring of protective coatings on carbon steel structures

- External surface monitoring of mechanical components

- Ventilation system surveillance program

- Welded canister seal and leakage monitoring program

- Bolted cask seal and leakage monitoring program

- Canister/cask internals structural and functional integrity program

The lessons learned from the application of TLAAs and AMPs support the knowledge base for extended long-term storage.

\subsubsection{Canister Basket Degradation}

Dry storage canisters include a basket assembly to maintain fuel assembly spacing during wet loading or unloading, which ensures retrievability (see requirements in Section 1.3) and subcriticality. The basket assembly is also designed to ensure thermal performance. The baskets are made of aluminum alloys, Inconel, carbon steel, or stainless steel, and the associated weld metals. Neutron poisons are also added to the dry storage canister to provide criticality control whenever a water moderator is in the canister.

Without a water moderator, the inert atmosphere in the canister will not support criticality. (Hanson et al. 2012) 
Any deformation of the canister basket could lead to physical binding of the stored fuel assemblies, which would impact retrievability. Aluminum baskets may be subject to creep as a result of extended time at an elevated temperature while under stress. Creep of fuel baskets may lead to lack of control of geometry, which would affect retrievability and thermal performance and might have implications for maintaining subcriticality in a water environment. Little is known about the initiation and rate of creep effects in aluminum. Over time, as the canister temperatures decrease, creep may become less likely. Steel basket assemblies are not expected to be subject to creep, based on the temperatures observed inside loaded canisters and the known properties of steel. (NRC 2012)

Canister basket corrosion could be an issue if residual moisture remains in the canister after drying or if excessively waterlogged rods are included. The structural integrity of the basket assembly could be reduced, which would impact the retrievability of the fuel assemblies. In addition, the thermal conductivity of the basket could be affected as the material thins. Stainless steel basket assemblies would be less susceptible to corrosion. (Sindelar et al. 2011)

Long-term exposure of austenitic stainless steel welds containing ferrite to elevated temperatures has the potential to embrittle the weld metal of stainless steel baskets in SNF casks. The degradation mechanism is well understood. However, there has been little gap assessment of this effect on basket welds exposed to long-term thermal aging. (NRC 2012)

\subsubsection{Welded Canister Issues}

Aggressive compounds in solution, including chlorides in marine atmospheres and pollutants such as oxidized sulfur species, could cause atmospheric stress corrosion cracking of stainless steel canisters. The deliquescence of deposits on the canister surfaces when wetted and the stresses in the canister from the fabrication process can promote stress corrosion cracking. As a result, it is likely that the conditions for stress corrosion cracking in stainless steel canisters will be present during extended storage and transportation (Sindelar et al. 2011). The effect is fairly well understood, and inspection techniques have been applied at nuclear power plants; but the long-term impact on DSSs has not been studied thoroughly. (NRC 2012)

When the canister has cooled sufficiently during extended storage (i.e., periods $>40$ years), condensation on the cask surface may occur. The deliquescence of deposits of aggressive compounds on the canister surfaces in the presence of condensation could promote localized aqueous corrosion of stainless steel canisters. As with stress corrosion cracking, it is likely that the conditions for localized aqueous corrosion of stainless steel canisters will be present during extended storage and transportation (Sindelar et al. 2011). Stainless steels are known to be susceptible to localized corrosion attack in welded regions. The effect is fairly well understood, and inspection techniques have been applied at nuclear power plants; but the long-term impact on DSSs has not been studied thoroughly. (NRC 2012)

\subsubsection{Atmospheric and Aqueous Corrosion of Bolted Casks}

Carbon steel, low-alloy steel, and cast iron used in casks, as well as the associated mechanical seals and closure bolts, are protected from the environment by coatings and polymer seals (Sindelar et al. 2011). Atmospheric or aqueous corrosion may occur if the coating systems are damaged or degrade over time so that the underlying steel or cast iron is exposed. The coating systems can be damaged by atmospheric conditions, continued exposure to high temperature, radiation exposure, or mechanical impacts. The corrosion process will proceed only if a sufficient water film thickness exists to support an electrochemical corrosion reaction. Coating or steel damage, and the accumulation of atmospheric deposits that promote corrosion in the presence of a stable aqueous phase on the cask surface, are more likely to occur during extended storage (i.e., periods $>40$ years). The effect is fairly well understood and, inspection techniques have been applied at nuclear power plants. Mitigation will require long-term inspection and coating repair maintenance activities. (NRC 2012) 


\subsubsection{Thermal-Mechanical Fatigue of Seals and Bolts}

Metallic gaskets and bolts are essential components in the confinement of a bolted closure and are both subject to aging when subjected to thermal and mechanical forces. Over long periods of time at elevated temperatures, the metallic seals on bolted casks may undergo creep. The creep of the metallic seals may, in turn, lead to a loss of the sealing force between the cask body and the cask lid. The creep rate will decrease with time as the cask temperature decreases (NRC 2012b). Therefore, the most significant creep degradation of the cask seal should occur early in the extended storage period. Likewise, carbon steel and low-alloy steel bolts are subject to general corrosion, stress corrosion cracking, embrittlement, and creep. With time, bolt failure can occur and, if it is sequential, a loss of gasket compression and leak tightness would be expected. Bolts are not expected to last for the extended storage periods considered. As a result, bolting is considered a maintenance item that would be replaced periodically. Forecasting century-long performance from 25,000-hour-long experiments is a difficult process; therefore, accurate assessments of gasket behavior are not available. (Sindelar et al. 2011)

\subsubsection{High-Burnup Storage Demonstration Planned at North Anna Power Station}

The Department of Energy (DOE) Office of Nuclear Energy (NE) is sponsoring the High Burnup Dry Storage Cask Research and Development Project (EPRI 2014) to understand the effects of high-burnup fuel ( $>45 \mathrm{GWd} / \mathrm{MTU}$ ) on long-term storage and transportation for PWR fuel. A TN-32B bolted-lid cask (the Research Project Cask) will be loaded with intact, high-burnup SNF from Dominion Virginia Power's North Anna Power Station with four different kinds of cladding: standard Zircaloy-4, low-tin Zircaloy-4, Zirlo, and M5. All the PWR SNF to be loaded into the cask is already present in the North Anna spent fuel pool. The TN-32B lid will be modified to allow the insertion of temperature probes inside the cask at various axial and radial locations for continuous temperature monitoring, and cask cavity gas samples will be obtained at various times during the storage period to obtain information on the presence of residual water and to identify if there has been a breach of cladding. The test program will also include a "sister rod" non-destructive and destructive post irradiation examination (PIE) evaluation of 25 SNF rods extracted from seven different spent nuclear fuel assemblies. The connotation "sister rod" indicates that these fuel rods have similar characteristics to fuel rods in the Research Project Cask because they have been extracted from assemblies that have the same design and similar operating histories (symmetric partners) or come from actual fuel assemblies that will be included in the Research Project Cask. Testing will be performed and data collected to provide an understanding of the mechanical properties changes that occurs to the SNF during drying that can be confirmed at the end of the Research Project Cask dry storage period.

The goals of the HDRP are to provide confirmatory data for model validation and potential improvement, to provide input to future SNF dry storage cask design, to support license renewals and new licenses for ISFSI facilities, and to support transportation licensing for high-burnup SNF. (EPRI 2014) No similar test is currently planned for high-burnup BWR fuel. 


\section{MONITORING}

In the nuclear industry, monitoring generally refers to a continuous activity, whereas inspection is a periodic activity that may or may not involve $100 \%$ of the SSCs to be inspected. There is a definite need to develop capabilities to allow monitoring and inspection using nondestructive techniques that do not call for penetrating confinement barriers.

The regulation in 10 CFR 72.122 requires storage confinement systems "must have the capability for continuous monitoring in a manner such that the licensee will be able to determine when corrective action needs to be taken to maintain safe storage conditions." And 10 CFR 72.128 requires "a capability to test and monitor components important to safety." Section IV.4 of SFST-ISG-5 (NRC 1998) states "the [NRC] staff has accepted routine surveillance programs and active instrumentation to meet the continuous monitoring requirements." SFST-ISG-5 also states "NRC staff has found that casks closed entirely by welding do not require monitoring. However, for casks with bolted closures, the staff has found that a seal monitoring system has been needed in order to adequately demonstrate that seals can function and maintain a helium atmosphere for the 20-year license period, and "the staff has accepted monitoring systems as not important to safety... . Although [their] function is to monitor confinement seal integrity, failure of the monitoring system alone does not result in a gross release of radioactive material.”

Monitoring/inspection can be applied for research purposes in demonstration projects, or more generally at the utilities. At the utilities in the United States, monitoring of the confinement boundary for bolted casks is required. This is usually done by monitoring the pressure between the redundant seals. Other routine monitoring/inspection activities include daily surveillance of overpack inlets and outlets for blockage, periodic radiation surveys, and visual inspection of the exterior of the cask or overpack. Recent monitoring of Calvert Cliffs, Hope Creek, and Diablo Canyon DSSs included temperature measurements, SaltSmart samples, and dry samples from the accessible areas. Currently, continuous lid temperature monitoring and volumetric measurements of canister shells by rotating scanners are being tested for early detection of changes in canister conditions.

For research purposes, monitoring/inspection can provide data to provide input to and evaluation of SSC degradation models. Several methodologies_-including active/passive acoustic measurement systems, gas mass spectroscopies, and magnetic measurements - have been proposed for internal and external monitoring of DSSs for fuel integrity, corrosion, and canister SCC (Meyer et al. 2014a; Meyer et al. 2014b; Meyer et al. 2013). However, none of these systems is expected to be completed in time for the HDRP cask.

Long-term monitoring is part of the AMP currently being developed. Proposed monitoring strategies for AMP include

- concrete structure monitoring

- monitoring of protective coatings on carbon steel structures

- external surface monitoring of mechanical components

- ventilation system surveillance

- welded canister seal and leakage monitoring

- bolted cask seal and leakage monitoring

- canister/cask internal structural and functional integrity monitoring

NRC guidance for AMPs for SCC (Dunn 2014) includes suggestions regarding sizes of samples, measurement frequencies, methodologies, and timing of inspections. 


\section{REFERENCES}

EPRI. 2014. High Burnup Dry Storage Cask Research and Development Project: Final Test Plan. Contract No.: DE-NE-0000593. Electric Power Research Institute, Palo Alto, California.

NRC Regulations Title 10, Code of Regulations, Part 71- "Packaging and Transportation of Radioactive Material”, Nuclear Regulatory Commission, Washington, DC.

NRC Regulations Title 10, Code of Regulations, Part 71- Licensing Requirements For The Independent Storage Of Spent Nuclear Fuel, High-“Level Radioactive Waste, And Reactor-Related Greater Than Class C Waste”, Nuclear Regulatory Commission, Washington, DC.

NRC. (2000). Standard Review Plan for Spent Fuel Storage Facilities, NUREG-1567, Nuclear Regulatory Commission, Washington, DC.

NRC. (2010). Standard Review Plan for Spent Fuel Dry Storage Systems at a General License Facility, NUREG-1536, Revision 1, Nuclear Regulatory Commission, Washington, DC.

NRC. (2011). Standard Review Plan for Renewal of Spent Fuel Dry Cask Storage System Licenses and Certificates of Compliance, NUREG-1927, Nuclear Regulatory Commission, Washington, DC.

NRC. (2015). Standard Review Plan for Renewal of Spent Fuel Dry Cask Storage System Licenses and Certificates of Compliance, NUREG-1927, Draft Revision 1, Nuclear Regulatory Commission, Washington, DC.

Haney, Catherine (2015), Retrievability Of Spent Fuel At Dry Storage Independent Spent Fuel Storage Installations, ML15170A160. Memorandum to NRC Commissioners.

Wong, E. (2015), “Fuel Retrievability for Storage Under Part 72”, NRC Presentation, Public Meeting on Retrievability of Spent Fuel from Storage at an IFSI.

Hanson BD, et al. 2012. Gap Analysis to Support Extended Storage of Used Nuclear Fuel ,PNNL-20509, Rev. 0, Pacific Northwest National Laboratory, Richland, Washington.

McKinnon MA and ME Cunningham. 2003. Dry Storage Demonstration for High-Burnup Spent Nuclear Fuel - Feasibility Study. PNNL-14390, Pacific Northwest National Laboratory, Richland, Washington.

EPRI. 1998. Data Needs for Long-Term Dry Storage of LWR Fuel. TR-108757, Electric Power Research Institute, Palo Alto, California.

NRC. (2003). Cladding Considerations for the transportation and Storage of Spent Fuel, Spent Fuel Project Office, Interim Staff Guidance-11, Revision 3, Nuclear Regulatory Commission, Washington, DC.

Burtseva TA, Y Yan, and MC Billone. 2010. Radial-Hydride-Induced Embrittlement of High-Burnup ZIRLO Cladding Exposed to Simulated Drying Conditions. ANL letter report to NRC, June 20, 2010. 
Daum, R. S., Majumdar, S., Tsai, H. C., Bray, T. S., Koss, D. A., Motta, A. T., and Billone, M. C., Mechanical property testing of irradiated Zircaloy cladding under reactor transient conditions, Small Specimen Test Techniques: Fourth Volume, 2002, p.

195-210.1)

Daum RS, S Majumdar, YY Liu, and MC Billone. 2006. Radial-hydride Embrittlement of High-burnup Zircaloy-4 Fuel Cladding. Journal of Nuclear Science and Technology 43(9):1-14.

Aomi M, T Baba, T Miyashito, K Kaminura, T Yasuda, and Y Shinohara. 2008. Evaluation of Hydride Reorientation Behavior and Mechanical Properties for High-Burnup Fuel-Cladding Tubes in Interim Dry Storage. J. ASTM International 5(9).

**Holston AA, V Grigoriev, G Lysell, R Källström, B Johansson, L Hallstadius, G Zhou, I Arimescu, and M Lloret. 2010. A Combined Approach to Predict the Sensitivity of Fuel Cladding to Hydrogen-Induced Failures during Power Ramps. In Proceedings of the 2010 LWR Fuel Performance Meeting, Top Fuel/WRFPM, p. 167. American Nuclear Society, La Grange Park, Illinois.

** Not delivered with this report

Michener TE, DR Rector, JM Cuta, RE Dodge, and CW Enderlin. 1995. COBRA-SFS: A ThermalHydraulic Code for Spent Fuel Storage and Transportation Casks. PNL-10782, Pacific Northwest Laboratory, Richland, Washington.

**STAR-CD User Guide Version 3.20. 2004. CD adapco Group, London.

McKinnon MA and VA Deloach. 1993. Spent Nuclear Fuel Storage - Performance Tests and Demonstrations. PNL-8451, Pacific Northwest Laboratory, Richland, Washington.

Saegusa, T. et al. (2010), Review And Future Issues On Spent Nuclear Fuel Storage. Nucl. Eng and Tech., Vol.42-3, June 2010.

Shirai, K., 2003, Experimental Studies of Free-Standing Spent Fuel Storage Cask subjected to Strong Earthquakes, Trans. of the 17th International Conference on Structural Mechanics in Reactor Technology Prague, Czech Republic, August 17 -22, 2003.

ASTM C1553-08 (2008), Standard Guide for Drying Behavior of Spent Nuclear Fuel, West Conshohocken, PA, 2008.

Knoll RW and ER Gilbert. 1987. Evaluation of Cover Gas Impurities and Their Effects on the Dry Storage of LWR Spent Fuel. PNL-6365, Pacific Northwest Laboratory, Richland, Washington.

Jung H. et al., 2013. Extended Storage and Transportation: Evaluation of Drying Adequacy. ML13169A039. U.S. Nuclear Regulatory Commission, Washington, D.C.

Wittman R. 2013. Radiolysis Model Sensitivity Analysis for a Used Fuel Storage Canister. FCRD-UFD2013-000357. PNNL-22773. Prepared for the U.S. Department of Energy Used Fuel Disposition Campaign, Washington, D.C.

Miller L, D Basu, K Das, T Mintz, R Pabalan, G Walter, and G Oberson. 2013a. Overview of Vacuum Drying Methods and Factors Affecting the Quantity of Residual Water after Drying - Public Version. ML13192A125. U.S. Nuclear Regulatory Commission, Washington, D.C. 
Miller L, G Walter, T Mintz, T Wilt, and G Oberson. 2013b. Vacuum Drying Test Plan - Public Version. ML13192A127. U.S. Nuclear Regulatory Commission, Washington, D.C.

Radulescu, G. et al. (2012). An Approach for Validating Actinide and Fission Product Burnup Credit Criticality Safety Analysis-Isotopic Composition Predictions, NUREG/CR-7108 (ORNL/TM-2011/509), Nuclear Regulatory Commission, Washington, DC.

Scaglione, JM. et al. (2012). An Approach for Validating Actinide and Fission Product Burnup Credit Criticality Safety Analysis_Criticality $\left(k_{\text {eff }}\right.$ ) Predictions, NUREG/CR-7109 (ORNL/TM-2011/514), Nuclear Regulatory Commission, Washington, DC.

Leal L., et al., Assessment of Fission Product Cross-Section Data for Burnup Credit Applications, ORNL/TM-2005/065, Oak Ridge National Laboratory, Oak Ridge, Tenn., December 2007.

NRC (2012). Burnup Credit in the Criticality Safety Analyses of PWR Spent Fuel in Transport and Storage Casks, Spent Fuel Project Office, Interim Staff Guidance-8, Revision 3, Nuclear Regulatory Commission, Washington, DC.

Mueller D. (2013), Computational Benchmark for Estimated Reactivity Margin from Fission Products and Minor Actinides in BWR Burnup Credit, NUREG/CR-7157, ORNL/TM-2012/96, U.S. Nuclear Regulatory Commission, Oak Ridge National Laboratory, 2013.

Banerjee, K. et al. (2015), Criticality Safety Assessment for As-loaded Spent Fuel Storage and Transportation Casks, International Workshop On Operational and Regulatory Aspects of Criticality safety, Albuquerque, New Mexico, May, 2015.

Marshall, WJ. et al. (2012), Consequences of Fuel Failure on Criticality Safety of Used Nuclear Fuel, ORNL/TM-2012/325, Oak Ridge National Laboratory, Oak Ridge, Tenn., September 2012.

Casado C. et al., "Peak Reactivity Characterization and Isotopic Inventory Calculations for BWR Criticality Applications," International Workshop on Advances in Applications of Burnup Credit for Spent Fuel Storage, Transport, Reprocessing, and Disposition, International Atomic Energy Agency, Cordoba, Spain, 2009.

Mueller, DE. et al. (2013b), Review and Prioritization of Technical Issues Related to Burnup Credit for BWR Fuel NUREG/CR-7158 (ORNL/TM-2012/261), Nuclear Regulatory Commission, Washington, DC.

Marshall, WJ. et al. (2015), Technical Basis for Peak Reactivity Burnup Credit for BWR Spent Nuclear Fuel in Storage and Transportation Systems, NUREG/CR-7194 (ORNL/TM-2014/240), Nuclear Regulatory Commission, Washington, DC.

Wagner, J. (2007), Technical Work Plan for Development of Technical Data Needed to Justify Full Burnup Credit in Criticality Safety Licensing Analyses Involving Commercial Spent Nuclear Fuel, DOC.20070213.0002, TWP-EBS-MD-000019, Rev. 01, prepared for the U.S. Department of Energy Office of Civilian Radioactive Waste Management by Sandia National Laboratories, Las Vegas, NV, February 2007.

Scaglione J. et al. (2015), A Quantitative Impact Assessment of Hypothetical Spent Fuel Reconfiguration in Spent Fuel Storage Casks and Transportation Packages, NUREG/CR-7203 (ORNL/TM-2013/92), Nuclear Regulatory Commission, Washington, DC. 
NRC. (2014). Spent Fuel Transportation Risk Assessment, NUREG-2125, Nuclear Regulatory Commission, Washington, DC.

Einziger RE and C Beyer. (2007), Characteristics and Behaviour of High Burnup Fuel that May Affect the Containment Source Terms for Cask Accidents. Nuclear Technology 159:134-146.

** Rondinella VV., (2011). Effects of Helium Build-up on Nuclear Fuel Evolution During Storage, In Proceedings of the 13th International High-Level Radioactive Waste Management Conference (IHLRWMC) April 10-14, 2011, Albuquerque, New Mexico. American Nuclear Society, La Grange Park, Illinois.

Lorenz RA, et al.,(1980). Fission Product Release from Highly Irradiated LWR Fuel. NUREG/CR-0722, U.S. Nuclear Regulatory Commission, Washington, D.C.

**Lee C.B. et al.,(2004),Post-irradiation Examination of High Burnup $\mathrm{UO}_{2}$ Fuel. In 2004 International Meeting on LWR Fuel Performance, p. 200. American Nuclear Society, La Grange Park, Illinois.

Olander D. 2009. Nuclear Fuels - Present and Future. Journal of Nuclear Materials 389:1.

**Aleshin Y. et al., (2010). The Effect of Pellet and Local Power Variations on PCI Margin. In Proceedings of the 2010 LWR Fuel Performance Meeting, Top Fuel/WRFPM, p. 427. American Nuclear Society, La Grange Park, Illinois.

Hanson BD. 1998. The Burnup Dependence of Light Water Reactor Spent Fuel Oxidation. PNNL-11929, Pacific Northwest National Laboratory, Richland, Washington.

Hanson BD et al., (2008), Fuel-In-Air FY07 Summary Report. PNNL-17275, Rev. 1, Pacific Northwest National Laboratory, Richland, Washington.

**Dag A et al.,(2010). Westinghouse New BWR Fuel - Towards the Flawless Target. In Proceedings of the 2010 LWR Fuel Performance Meeting, Top Fuel/WRFPM, p. 532. American Nuclear Society, La Grange Park, Illinois.

NRC (2007). Classifying the Condition of Spent Nuclear Fuel for Interim Storage and Transportation Based on Function, Spent Fuel Project Office, Interim Staff Guidance-1, Revision 2, Nuclear Regulatory Commission, Washington, DC.

EPRI. 2006. Recovery of Irradiation Damage by Post-Irradiation Thermal Annealing: Relevance to Hydrogen Solubility and Dry Storage Issues. TR-1013446, Electric Power Research Institute, Palo Alto, California.

**Ito K, et al.. 2004. Evaluation of Irradiation Effect on Spent Fuel Cladding Creep Properties. In Proceedings of the 2004 International Meeting on LWR Fuel Performance, p. 440. American Nuclear Society, La Grange Park, Illinois.

NWTRB. 2010. Evaluation of the Technical Basis for Extended Dry Storage and Transportation of Used Nuclear Fuel. U.S. Nuclear Waste Technical Review Board, Arlington, Virginia.

EPRI. 2002. Dry Cask Storage Characterization Project. TR-1002882, Electric Power Research Institute, Palo Alto, California. 
Siefken LJ, EW Coryell, EA Harvego, and JK Horost. 2001. MATPRO - A Library of Materials Properties for Light-Water-Reactor Accident Analysis. In SCDAP/RELAP5/MOD 3.3 Code Manual. NUREG/CR-6150, Vol. 4, Rev. 2, U.S. Nuclear Regulatory Commission, Washington, D.C.

**Garde AM, et al.,. 1996. Effects of Hydride Precipitate Localization and Neutron Fluence on the Ductility of Irradiated Zircaly-4. In Zirconium in the Nuclear Industry: Eleventh International Symposium, ER Bradley and GP Sabol (eds). ASTM STP 1295, pp. 407-428. American Society for Testing and Materials, Philadelphia, Pennsylvania.

Kearns JJ. 1967. Terminal Solubility and Partitioning of Hydrogen in the Alpha Phase of Zirconium, Zircaloy-2 and Zircaloy-4. Journal of Nuclear Materials 22:292-303.

**Kammenzind BF, et al., 1996. Hydrogen Pickup and Redistribution in Alpha-Annealed Zircaloy-4. In Zirconium in the Nuclear Industry: Eleventh International Symposium, ER Bradley and GP Sabol (eds), ASTM STP 1295, pp. 338-369. American Society for Testing and Materials, Philadelphia, Pennsylvania.

Beyer C.E.. 2001 . Letter from C. E. Beyer, Pacific Northwest National Laboratory, to K. Gruss, NRC. Subject: Transmittal of "Update of CSFM Methodology for Determining Temperature Limits for Spent Fuel Dry Storage in Inert Gas.” November 27, 2001.

**Bouffioux, P. and L Lefras, (2000), "Effect of Hydriding on the Residual Cold Work Recovery and Creep of Zircaloy 4 Cladding Tubes” in Proc of LWR Fuel Performance Meeting, April 10, 2000, Park City, Utah.

Kimball C and M Billone. (2003). Dry Cask Storage Characterization Project. EPRI Report 1002882, Electric Power Research Institute, Palo Alto, CA.

EPRI. (2007), "Spent Fuel Transportation Applications-Assessment of Cladding Performance, A Synthesis Report-Final Report.” EPRI-TR-1015048. Palo Alto, CA: Electric Power Research Institute. 2007.

EPRI (2000), Creep as the Limiting Mechanism for Spent Fuel Dry Storage, Palo Alto, CA 2000. 1001207.

**Daum RS, S. Majumdar, and MC Billone. 2008. Experimental and Analytical Investigation of the Mechanical Behavior of High-Burnup Zircaloy-4 Fuel Cladding. Journal of ASTM International 5(5): Paper ID JAI101209, available online at www.astm.org.

Billone MC, et al., 2013a. Embrittlement and DBTT of High-Burnup PWR Fuel Cladding Alloys. FCRDUFD-2013-000401. ANL-13/16. Prepared for the U.S. Department of Energy Used Fuel Disposition Campaign, Washington, D.C.

Billone MC, TA et al., 2013b. "Ductile-To-Brittle Transition Temperature for High-Burnup Cladding Alloys Exposed to Simulated Drying-Storage Conditions,” Journal of Nuclear Materials, 433(2013) 431448.

Wang J. et al., (2015), FY 2015 Status Report: CIRFT Testing of High-Burnup Used Nuclear Fuel Rods from Pressurized Water Reactor and Boiling Water Reactor Environments, ORNL/SPR-2015/313

Puls MP. 2009. Review of the thermodynamic basis for models of delayed hydride cracking rate in zirconium alloys. Journal of Nuclear Materials 393(2009):350-367. 
McRae GA, et al., 2010. The First Step for Delayed Hydride Cracking in Zirconium Alloys. Journal of Nuclear Materials 396(2010):130-143.

BSC. 2004. Clad Degradation - FEPs Screening Arguments. ANL-WIS-MD-000008, REV 02, Bechtel SAIC Co. LLC, Las Vegas, Nevada.

EPRI. 2002. Technical Bases for Extended Dry Storage of Spent Nuclear Fuel. TR-1003416, Electric Power Research Institute, Palo Alto, California.

Rothman AJ. 1984. Potential Corrosion and Degradation Mechanisms of Zircaloy ${ }^{\mathrm{TM}}$ Cladding on Spent Nuclear Fuel in a Tuff Repository. Report Attachment 10 to MRB-0418, JUCID-20172, Lawrence Livermore National Laboratory, Livermore, California.

Kim YS. 2008. Delayed Hydride Cracking of Spent Fuel Rods in Dry Storage. Journal of Nuclear Materials 378:30-34.

IAEA. 2004. Delayed Hydride Cracking in Zirconium Alloys in Pressure Tube Nuclear Reactors. IAEATECDOC-1410, International Atomic Energy Agency, Vienna, Austria.

Huang FH et al., 1991. Delayed Hydride Cracking Behavior for Zircaloy-2 Tubing. Metallurgical Transactions A 22A:2049-2060.

Chao CK, KC Yang, and CC Tseng. 2008. "Rupture of Spent Fuel Zircaloy Cladding in Dry Storage Due to Delayed Hydride Cracking.” Nuclear Engineering and Design 238:124-129.

Kim YS. 2009. Hydride Reorientation and Delayed Hydride Cracking of Spent Fuel Rods in Dry Storage. Metallurgical and Materials Transactions A 40A:2867-2875.

**Nakatsuka M, et al., 2010. Critical Failure Strains for Incipient Crack Formation in the Oxide and Hydride Layers in the Outer Surface Region of Zircaloy Fuel Cladding Tubes. In Proceedings of the 2010 LWR Fuel Performance Meeting/TOPFUEL/WRFPM, Orlando, Florida, p. 561. American Nuclear Society, La Grange Park, Illinois.

NRC. 2012a. Identification and Prioritization of the Technical Information Needs Affecting Potential Regulation of Extended Storage and Transportation of Spent Nuclear Fuel. Draft for comment. ML12130A189. U.S. Nuclear Regulatory Commission, Washington, D.C.

BSC. 2004b. CSNF Waste Form Degradation: Summary Abstraction. ANL-EBS-MD-000015, REV 02. Bechtel SAIC Co. LLC, Las Vegas, Nevada.

Collins E. (2015). Email message from E. Collins (ORNL) to Bruce B. Bevard (ORNL), Question from HTGE, October 8, 2015, Oak Ridge National Laboratory, Oak Ridge, TN.

Kohli R, et al., 1985. The Behavior of Breached Boiling Water Reactor Fuel Rods on Long-Term Exposure to Air and Argon at 598 K. Nuclear Technology 69:186.

Sunder S and NH Miller. 1996. Oxidation of CANDU uranium oxide fuel by air in gamma radiation at $150^{\circ}$ C. Journal of Nuclear Materials 231:121-131. 
Delegard CH, et al., 2009. Final Report-Evaluation of Chemical Effects Phenomena in Post-LOCA Coolant. NUREG/CR-6988, U.S. Nuclear Regulatory Commission, Washington, D.C.

Goll W, ET AL., 2001. Short-Time Creep and Rupture Tests on High Burnup Fuel Rod Cladding. Journal of Nuclear Materials 289:247-253.

Tsai H and MC Billone. 2003. Characterization of High-Burnup PWR and BWR Rods, and PWR Rods after Extended Dry-Cask Storage. In Proceedings of the 2002 Nuclear Safety Research Conference, pp. 157-168. NUREG/CP-0180, U.S. Nuclear Regulatory Commission, Washington, D.C.

Murty KL. 2000. The Internal Pressurization Creep of Zr Alloys for Spent-Fuel Dry Storage Feasibility. Journal of the Minerals, Metals and Materials Society (JOM) 52:9(2000)34.

**Gilbert ER, et al., 2002. Update of CSFM Creep and Creep Rupture Models for Determining Temperature Limits for Dry Storage of Spent Fuel. Presentation to the International Congress on Advanced Nuclear Power Plants (ICAPP) ANS Embedded Topical Meeting, June 9-13, 2002, Hollywood, Florida.

Chopra, OK., et al. (2014). Managing Aging Effects on Dry Cask Storage Systems for Extended LongTerm Storage and Transportation of Used Fuel, ANL-13/15, (FCRD-UFD-2014-000476 Rev. 2) Argonne National Laboratory, Lemont, IL.

EPRI. (1990). NUHOMS Modular Spent-Fuel Storage System: Performance Testing, EPRI NP-6941 and PNL-7327, Electric Power Research Institute, Palo Alto, California.

Sindelar, RL. et al. (2011). Materials Aging Issues and Aging Management for Extended Storage and Transportation of Spent Nuclear Fuel, NUREG/CR-7116 (SRNL-STI-2011-00005), Nuclear Regulatory Commission, Washington, DC.

NRC (2007). Classifying the Condition of Spent Nuclear Fuel for Interim Storage and Transportation Based on Function, Spent Fuel Project Office, Interim Staff Guidance-1, Revision 2, Nuclear Regulatory Commission, Washington, DC.

NRC. 1998. Confinement Evaluation. SFST-ISG-5, U.S. Nuclear Regulatory Commission, Washington, D.C.

Meyer RM, et al., 2013. NDE to Manage Atmospheric SCC in Canisters for Dry Storage of Spent Fuel: An Assessment. PNNL-22495, ML13276A196, Pacific Northwest National Laboratory, Richland, WA.

Meyer RM, et al., 2014a. "Eddy Current for Sizing Cracks in Canisters for Dry Storage of Used Nuclear Fuel.” Proceedings of NACE International Corrosion 2014, paper no. 4166, San Antonio, TX, March 9 13, 2014.

Meyer RM, et al., 2014b. Passive Optical Impurity Monitoring of Dry Storage Containers for Spent Fuel. ANS 2014 Annual Meeting. June 15-19, 2014, Reno, Nevada. American Nuclear Society, La Grange Park, Illinois.

Dunn DS. 2014. Aging Management Program Example for Stress Corrosion Cracking. ML14192A702. U.S. Nuclear Regulatory Commission, Washington, D.C. 
PNNL. 2012, Review of Used Nuclear Fuel Storage and Transportation Technical Gap Analyses, PNNL21596, Pacific Northwest National Laboratory, Richland, Washington.

Bare et al., 2001, Dry Cask Storage Characterization Project-Phase l: CASTOR V/21 Cask Opening And Examination, Rev 1, NEEL/EXT-01-00183, Idaho National Engineering and Environmental Laboratory Bechtel BWXT Idaho, LLC.

IAEA. 1997. Further analysis of extended storage of spent fuel. IAEA-TECDOC-944, International Atomic Energy Agency, Vienna, Austria. 


\section{APPENDIX A. DOCUMENT COMMUNICATIONS}




\section{APPENDIX A. DOCUMENT COMMUNICATIONS}

Q1-We would like to get information which shows that damage of the fuel cladding, e.g. pinhole or hairline crack does not grow worse during wet storage in spent fuel pool in certain condition of water chemistry or related management. In UKABWR spent fuel will be stored in SFP for 10 years before they are removed to dry storage site. Is there any operation experience or analysis regarding this issue in public document?

R- The potential for monitoring hairline cracks in a single rod through chemistry would be quite difficult, and we are not aware of examples where discrete fuel failures could be detected in SFP chemistry. The SFP water volume is $\sim 4-5$ times larger than the RCS volume, plus it is open to the atmosphere, making it almost impossible to detect most fission products, particularly the ones generally used for fuel failure detection. The SFP is typically on continuous recirculation and there is some affinity on the cleanup demineralizer for cesium and iodines, so concentrations are very near the level of detection (MDA).

Some plants have had "open” defect fuel failures (i.e. loss of fuel to the RCS). This is usually confirmed by the detection of isotopes such as Np-239 or Am-241; however, these are very insoluble and dense, so that detection in the SFP, where mixing is much less that the RCS, is unlikely.

However, several R\&D programs have been conducted to establish the behavior of defective fuel rods in wet storage and more work needs to be done. The text below is extracted from IAEA TECDOC944 (IAEA-1997).

\section{“3.1.1.4. Behavior of defective fuel}

Canada has conducted the most comprehensive wet storage fuel integrity surveillance program. Beginning in 1977, both intact and deliberately defective CANDU test fuel was identified and characterized. A subsequent reexamination was made in 1988. This fuel, after some 27 years in storage, showed no measurable oxidation of the cladding surface and no changes were observed in the condition of the fuel. Examination of the $\mathrm{UO}_{2}$ in the immediate area of the intentional defect showed a very thin surface layer of oxidized $\mathrm{UO}_{2}$ in the form of $\mathrm{UO}_{3}$ hydrate, but there was no evidence of a diametral increase in the element due to $\mathrm{UO}_{2}$ oxidation in defective fuel that was stored wet for up to 21 years. This evidence suggests that pool storage of defected bundles can continue for at least 50 years with no significant degradation. This surveillance program in Canada is scheduled to continue for the next 50 years with the next reexamination to occur in 2000. At the time of the reexamination, the undefected fuel will have been stored for up to 30 years while the intentionally defective fuel will have been stored for up to 33 years.

In Germany, a surveillance program with intact and operational defective fuel rods has been conducted for 18 years. No changes were observed in the nature of the defects over this period of time. The defects included cracks, hydride failures, boils and wear spots.

The Republic of Korea has also conducted a surveillance program on PWR fuel with known defects and has seen no changes after 5 years of storage.

Russia reported no changes in RMBK spent fuel water activity over a 25-year period with standard cleanup system operation. This indicates that there is no defect propagation mechanism working in 
the storage phase. For WWER, fuel pool activity variations are associated with handling operations and the number of defective fuel assemblies stored.

In Sweden, at CLAB, two shipments of leaking fuel have been received. The first consisted of five leaking BWR-assemblies from Ringhals 1; the second shipment had three leaking PWR assemblies from Ringhals 3 The assemblies were transported in special bottles During unloading at CLAB, the assemblies were removed from their bottles and sipped. No significant ${ }^{134} \mathrm{Cs}$ and ${ }^{137} \mathrm{Cs}$ leakage was observed. The assemblies were therefore treated as normal fuel and were placed in ordinary fuel storage canisters. Experience indicates that the ${ }^{134} \mathrm{Cs}$ and ${ }^{137} \mathrm{Cs}$ concentrations increase slightly in the storage pools (containing 10-11 000 assemblies) After approximately three weeks, the concentration in the pool returns to normal as a result of the normal continuous cleaning."

In the context of the Waste Confidence rule back in the 1980's (From IAEA-TECDOC-414):

In the USA , fuel integrity considerations were analyzed in the Waste Confidence Rulemaking including the following:

- cladding behaviour in extended wet storage;

- behaviour of fuel with cladding breaches in extended wet storage;

- behaviour of fuel assembly hardware, (e.g. grid spacers and end fittings) in extended wet storage;

- durability of storage pool components (storage racks, piping, liners) in extended storage.

The US Nuclear Regulatory Commission has ruled that "spent fuel generated in any reactor can be stored safely and without significant environmental impacts for at least 30 years beyond the expiration of that reactor's operating license at that reactor's spent fuel storage pool, or at either onsite or offsite independent spent fuel storage installations.

Q2-In UKABWR temperature limit of fuel cladding for normal operation is 400 degree-C for GE14 with 55GWD/MTU (maximum bundle average) is assumed. The temperature limit is the same as that required in NUREG is 400 degree $C$. We would like information which supports this temperature limit for high burnup fuel (HBF). The temperature limit has impact on fuel drying method e.g. forced hot helium gas circulation (produced by HOLTEC) in the canister or vacuum drying

A-The answer is included in section 2.3.2

Q3-We would like get information of negative impact of remaining moisture inside a canister onto fuel cladding integrity for long term storage, especially for $\mathrm{HBF}$. In section 2.1.3 you referenced a study which says that degradation of fuel cladding is not expected to be significant over 300 years. Could you describe more specific information on this issue?

A-Inadequate drying can cause a number of problems in dry cask storage.

These mechanisms can be classified as (Jung 2013):

- Cladding thinning

- Spent nuclear fuel oxidation and cladding unzipping

- Flammability.

- Hydrogen-absorption-induced damage

o Cladding

o Canister internals

- Aqueous corrosion

Depending on the amount of water left after drying process degradation phenomena and severity changes. 
Under contract with the NRC, the Center for Nuclear Waste Regulatory Analysis (CNWRA) performed studies on the sources and possible locations of water remaining in a canister, even with a drying operation that followed current protocols (Jung et al. 2013); an analysis of consequences of either $0.1 \mathrm{~L}$ or $1 \mathrm{~L}$ of water remaining in a canister (Miller et al. 2013a); and a test plan recommending a path forward on how to experimentally quantify the residual water remaining in a canister, to determine the effect of a number of variables, and to provide a basis for the drying protocols (Miller et al. 2013b).

The analyses examined the potential degradation that could occur to cladding or canister internals if either $0.1 \mathrm{~L}$ or $1 \mathrm{~L}$ of water remained. The effects of radiolysis considering some recombination, though not to the extent that the UFDC analysis (Wittman 2013) did, were also considered. An integrated model, which included a qualitative assessment of the extent of corrosion-induced damage, was developed. The analysis concluded that for below $1 \mathrm{~L}$ of water, the degradation of fuel, cladding, or other internal components would not be significant over 300 years. However, CNWRA (Jung et al. 2013) concluded that above $0.32 \mathrm{~L}$ of water remaining, radiolysis-produced $\mathrm{H}_{2}$ could exceed flammability limits after about 72 years.

There are still no experimental data to validate models or assumptions for the quantity of residual water remaining in a canister even after an established drying procedure has been followed, nor are there data to validate models on radiolysis. The most important need is to obtain experimental data to quantify the residual water remaining after a drying procedure as a function of key variables (e.g., total heat load, local temperatures and gradients, and quantity and size of defects in waterlogged fuel rods).

A report prepared by Wittman R., Radiolysis Model Sensitivity Analysis for a Used Fuel Storage Canister, FCRD-UFD-2013-000357, PNNL-22773, will be included in the delivered references.

Q4- We have to provide some evidences for mis-loading fault which shows fuel cladding integrity is maintained in the mis-loaded condition. Is there information of experience or analysis of fuel cladding integrity in mis-loaded condition, namely cladding temperature increase during misloading timing and the ability to detect the mis-loading?

A-NRC Information Notice 2014-09: Spent Fuel Storage Or Transportation System Misloading, provides descriptions, causes (mainly for not following zone loading maps) and actions taken for misloadings in Palisades (ventilated storage cask-24), Grand Gulf (HI-STORM 100), North Anna and Surry (NUHOMS DSC) sites, causes and actions. In each case, an exemption was requested from 10 CFR 72 (licensing requirements for independent storage of SFP) since decay heat rates were exceeded. For each case, licensee provided detailed calculations to ensure that the thermal effect of the misloaded fuel assemblies to be minimal, and that the thermal margins were sufficient to mitigate the effects of the misloaded fuel assemblies so as to provide adequate heat removal capabilities. Structural and pressure considerations, structural implications on the cask system were discussed, and the design basis shielding analysis were verified remained bounding.

Q5-We would like get information of monitoring process for integrity of required function of storage cask/canister or fuel cladding, such as containment or cooling, for long term storage. Information of operation experience or analysis on monitoring technology will be helpful, such as monitoring demonstration for PWR HBF. 
A-This is an active research area. Long-term monitoring is currently being discussed as part of the aging management plan (AMP). More information is included in Section 3. Information regarding current research will be provided with references.

Q6-In section 2.1.1. you mentioned that there are some data which shows that high burnup fuel claddings can become brittle at lower temperature. This information will be important for discussion of fuel integrity in frequent fault such as unexpected fast landing of cask by crane or collision of cask with other object. Could you prepare more specific information about this issue?

A-The information is based on research conducted by Billone et al. (2013a, 20113b). More information is included in Section 2.3.2. The research paper and the report will be delivered with the references.

Q7-In the event of unsealed canister tipover after removing the cask from the spent fuel pool, we assume that the fuels in the cask will fail and the volatile radioactive nuclides in the failed fuel will be released. After tipover, the water inside the canister will be flow out and the fuel cladding temperature will rise with the fuel exposed to air. We are concerned that the resulting fuel cladding temperatures may be high enough to develop U3O8. This question was already asked by the UK regulator. The UK regulator is concerned that the U3O8 conversion will unlock additional gases that will need to be included in the dose assessment. Do you have any information about this?

A-Answer is included in Section 2.2.3.

Q8-If possible, please add the information of 'fraction of Rim Layer Fracture' under external loading such as cask drop. If you have any guidance on the proper release fractions to be used for a 20m drop of GE14 HBF, it would be very helpful. We are using NUREG-1864 values, but they may be very conservative.

A-Fraction of rim layer fracture under external loading is one of the areas in which we would like to have tests. This is an ongoing research topic.

Q9-The pellet conditions of high burnup BWR fuels are similar to PWR fuels. But the corrosion and hydride conditions of BWR fuels are quite different from PWR fuels. We expect you to provide BWR cladding data or the justification as to why the sufficient PWR cladding data can be utilized for BWR fuel.

A-Although Zry-4 and Zry-2 chemical and mechanical properties are different and are exposed to different operating environments, a recent report by ORNL, CIRFT Testing of High-Burnup Used Nuclear Fuel Rods from the Pressurized Water Reactor and Boiling Water Reactor Environment (Wang et al. 2015), shows that stress strain failure and overall Cyclic Integrated Reversible-Bending Fatigue Tester (CIRFT) fatigue failure frequencies are similar for both PWR and BWR cladding. This is an important finding since it shows that PWR and BWR high-burnup clad behaves similarly under external forces. This report is mentioned in Section 2.3.2 and it will be provided with the references.

Q10-We have concern about progress of NRC RIS (2015-XX “Considerations in Licensing High Burnup Spent Fuel in Dry Storage and Transportation”) regarding HBF cladding integrity in pinch-mode. We would like information of this issue if you have.

http://pbadupws.nrc.gov/docs/ML1432/ML14323A787.pdf

http://pbadupws.nrc.gov/docs/ML1417/ML14175A203.pdf 
A-This is also another research interest and it is included in our test plans for this year.

Q11-Need assurance that the fuel structure will remain intact after the long period (140 years) in dry(about 400C) and wet (about 65C) storage. There are no corrosion mechanism or radiation embrittlement that would degrade the fuel structure.

And could you research and describe the aging at such conditions at Section 2.4 ?

During long term storage, such as more than 140 years, how is the fuel integrity to be monitored or inspected?

A- This question can be answered with a time dependent, integrated performance assessment model (including uncertainties) with some specificity on the initial conditions and boundary conditions and associated

assumptions. This report describes the processes involved but does not address the time scale in the question.

Q12-Impact of mechanical loadings on fuel -

Following comment or request is the fuel integrity during transfer in side reactor building, or on site transfer drop issues.

Need assurances that the normal handling loadings associated with placing fuel into dry storage and retrieval will not damage fuel. ( by Bernard-san)

Related to the above comment of mechanical loading on fuel, cask toppling may be considered as frequent fault condition in UK GDA assessment and we need information that external stress by cask toppling will not damage fuel. (by HGNE SFIS team)

A-Cask tipping is a low-probability accident. In seismic regions, casks are bolted to the ground. Canister integrity and possible increase in leakage are the main concerns for cask tipping/topping and dropping accidents. External stress caused by topping is too large to ensure fuel integrity. Fuel and canister drop tests have been performed for dry storage transportation accidents. Fuel integrity under external source is an important research area for SNF transportation. Ring compression tests and CIRFT reports mentioned in Section 2.3.2 discuss the effect of external loads on clad integrity. These reports will be delivered as part of the references.

Q13-Need research to obtain the data of experience regarding damaged fuel. Pin hole or hair line crack on cladding will not develop with sufficient wet or dry condition (by HGNE SFIS team) How is possibility of damage for BWR high burn up fuel, more than $55 \mathrm{GWt} / \mathrm{d}$

A-Fuel assemblies with clad failures described in ISG 1 and ISG 2 are placed in damaged fuel canisters. However, even for undamaged clad, it is possible for clad zipping to develop at very high temperatures. CIRFT report (Wang et al. 2015) shows that even if cladding zipping occurs, fuel pellets can be retrievable. Also, even in the case of complete clad failure and canister flooding, leakage rates stay under acceptable limits for long-term storage (Banerjee et al. 2015). All fuel integrity mechanisms mentioned in this report are applicable to $\mathrm{HBU}$ ( $>45 \mathrm{GWd} / \mathrm{t}$ ).

Q14-Information regarding Hydrogen reorientation and Delayed Hydride Cracking. To confirm this issues will be described in section 2.2 Temperature effects or phase change?

A-Delayed hydride cracking is included in Section 2.3.3

Q15-Recovery of irradiation effect It will be described in sec.2.4.1 Temperature effect?

A- Annealing of radiation effect is discussed in Section 2.3.1 
Q16-Basket Degradation. It will be reported as practical basket materials, B-SUS, B-Al and others?

A- Deficiencies with current basket materials are noted and referenced in Section 2.4.2

Q17-Will inspection or monitor during storage be covered in section 2.6.6 Container Aging Management?

High Burnup Storage Demonstration test plan at North Anna PS, PWR plan. If possible, plan for BWR one will be reported.

A-Monitoring information is included in Section 3. There are no US plans for high-burnup storage testing of BWR fuel.

Q18-Please add the abbreviations such as SPPs, DBTT and RHT on ACRONYMS listed on the page of viii.

A-Abbreviations are included in the ACRONYMS list.

Q19- Please provide the specified data on the report and make the description based on it. For example, the3rd paragraph of section 2.2.1, there is a description that "no significant difference" but we do not understand what level it meant.

It would be helpful to understand the description of the report if it's basic data or figures would be provided within the report.

Also, name of person and years are shown as references but it should be linked with specific documents. Please attach the references with the report, if possible.

A-The reference document is included.

Q20-Please include the list of current R\&D status and/or future plan that describes how each safety function can be maintained.

Ex)

\begin{tabular}{|l|l|l|l|l|l|}
\hline & Maintain Integrity & Cooling & Shielding & Subcriticality & Retrievability \\
\hline Residual Water & & & & & \\
\hline Thermal & & & & & \\
\hline Oxidization & & & & & \\
\hline Creep & & & & & \\
\hline $\begin{array}{l}\text { Hydroid } \\
\text { reorientation }\end{array}$ & & & & & \\
\hline \multicolumn{1}{|c|}{ Etc. } & & & & & \\
\hline
\end{tabular}

A-Appendix D provides summary and gap analyses tables.

Q21-Several kinds of the maximum fuel cladding temperatures are described, e.g. 400 and 570 ${ }^{\circ} \mathrm{C}$. Could you please explain in more detail which temperature should we use?

The drying temperature for damaged fuel is same as that of intact fuel ? 
A- $400^{\circ} \mathrm{C}$ is the maximum clad temperature limit during the entire drying process. $570^{\circ} \mathrm{C}$ is the maximum temperature limit that is allowed for short durations during the drying process.

Q22-If high burnup ZIRLO, Ziry-4 and Ziry-2 cladding can become brittle at lower temperatures, we would like to have summary of this evidence. On what rage of temperature, such behavior is found?

How is a difference between the dry condition, fuel integrity between BWR and PWR fuel ? Is it possible to estimate BWR spent fuel performance based on PWR fuel data ?

A-The statement is based on Billone's work (Billone, 2013b) The reference is provided.

This question is related to previous questions Q9 and Q13. Results of CIRFT testing (Section 2.3.2, Wang 2015) provides evidence $\mathrm{Zr}$-2 behavior can be predictable from $\mathrm{Zr}$-4 behavior based on high burnup Zr-2 and Zr-4 bending test results.

Q23-We would like detailed information of the reference document about the examination of the CASTOR V/21 (INEL DCSS) and REA-2023 for the effect of residual moisture onto fuel assemblies inside the cask.

A-Reference document (Bare 2001) is included.

Q24-It states that "NUREG-1536 .equal to 4.0.10-4 MPa."

Is the correct number 4.0E-4 MPa?

A-Yes the correct number is $4.0 \times 10^{-4} \mathrm{MPa}$.

Q25-We would like detailed information of the reference document of the study under CNWRA by Jung et. al, for potential impact of residual water inside a dry cask onto SNF, which shows no significant impact for up to $\mathbf{3 0 0}$ years.

A- The reference document is included.

Q26-It is described that the canister environment could meet the condition of flammability for relatively low initial temperature and backfill pressure. Could you give us specific range of temperature and backfill pressure?

A- References for $\mathrm{G}$ factor (Green,1994), flammability limits (Coward,1952) and deflagration (NFPA,2002) are provided.

Green, J.R. 1994. Progress Report for the Enhancement of Radcalc: Isotope Database, Gamma Absorption Fractions, and $\mathrm{G}\left(\mathrm{H}_{2}\right)$ Values. WHC-SD-TP-RPT-014, Rev. 0. Richland,

Coward, H.F. and Jones, G.W. 1952. Limits of Flammability of Gases and Vapors. Bulletin 503. Washington, D.C.: U.S. Government Printing Office. TIC: 241049.

NFPA 68. 2004. Guide for Venting of Deflagrations, with Errata No. 68-02-1. 2002

Edition. Quincy, Massachusetts: National Fire Protection Association. TIC: 258044.

Q27-We would like detailed information of the reference document of the study by Wittman, for $\mathrm{H} 2$ flammability inside the canister.

A- The reference document is included. 
Q28-We would like detailed information of the reference document of the study by Banerjee on reactivity change in the system considering fuel reconfiguration.

A- The reference document is included.

Q29-Regarding the sentence "Gross ruptures or breaches are defined in NUREG-1536 (NRC 2010) as any cladding breach greater than $1 \mathrm{~mm}$ ”, Is correct with 1mm? Shouldn’t it be “1\% plastic strain”?

A-NUREG-1536 Section 8.6 (NRC 2010) states that other than for fine powder, a cladding crack width of at least $2-3 \mathrm{~mm}$ is required to release a fragment of the pellet. Using this reasoning, a gross breach is defined as any cladding breach greater than $1 \mathrm{~mm}$.

ISG-1 (NRC 2007) also defines gross rupture as "A breach in spent fuel cladding that is larger than a pinhole leak or a hairline crack. An acceptable examination for a gross breach is a visual examination that has the capability to determine the fuel pellet surface may be seen through the breached portion of the cladding."

Q30-It states that “One important, ...sometimes exceeding 100.1020 n/cm2.” Is the correct number $1.0 \mathrm{E} 22 \mathrm{n} / \mathrm{cm} 2$ ?

A-Yes.

Q31-It is described that "NRC staff has found that casks closed entirely by welding do not require monitoring...” Please explain on what basis this statement was made if available.

A- Monitoring refers to continuous monitoring of the cask. Periodic inspections are still required, and performed for DSCs. 


\section{APPENDIX B. BIBLIOGRAPHY}




\section{APPENDIX B. BIBLIOGRAPHY}

Hanson BD, et al. 2012. Gap Analysis to Support Extended Storage of Used Nuclear Fuel ,PNNL-20509, Rev. 0, Pacific Northwest National Laboratory, Richland, Washington.

This report documents the initial gap analysis performed to identify data and modeling needs to develop the desired technical bases to enable the extended storage of UNF. For most SSCs important to safety, additional data are required, often because there are limited data on the new materials used in more modern fuels or dry storage cask systems or because the effects of high burnup and extended storage are not fully known. Based upon the importance of the SSC to licensing a dry storage system or an independent spent fuel storage installation (ISFSI), the potential effects of extended storage or high burnup on the degradation mechanism, and a combination of the data needs, regulatory considerations, likelihood of occurrence, the consequence of degradation, the means to remediate the degradation, and the impact of degradation on cost, operations, and future waste management strategies, a research and development (R\&D) priority (Low, Medium, or High) is assigned. The $R \& D$ priority cannot be higher than the ranking assigned for importance to licensing; obviously, a structure, system, or component ranked of Low importance to licensing does not require a Medium or High priority for R\&D. However, a structure, system, or component can be of High importance to licensing, but the R\&D needs can be lower depending on the prioritization criteria.

PNNL. 2012, Review of Used Nuclear Fuel Storage and Transportation Technical Gap Analyses, PNNL21596, Pacific Northwest National Laboratory, Richland, Washington.

There are a collective total of 94 technical data gaps identified by the various reports to support extended storage and transportation of UNF. This report focuses on the gaps identified as Medium or High in any of the gap analyses and provides the UFDC's gap description, any alternate gap descriptions or different emphasis by another organization, the rankings by the various organizations, evaluation of the consistency of priority assignment and the bases for any inconsistencies, and UFDC-recommended action based on the comparison. Gaps that are ranked Low by all organizations and countries are not evaluated in this report.

EPRI. 2012. International Perspectives on Technical Data Gaps Associated with Extended Storage and Transportation of Used Nuclear Fuel. Draft, Electric Power Research Institute, Palo Alto, California

With the prospect of spent nuclear fuel being stored at reactor sites for the foreseeable future, EPRI established the Extended Storage Collaboration Program (ESCP) in 2009 to investigate aging effects and mitigation options for the extended storage and transportation of spent nuclear fuel. ESCP's International Subcommittee developed this summary of the regulatory status, operational status, fuel inventory, and technical gaps identified for extended storage of spent fuel for each country involved. 
Billone MC, et al., 2013a. Embrittlement and DBTT of High-Burnup PWR Fuel Cladding Alloys. FCRDUFD-2013-000401. ANL-13/16. Prepared for the U.S. Department of Energy Used Fuel Disposition Campaign, Washington, D.C.

The goal of the testing program is to determine drying-storage conditions for which the cladding remains ductile at ambient temperature, in other words, with the DBTT $\leq 20^{\circ} \mathrm{C}$. The new work focused on the effects of lower peak cladding hoop stresses at $400^{\circ} \mathrm{C}$ to determine conditions for which the DBTT would be $\leq 20^{\circ} \mathrm{C}$. HB ZIRLO ${ }^{\text {TM }}$ subjected to peak hoop stresses of 80 and $90 \mathrm{MPa}$ exhibited DBTTs of $<20^{\circ} \mathrm{C}$ and $20^{\circ} \mathrm{C}$, respectively. Both sample materials contained about $530 \mathrm{wppm} \mathrm{CH}$. Along with the DBTT reduction, the effective lengths of radial hydrides decreased from $67 \%$ (for $140 \mathrm{MPa}$ ) to 30\% (for 110 $\mathrm{MPa}$ ) to $19 \%$ (for $90 \mathrm{MPa}$ ) to $9 \%$ (for $80 \mathrm{MPa}$ ) of the cladding wall thickness. A test was also conducted with HBU M5 ${ }^{\circledR}$ with $90-\mathrm{MPa}$ peak cladding hoop stress at $400^{\circ} \mathrm{C}$. Following slow cooling, the DBTT was $<20^{\circ} \mathrm{C}$. The effective length of radial hydrides decreased with the decrease in peak hoop stress at $400^{\circ} \mathrm{C}$ : from $72 \%$ (for $140 \mathrm{MPa}$ ) to $61 \%$ (for $110 \mathrm{MPa}$ ) to $31 \%$ (for $90 \mathrm{MPa}$ ). However, because of the low $\mathrm{CH}$ (about 60 to $90 \mathrm{wppm}$ ) in the HBU M5® samples, radial hydrides were thinner and spaced farther apart than the ones observed in HBU ZIRLO ${ }^{\mathrm{TM}}$ with much higher $\mathrm{CH}$. In summary, a DBTT of $\leq 20^{\circ} \mathrm{C}$ can be achieved for peak drying-storage hoop stresses $\leq 110 \mathrm{MPa}$ for HBU Zry- 4 and $\leq 90 \mathrm{MPa}$ for HBU ZIRLOTM and M5®

Billone MC, TA et al., 2013b. "Ductile-To-Brittle Transition Temperature for High-Burnup Cladding Alloys Exposed to Simulated Drying-Storage Conditions," Journal of Nuclear Materials, 433(2013) 431448.

Radial hydrides may precipitate during slow cooling and provide an additional embrittlement mechanism as the cladding temperature decreases below the ductile-to-brittle transition temperature (DBTT). A test procedure was developed to simulate the effects of drying-storage temperature histories. Following drying-storage simulation, samples were subjected to ring compression test (RCT) loading, which was used as a ductility screening test and to simulate pinch-type loading that may occur during cask transport. RCT samples with $<2 \%$ offset strain prior to $>50 \%$ wall cracking were assessed as brittle. Prior to testing high-burnup cladding, many tests were conducted with pre-hydrided Zircaloy-4 (Zry-4) and ZIRLO ${ }^{\text {TM }}$ to determine target $400^{\circ} \mathrm{C}$ hoop stresses for high-burnup rodlets. Zry-4 cladding segments, from a 67GWd/MTU fuel rod, with 520 to 620 wppm hydrogen and ZIRLO ${ }^{\text {TM }}$ cladding segments from a 70GWd/MTU fuel rod, with 350 to 650 wppm hydrogen were defueled and tested. Following drying-storage simulation, the extent of radial-hydride precipitation was characterized by the radial-hydride continuity factor. It was found that the DBTT was dependent on: cladding material, irradiation conditions, and drying-storage histories (stress at maximum temperature). High-burnup ZIRLO ${ }^{\text {TM }}$ exhibited higher susceptible to radial-hydride formation and embrittlement than high-burnup Zry-4. It was also observed that uniformly pre-hydrided, nonirradiated cladding was not a good surrogate for high-burnup cladding because of the high density of circumferential hydrides across the wall and the high metal-matrix ductility for prehydrided cladding.

Jung H. et al., 2013. Extended Storage and Transportation: Evaluation of Drying Adequacy. ML13169A039. U.S. Nuclear Regulatory Commission, Washington, D.C.

This study examines potential impacts of residual water remaining inside a dry storage cask1 for spent nuclear fuel (SNF) after the drying process. Residual water could cause chemical degradation of SNF, cladding, and other internal components inside the cask, such as SNF baskets and neutron absorbing plates. Scoping analyses were conducted to assess potential impacts of residual water on cask internals, flammability, and criticality. The analyses evaluated potential degradation mechanisms, including 
oxidation and hydration of SNF, cladding unzipping, oxidation and hydrogen-absorption-induced damage of cladding, and corrosion of internal structural materials. The evaluation also included the potential for a flammable canister environment resulting from hydrogen and oxygen generated by radiolytic decomposition of water (i.e., radiolysis). In addition to possible effects on cask performance during storage, degradation of canister internals and potential flammability of the canister environment would complicate retrieval of SNF assemblies from the cask, transport, and ultimate disposal. For the conditions analyzed, the overall conclusion is that degradation of cladding, fuels, and other internal components is not expected to be significant over the analyzed period, up to 300 years of storage time. With no significant degradation of cladding, fuel, and internal components, criticality safety is not affected. At the higher end of analyzed range of residual water, and for relatively low initial temperature and backfill pressure, the canister environment could meet the condition of flammability in terms of the amount of hydrogen and available oxygen present, given a source of ignition. The study made several assumptions to constrain the conditions analyzed and the structure of the models used. The analyses assumed that the canister remained sealed and that no air entered or backfill gas was lost. Based on information found in the literature, the analyses assumed that the amount of residual water in the canister yields a range from 5.5 to 55 moles ( 0.1 to 1 liter (L) (3.5 to 35 ounces (oz))) of water, mostly in the vapor phase.

Wittman R. 2013. Radiolysis Model Sensitivity Analysis for a Used Fuel Storage Canister. FCRD-UFD2013-000357. PNNL-22773. Prepared for the U.S. Department of Energy Used Fuel Disposition Campaign, Washington, D.C.

This report is on a radiolysis computer model analysis that estimates the generation of radiolytic products for a storage canister. The analysis considers radiolysis outside storage canister walls and within the canister fill gas over a possible 300-year lifetime. Previous work relied on estimates based directly on a water radiolysis G-value. This work also includes that effect with the addition of coupled kinetics for 111 reactions for 40 gas species to account for radiolytic-induced chemistry, which includes water recombination and reactions with air. The main results for radiolysis inside the canister fill gas are described as follows.

- Significant radiolysis of water vapor requires the presence of residual air to disable recombination.

- Reactions between residual water (1 L) and air in $4500 \mathrm{~L}$ of free space result in percent levels of $\mathrm{H}_{2}, \mathrm{O}_{2}$ and $\mathrm{HNO}_{3}$ at 300 years, and about one-half the maximum values reached in the first 16 years.

- Calculations indicate that a much greater volume of residual water $(20 \mathrm{~L})$ would be required to reach the $4 \% \mathrm{H} 2$ flammability limit in 16 years, and between 3 and $4 \mathrm{~L}$ of water would be required to reach the $4 \%$ $\mathrm{H}_{2}$ flammability limit in 300 years.

- Increased residual air results in greater $\mathrm{H}_{2}$ and $\mathrm{HNO}_{3}$ concentrations, but also in the depletion of $\mathrm{O}_{2}$ because it is more effectively removed by a radiolytically induced reaction with $\mathrm{N}_{2}$.

- For lower $(0.1 \%)$ residual air, $\mathrm{O}_{2}$ is initially depleted and then generated for storage times greater than 50 years, resulting in approximately $0.5 \% \mathrm{O}_{2}$.

- For lower $(0.1 \mathrm{~L})$ residual water and $1 \%$ air, all radiolytic products are less than $1 \%$. The main results for radiolysis outside the canister follow.

- The main radiolytic products formed in moist air are $\mathrm{HNO}_{3}, \mathrm{~N}_{2} \mathrm{O}, \mathrm{NO}_{2}$, $\mathrm{CO}$, and small amounts of $\mathrm{O}_{3}$.

- Even for extremely long residence times, the highest concentrations are less than $50 \mathrm{ppm}$ and are less than 1 ppm for more typical flow conditions.

- Dry air gives similar concentrations as moist air with the exception of increased $\mathrm{NO}_{2}$ and the near absence of $\mathrm{HNO}_{3}$. 
Banerjee, K. et al. (2015), Criticality Safety Assessment for As-loaded Spent Fuel Storage and Transportation Casks, International Workshop On Operational and Regulatory Aspects of Criticality safety, Albuquerque, New Mexico, May, 2015.

Loaded cask systems tend to have excess and uncredited margins (i.e., the difference between the licensing basis and the as-loaded calculations). These uncredited margins can be quantified by using more detailed canister-specific evaluations that credit the actual as-loaded cask inventory. This paper summarizes an assessment of canister-specific, as-loaded criticality margins for SNF stored in dry casks (a total of 206 as-loaded casks were analyzed) at seven reactor sites including six pressurized water reactor (PWR) sites and one boiling water reactor (BWR) site. The calculated keff margin typically varies from 0.05 to almost $0.30 \Delta \mathrm{k}_{\text {eff }}$ for the seven selected reactor sites. The results demonstrate that some loaded casks have significant uncredited safety margins.

Wang J. et al., (2015), FY 2015 Status Report: CIRFT Testing of High-Burnup Used Nuclear Fuel Rods from Pressurized Water Reactor and Boiling Water Reactor Environments, ORNL/SPR-2015/313 Puls MP. 2009. Review of the thermodynamic basis for models of delayed hydride cracking rate in zirconium alloys. Journal of Nuclear Materials 393(2009):350-367.

This report describes testing designed to determine the ability of high burnup (HBU) ( $>45$ GWd/MTU) spent fuel to maintain its integrity under normal conditions of transportation. An innovative system, Cyclic Integrated Reversible-bending Fatigue Tester (CIRFT), has been developed at Oak Ridge National Laboratory (ORNL) to test and evaluate the mechanical behavior of spent nuclear fuel (SNF) under conditions relevant to storage and transportation. The CIRFT system is composed of a U-frame equipped with load cells for imposing the pure bending loads on the SNF rod test specimen and measuring the insitu curvature of the fuel rod during bending using a set up with three linear variable differential transformers (LVDTs). The objective of this research is to collect experimental data on spent nuclear fuel (SNF) from pressurized water reactors (PWRs), including H. B. Robinson (HBR) and North Anna (NA) Zircaloy-4 cladding and NA and Catawba of M5 cladding, and the Limerick Generating Station boiling water reactor (BWR) under simulated transportation environments using the Cyclic Integrated ReversibleBending Fatigue Tester (CIRFT), an enabling hot-cell testing technology developed recently at Oak Ridge National Laboratory (ORNL). This data will be used to support ongoing spent fuel modeling activities, in addition to addressing licensing issues associate with SNF transport. An important finding of this report is the similarity observed between HBU Zircolay-4 and Zirlocay-2 clad behavior under fatigue testing.

Aomi M, T Baba, T Miyashito, K Kaminura, T Yasuda, and Y Shinohara. 2008. Evaluation of Hydride Reorientation Behavior and Mechanical Properties for High-Burnup Fuel-Cladding Tubes in Interim Dry Storage. J. ASTM International 5(9).

The hydride stress reorientation behavior and the mechanical properties of irradiated cladding tubes were investigated to evaluate the high-burnup fuel-cladding tube properties in interim dry storage. As for the boiling water reactor (BWR) Zircaloy-2_Zry-2_ cladding, the hydride reorientation to the radial direction occurred at relatively low hoop stresses during the hydride reorientation treatment (HRT), such as less than $70 \mathrm{MPa}$. The increase of reorientation with hoop stress was not monotonic for the specimens in which a part of the hydrides remained precipitated at the HRT temperature, such as the case for 50GWd/t type cladding at a $300^{\circ} \mathrm{C}$ HRT. The degree of reorientation depended on the HRT solution temperature rather than on the estimated temperature at which the hydride precipitation occurred under the relatively moderate HRT conditions. In the relatively low cooling rate HRT, the hydride preferential precipitation in the $\mathrm{Zr}$ liner increased for $\mathrm{Zr}$ lined cladding compared to that in a relatively high cooling rate. The ductility 
of the specimens after the $300^{\circ} \mathrm{C}$ HRT showed relatively good correlation to the Polymax index which reflects the length or continuity of the hydrides regardless of their orientation. The ductility of the specimens after the $400^{\circ} \mathrm{C}, 0 \mathrm{MPa}, 30^{\circ} \mathrm{C} / \mathrm{h}$ HRT increased in ring compression testing at room temperature compared to no HRT_as-irradiated_specimens, and it indicated recovery of irradiation damage occurred at the $400^{\circ} \mathrm{C}$ annealing temperature and affected the ductility of the irradiated Zry-2 cladding.

EPRI. 2014. High Burnup Dry Storage Cask Research and Development Project: Final Test Plan. Contract No.: DE-NE-0000593. Electric Power Research Institute, Palo Alto, California.

This document describes a Test Plan for the High Burnup Dry Storage Cask Research and Development Project1 (also referred to as the "High Burnup Dry Storage Research Project" (HDRP)) sponsored by the U.S. Department of Energy - Office of Nuclear Energy (DOE-NE) under contract DE-NE-0000593 to the Electric Power Research Institute (EPRI). In conjunction with U.S. national laboratories, EPRI is leading a project team2 to develop and implement a Test Plan to collect data from an SNF dry storage system containing high burnup fuel.3 The Test Plan for the HDRP outlines the data to be collected; the high burnup fuel to be included; and the storage system design, procedures, and licensing necessary to implement the Test Plan. The main goals of the proposed test are to provide confirmatory data for model validation and potential improvement, provide input to future SNF dry storage cask design, support license renewals and new licenses for Independent Spent Fuel Storage Installations (ISFSIs), and support transportation licensing for high burnup SNF.

Nagase, F. and Fuketa, T., Investigation of hydride rim effect on failure of Zircaloy-4 cladding with tube burst test, Journal of Nuclear Science and Technology, 2005, 42(1), p.58-65.

To promote a better understanding of failure behavior of high burnup PWR fuel rods during reactivity initiated accidents (RIAs), tube burst tests have been performed with artificially hydrided Zircaloy-4 specimens at room tem- perature and at $620 \mathrm{~K}$. Pressurization rate was increased to a maximum of 3.4 $\mathrm{GPa} / \mathrm{s}$ in order to simulate rapid pellet/ cladding mechanical interaction (PCMI) that occurs in high burnup fuel rods during a pulse-irradiation in the Nuclear Safety Research Reactor (NSRR). Hydrogen content in the specimens ranged from 150 to 1,050 ppm. Hydrides were accumulated in the cladding periphery and formed 'hydride rim' (radially-localized hydride layer) as observed in high burnup PWR fuel claddings. The hydrided cladding tubes failed with an axial crack at the room temperature tests. Brittle fracture appeared in the hydride rim, and failure morphology was similar to that observed in the NSRR experi-ments. The hydrides rim obviously reduced burst pressure and residual hoop strain at the tests. The residual hoop strain was very small even at $620 \mathrm{~K}$ when thickness of the hydride rim exceeded $18 \%$ of cladding thickness. The present result accordingly indicates an important role of the hydrides layer in high burnup fuel rod failure under RIA conditions. 


\section{APPENDIX C. DRY STORAGE DEMONSTRATION PROJECTS}





\section{APPENDIX C. DRY STORAGE DEMONSTRATION PROJECTS}

As a result of the Nuclear Waste Policy Act of 1982, DOE, in cooperation with the private sector, conducted several SNF dry storage performance tests and demonstrations through cooperative agreements with the Electric Power Research Institute (EPRI), Lawrence Livermore National Laboratory, Idaho National Engineering and Environment Laboratory (now Idaho National Laboratory [INL]), Los Alamos National Laboratory, and various nuclear utilities. (McKinnon, MA and ME Cunningham 2003) Before 1982, DOE conducted belowground SNF storage testing at the Nevada Test Site using SNF from a nuclear utility company. The Surry Power Station and the H. B. Robinson Nuclear Plant have the longest operating ISFSIs in the United States, each having been placed in service in 1985.

\section{NEVADA TEST SITE AND TURKEY POINT NUCLEAR POWER PLANT}

Early thermal testing of spent or used fuel in dry cask storage to develop thermal models occurred at the Engine Maintenance, Assembly, and Disassembly facility (E-MAD) at the Nevada Test Site in 1978 with a spent fuel sealed storage cask test. The heavily instrumented sealed storage cask with a single fuel assembly was placed on a concrete pad adjacent to the E-MAD and monitored. (Hanson et al. 2012)

A demonstration of below-grade storage of SNF in granite rock at the Nevada Test Site was conducted between 1978 and 1985. Facility construction occurred between 1978 and 1980. In 1980, Florida Power and Light provided 13 Westinghouse $15 \times 15$ PWR spent fuel assemblies in individual canisters from the Turkey Point Nuclear Power Plant for the demonstration. The wet-pool cooling time before the test was 2.5 years. Visual observation, gas tests, and wet sip testing at the Turkey Point pool indicated that all the fuel was intact and contained no leaking fuel rods. Individual SNF canisters were emplaced in 1980 and subsequently permanently retrieved in 1983. The canisters were exchanged in 1981 and 1982 to demonstrate fuel handling capability. Post-test characterization was completed in 1985. The test demonstrated safe and reliable packaging, transportation, short-term storage, and retrieval of SNF. The Nevada Test Site demonstration layout is depicted in Fig. 1. (Patrick WC 1986)

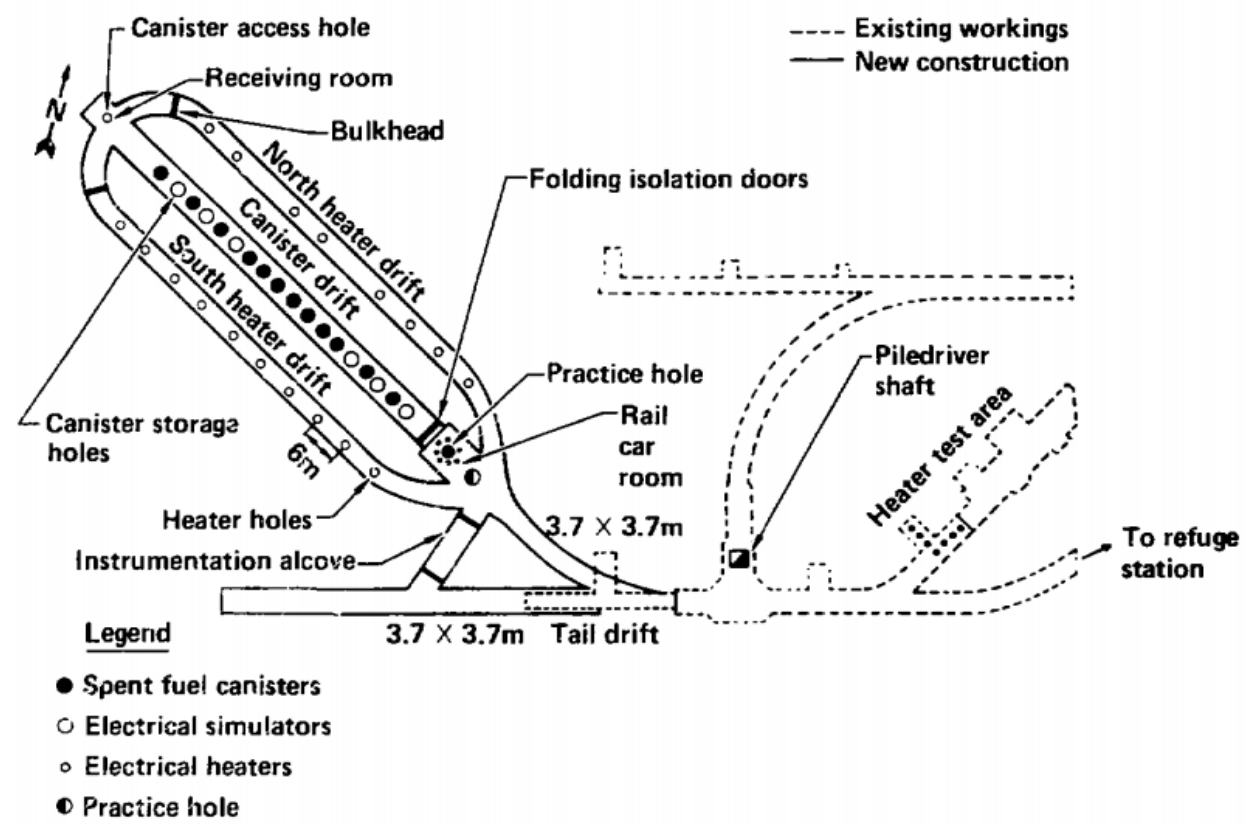

Fig. 1. Nevada Test Site Demonstration Project (Patrick WC 1986) 


\section{GENERAL ELECTRIC-MORRIS FACILITY AND COOPER NUCLEAR STATION}

Nebraska Power Cooper Nuclear Station provided 52 General Electric (GE) 7×7 BWR spent fuel assemblies for research on dry cask storage. The burnup was between 24 and $28 \mathrm{GWd} / \mathrm{MTU}$. The wetpool cooling time was between 2.3 and 3.4 years. The assemblies were performance tested between 1983 and 1985 in an REA 2023 cask at the GE-Morris facility in Illinois. At the conclusion of the test, the fuel was unloaded into the GE-Morris pool and the cask was shipped to INL for storage. The testing consisted of a series of runs that included two loads, two cask orientations, and three backfill environments. The BWR fuel assemblies from the Cooper Reactor used in the REA 2023 cask performance test were sipped "in-basin" and "in-vessel" to investigate fuel rod integrity before dry storage and to determine whether any of the fuel rods developed leaks during cask testing. Sipping consisted of placing a hood over the selected assembly and analyzing the water that was drawn off the top of the assembly. The cask performance was evaluated using various analysis codes, including ORIGEN2 (decay heat), HYDRA and COBRA-SFS (heat-transfer), and QAD and DOT (shielding). (McKinnon et al. 1986)

The REA 2023 BWR cask tested at the GE-Morris facility is depicted in Fig. 2. (McKinnon, MA and VA DeLoach 1993)

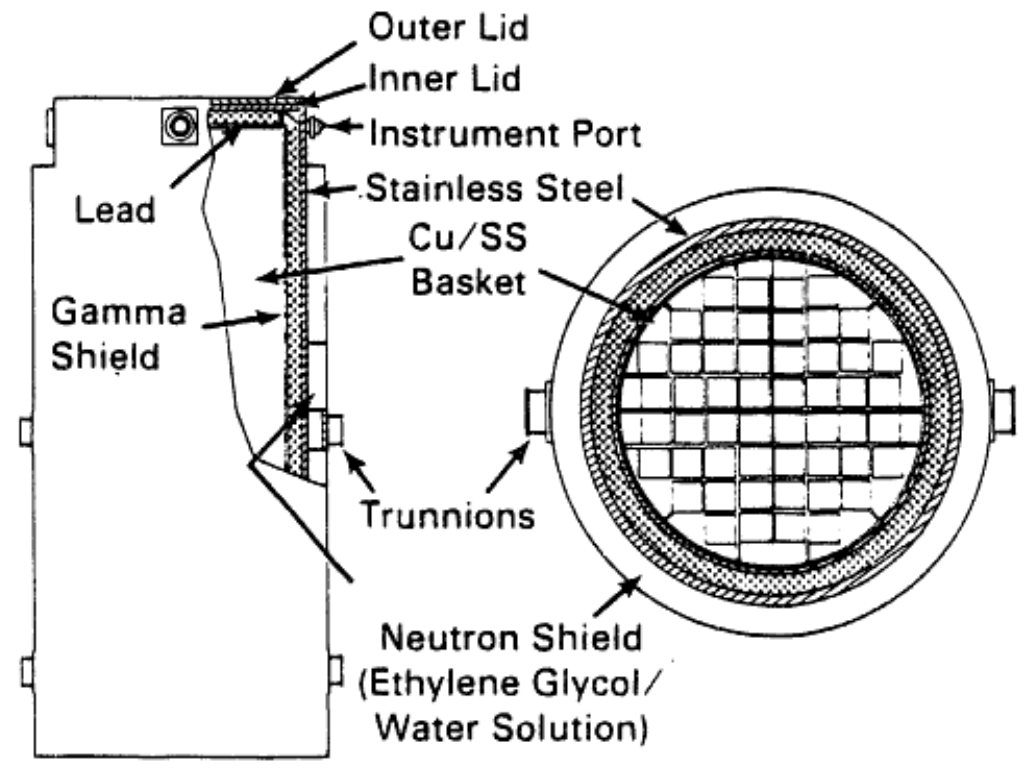

Fig. 2. REA 2023 BWR cask. (McKinnon ME and VA Deloach 1993)

\section{IDAHO NATIONAL LABORATORY AND SURRY POWER STATION}

Dominion Surry Power Station provided 21 Westinghouse $15 \times 15$ PWR spent fuel assemblies for research on dry cask storage. The fuel assemblies were ultrasonically tested in the Surry spent fuel pool using a Babcock \& Wilcox Failed Fuel Rod Detection System before being selected for the cask test. The burnup was between 24 and $35 \mathrm{GWd} / \mathrm{MTU}$. The wet-pool cooling time was between 2.2 and 3.8 years.

(McKinnon, MA and VA DeLoach 1993) The assemblies were stored in a CASTOR-V/21 cask at INL. The cask was placed in service at the Test Area North Hot Shop facility in 1985. The cask lid was modified to allow for ten additional instrumentation penetrations. The cask was opened in 1999 to evaluate the status of the fuel and the cask. There was no evidence of cask, shielding, or fuel rod degradation during long-term (14 years) storage that would affect cask performance or fuel integrity. (EPRI 2002) 
As part of the demonstration project, Surry installed, loaded, and monitored a CASTOR V/21 cask, a MC-10 cask, and a Nuclear Assurance NAC-I28 cask at the Surry ISFSI facility. INL tested a variety of casks under several agreements. (Hanson et al. 2012)

\section{H. B. ROBINSON NUCLEAR PLANT}

Carolina Power and Light tested three NUTECH Horizontal Modular Storage (NUHOMS) canisters capable of holding seven fuel assemblies each at the H. B. Robinson Nuclear Plant. The testing included the design, construction, and licensing of an ISFSI facility at the site, which occurred between 1984 and 1987. Demonstration testing with electrical heaters, and later with 21 Westinghouse $15 \times 15$ PWR spent fuel assemblies took place in 1988 and 1989. The burnup was between 31 and 34 GWd/MTU. The wetpool cooling time was 5 years. (McKinnon, MA and VA DeLoach 1993) The testing showed that the NUHOMS design was conservative, and additional canisters were loaded at the H. B. Robinson ISFSI. The NUHOMS Demonstration System at the H. B. Robinson ISFSI is depicted in Fig. 3. (EPRI 1990)

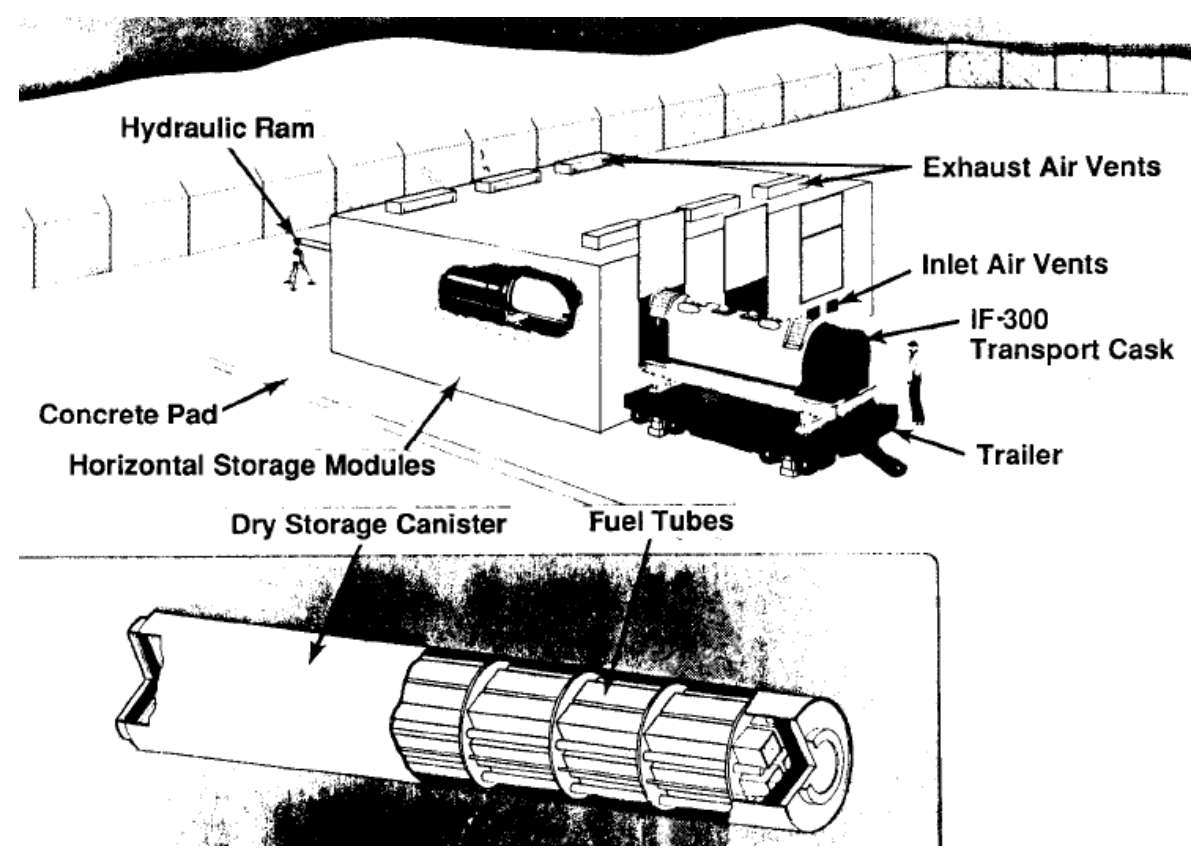

Fig. 3. NUHOMS Demonstration System (EPRI 1990) 
APPENDIX D. SUMMARY AND GAP ANALYSIS 


\section{APPENDIX D. SUMMARY AND GAP ANALYSIS}

\section{Summary of High- and Medium-Priority Degradation Mechanisms That Could Impact the Performance of SSC During Extended Storage (Hanson, 2012)}

\begin{tabular}{|c|c|c|c|}
\hline SSC & $\begin{array}{l}\text { Degradation } \\
\text { mechanism }\end{array}$ & $\begin{array}{l}\text { Importance } \\
\text { of } R \& D\end{array}$ & Approach to closing gaps \\
\hline \multirow{5}{*}{ Cladding } & $\begin{array}{l}\text { Annealing of } \\
\text { radiation damage }\end{array}$ & Medium & $\begin{array}{l}\text { Long-term, low-temperature annealing will be analyzed } \\
\text { through advanced modeling and simulation with some } \\
\text { experimental work to support the model. }\end{array}$ \\
\hline & $\begin{array}{l}\text { H2 effects: } \\
\text { embrittlement and } \\
\text { reorientation }\end{array}$ & High & $\begin{array}{l}\text { A comprehensive experimental and modeling program } \\
\text { to examine the factors that influence hydride } \\
\text { reorientation will be performed, with a focus on new } \\
\text { cladding materials and high burnup fuels. Additional } \\
\text { experimentation and modeling to provide the link } \\
\text { between unirradiated and irradiated cladding } \\
\text { performance will be initiated. }\end{array}$ \\
\hline & $\begin{array}{l}\text { H2 effects: delayed } \\
\text { hydride cracking }\end{array}$ & High & $\begin{array}{l}\text { Experimental work combined with modeling will be } \\
\text { initiated. }\end{array}$ \\
\hline & Oxidation & Medium & $\begin{array}{l}\text { Experimental work to determine the mechanism for the } \\
\text { rapid cladding oxidation observed will be initiated }\end{array}$ \\
\hline & Creep & Medium & $\begin{array}{l}\text { Long-term, low-temperature, low-strain creep will be } \\
\text { analyzed through advanced modeling and simulation } \\
\text { with some experimental work to support the model. }\end{array}$ \\
\hline $\begin{array}{l}\text { Fuel } \\
\text { assembly } \\
\text { hardware }\end{array}$ & $\begin{array}{l}\text { Corrosion (stress } \\
\text { corrosion cracking) }\end{array}$ & Medium & $\begin{array}{l}\text { Because the fuel assembly hardware components of } \\
\text { concern are the same as or similar to those that also } \\
\text { serve as a cladding, the results of cladding tests and } \\
\text { analyses will be used. }\end{array}$ \\
\hline \multirow{4}{*}{$\begin{array}{l}\text { Neutron } \\
\text { poisons }\end{array}$} & $\begin{array}{l}\text { Thermal aging } \\
\text { effects }\end{array}$ & Medium & \multirow{4}{*}{$\begin{array}{l}\text { Development of an accurate source term and radiation } \\
\text { and thermal profiles is needed. Experimental work and } \\
\text { modeling together in collaboration with universities } \\
\text { under the Nuclear Energy University Program will be } \\
\text { initiated. }\end{array}$} \\
\hline & Creep & Medium & \\
\hline & $\begin{array}{l}\text { Embrittlement and } \\
\text { cracking }\end{array}$ & Medium & \\
\hline & $\begin{array}{l}\text { Corrosion } \\
\text { (blistering) }\end{array}$ & Medium & \\
\hline \multirow{2}{*}{$\begin{array}{l}\text { Container } \\
\text { (welded } \\
\text { canister) }\end{array}$} & $\begin{array}{l}\text { Atmospheric } \\
\text { corrosion (including } \\
\text { marine } \\
\text { environment) }\end{array}$ & High & \multirow{3}{*}{$\begin{array}{l}\text { Analyses of the conditions that will exist on the cask } \\
\text { and canister surfaces will be performed. Collaboration } \\
\text { with the Electric Power Research Institute-led } \\
\text { Extended Storage Collaboration Program and } \\
\text { International Subcommittee, especially the Japanese } \\
\text { Central Research Institute of Electric Power Industry } \\
\text { and the German Federal Institute for } \\
\text { Materials Research and Testing, will be } \\
\text { initiated. }\end{array}$} \\
\hline & $\begin{array}{l}\text { Thermomechanical } \\
\text { fatigue of seals and } \\
\text { bolts }\end{array}$ & Medium & \\
\hline $\begin{array}{l}\text { Container } \\
\text { (bolted } \\
\text { casks) }\end{array}$ & $\begin{array}{l}\text { Atmospheric } \\
\text { corrosion } \\
\text { (including marine } \\
\text { environment) }\end{array}$ & High & \\
\hline
\end{tabular}




\begin{tabular}{|l|l|c|l|}
\hline & Aqueous corrosion & High & \\
\hline \multirow{3}{*}{ Overpack } & Freeze-thaw & Medium & $\begin{array}{l}\text { Development of detailed aging management programs } \\
\text { will be performed. Inspection tasks to provide the } \\
\text { means for early detection will be initiated. }\end{array}$ \\
\cline { 2 - 3 } & $\begin{array}{l}\text { Corrosion of } \\
\text { embedded steel }\end{array}$ & Medium & \begin{tabular}{l} 
mean \\
\hline
\end{tabular}
\end{tabular}


Gap Analysis (PNNL 2012)

Ability of Assembly and Canister to Transport after Storage

\begin{tabular}{|c|c|c|c|c|c|c|c|c|c|c|}
\hline $\begin{array}{l}\text { UFDC's gap } \\
\text { description }\end{array}$ & \multicolumn{10}{|c|}{$\begin{array}{l}\text { The UFDC did not identify this topic specifically as a gap. However, the ability of the } \\
\text { assembly and canister to be transported after storage is one of the stated objectives of } \\
\text { the UFDC program (see Section 1.0). UFDC uses the cross-cutting gap "Stress } \\
\text { Profiles" as the means of addressing this gap. }\end{array}$} \\
\hline $\begin{array}{l}\text { Alternate } \\
\text { description }\end{array}$ & \multicolumn{10}{|c|}{$\begin{array}{l}\text { The United Kingdom identified the need to determine the condition of the fuel for } \\
\text { transportation after approximately } 100 \text { years of storage and the ability of the fuel and } \\
\text { canister to withstand normal and accident transport conditions (EPRI 2012). This gap is } \\
\text { similar to the stress profiles gap (see Section 3.1.12), and closing it requires research } \\
\text { into closing the individual SSC degradation gaps as well as the stress profiles gap. }\end{array}$} \\
\hline \multirow{2}{*}{ Priority } & UFDC NWTRB & NRC & EPRI & IAEA & Germany & Hungary & Japan & ROK & Spain & $\mathrm{UK}$ \\
\hline & & & & & & & & & & $\mathrm{M}$ \\
\hline $\begin{array}{l}\text { Consistency } \\
\text { of priority }\end{array}$ & \multicolumn{10}{|c|}{ The United Kingdom is the only country to give priority to this gap. } \\
\hline $\begin{array}{l}\text { UFDC } \\
\text { action }\end{array}$ & \multicolumn{10}{|c|}{$\begin{array}{l}\text { This gap is adequately covered by addressing the SSC-related gaps, especially for } \\
\text { cladding, assembly hardware, and the cask/canister, as well as the "Stress Profiles" gap. } \\
\text { No additional gap will be added, and the priorities for the UFDC gaps remain the same. }\end{array}$} \\
\hline
\end{tabular}

NWTRB = Nuclear Waste Technical Review Board 


\section{Activity Transport in Canister}

\begin{tabular}{|c|c|c|c|c|c|c|c|c|c|c|c|}
\hline & \multicolumn{11}{|c|}{$\begin{array}{l}\text { The UFDC did not identify this topic as a gap } \\
\text { In the United States, regulation requires an “analysis of the potential dose equivalent or } \\
\text { committed dose equivalent to an individual outside the controlled area from accidents or } \\
\text { natural phenomena events that result in the release of radioactive material to the } \\
\text { environment or direct radiation from the ISFSI..." (10 CFR 72.24[m]). Table 5-2 of } \\
\text { NUREG-1536 rev } 1 \text { (NRC 2010) (Table 7.1 of rev 0) provides fractions of radioactive } \\
\text { materials available for release from spent fuel that "should be used in the confinement } \\
\text { analyses to demonstrate compliance with } 10 \text { CFR Part 72” (NRC 2010). However, } \\
\text { because of the lack of a credible event that could breach confinement, license applicants } \\
\text { either do not perform such a calculation or use conservative release fractions such as } \\
\text { those provided in NUREG-1536 for non-mechanistic hypothetical events to show even } \\
\text { those conditions result in doses well within the } 10 \text { CFR } 72.106 \text { limit. }\end{array}$} \\
\hline $\begin{array}{l}\text { Alternate } \\
\text { description }\end{array}$ & \multicolumn{11}{|c|}{$\begin{array}{l}\text { In the United Kingdom, the regulator does not publish specific requirements of the } \\
\text { utilities other than a list of } 36 \text { general License Conditions. "In the UK the utility is } \\
\text { required to demonstrate ownership of all aspects of the safety case, and to justify the } \\
\text { technical bases of the safety case as well as demonstrating compliance with them." } \\
\text { (EPRI 2012). As a consequence, requirements for specific calculations such as those } \\
\text { required in } 10 \text { CFR 72.24(m) do not exist, and the utility must determine which } \\
\text { calculations are necessary to demonstrate safety. } \\
\text { For this reason, the United Kingdom is interested in the "need to develop a model of } \\
\text { activity transport/behavior in canister following fuel failure" (EPRI 2012). This includes } \\
\text { "fission gas transport in the fuel matrix during a fault situation (i.e., can gap release be } \\
\text { enhanced by other mechanisms," and the need to determine the actual releases to the } \\
\text { environment following a fault scenario (EPRI 2012). }\end{array}$} \\
\hline \multirow{2}{*}{ Priority } & UF & NWTRB & NRC & EPRI & IAEA & Germany & Hungary & Japan & ROK & Spain & \\
\hline & & & & & & & & & & & \\
\hline $\begin{array}{l}\text { Consisten } \\
\text { priority }\end{array}$ & \multicolumn{11}{|c|}{ The United Kingdom is the only country or organization to identify this as a gap. } \\
\hline & \multicolumn{11}{|c|}{$\begin{array}{l}\text { The release fractions assumed in NUREG-1536 (NRC 2010) are conservative and thus } \\
\text { R\&D to provide more realistic release fractions under various conditions would be of } \\
\text { benefit, but is considered to be of low priority. This priority could increase if further } \\
\text { analyses show that such an approach is necessary to counter potential increased failure } \\
\text { rates because of materials degradation over extended periods. }\end{array}$} \\
\hline
\end{tabular}




\section{Burnup Credit}

\begin{tabular}{|c|c|c|c|c|c|c|c|c|c|c|c|}
\hline $\begin{array}{l}\text { UFDC's gap } \\
\text { description }\end{array}$ & \multicolumn{11}{|c|}{$\begin{array}{l}\text { Burnup credit is allowance in the criticality safety analysis for the decrease in fuel } \\
\text { reactivity resulting from irradiation. The level of burnup credit depends on the isotopes } \\
\text { modeled in the criticality analysis. Actinide-only burnup credit generally refers to } \\
\text { calculations employing only actinides with the highest reactivity worth. Full burnup } \\
\text { credit refers to a combination of the uranium and plutonium isotopes evaluated in } \\
\text { actinide-only burnup credit, plus a number of fission products and minor actinides. } \\
\text { Although some data are available and have been used to validate and attain regulatory } \\
\text { approval for a burnup credit argument, additional data are needed to attain "full burnup } \\
\text { credit”; reduce the bias and bias uncertainty in the isotopic concentration predictions, } \\
\text { reactivity worth, and cross sections; and reduce the uncertainty/penalty in the assembly } \\
\text { burnup assignment. }\end{array}$} \\
\hline $\begin{array}{l}\text { Alternate } \\
\text { description }\end{array}$ & \multicolumn{11}{|c|}{ Description of burnup credit is consistent in all the gap reports that discuss it. } \\
\hline \multirow{2}{*}{ Priority } & UFD & NWTRB & NRC & EPRI & IAEA & Germany & Hungary & Japan & ROK & Spain & UK \\
\hline & $\mathrm{H}$ & & & & & & $\mathrm{H}$ & & & & \\
\hline $\begin{array}{l}\text { Consistency of } \\
\text { Priority }\end{array}$ & \multicolumn{11}{|c|}{$\begin{array}{l}\text { All the gap analyses that identified burnup credit as important to dry storage and } \\
\text { transportation are consistent in priority assignment. }\end{array}$} \\
\hline $\begin{array}{l}\text { UFDC } \\
\text { action }\end{array}$ & \multicolumn{11}{|c|}{$\begin{array}{l}\text { No change in the UFDC priority is needed, based on this comparison. However, if } \\
\text { Revision } 3 \text { of ISG-8 (NRC 2012b) is implemented as in its current draft form, the need } \\
\text { for additional data to support storage and transportation licenses will be lessened and the } \\
\text { priority will be lowered. Additional R\&D for burnup credit could be necessary to support } \\
\text { geologic disposal efforts. }\end{array}$} \\
\hline
\end{tabular}




\section{Dry Transfer Development}

\begin{tabular}{|c|c|c|c|c|c|c|c|c|c|c|c|}
\hline $\begin{array}{l}\text { UFDC's gap } \\
\text { description }\end{array}$ & \multicolumn{11}{|c|}{$\begin{array}{l}\text { With the closing of the INL test area north facility, the ability to load and unload } \\
\text { assemblies to or from dry storage casks in a dry environment was lost in the United States. } \\
\text { There are two categories of needs for dry transfer facilities: retrieval of limited amounts of } \\
\text { fuel to support research, and the ability to handle larger amounts of fuel as needed to } \\
\text { repackage stored fuel for further storage, transportation, or disposal. The need for the first } \\
\text { of these is covered under the fuel transfer options gap (see Section 3.1.9). The second is } \\
\text { less immediate but is suggested for repackaging fuel from "ISFSI-only" sites if needed, for } \\
\text { post-accident recovery of damaged fuel (NUREG-1536, NRC 2010), and to provide a } \\
\text { consolidated storage facility that could have "flexible, safe, and cost-effective waste } \\
\text { handling services (i.e., repackaging or sorting of fuel for final disposal) and could facilitate } \\
\text { the standardization of cask systems" (BRC 2012). }\end{array}$} \\
\hline $\begin{array}{l}\text { Alternate } \\
\text { description }\end{array}$ & \multicolumn{11}{|c|}{$\begin{array}{l}\text { The NWTRB recommends the "design and demonstration of dry-transfer fuel systems for } \\
\text { removing fuel from casks and canisters following extended dry storage" (NWTRB 2010, } \\
\text { pp. } 14 \text { and 125). } \\
\text { Spain notes the need for development of "inspections, methods and tools required to open } \\
\text { the cask and transfer the fuel from the individual (container) to the centralized repository } \\
\text { (vault)." (EPRI 2012) }\end{array}$} \\
\hline \multirow[b]{2}{*}{ Priority } & UFDC & NWTRB & NRC & EPRI & IAEA & Germany & Hungary & Japan & $\mathrm{ROK}$ & Spain & $\mathrm{UK}$ \\
\hline & & $\mathrm{H}$ & & & $\mathrm{X}$ & & & & & M & \\
\hline $\begin{array}{l}\text { Consistency } \\
\text { of priority }\end{array}$ & \multicolumn{11}{|c|}{ There is no consensus on the priority of this gap among those who rate it. } \\
\hline $\begin{array}{l}\text { UFDC } \\
\text { action }\end{array}$ & \multicolumn{11}{|c|}{$\begin{array}{l}\text { This gap will not be added explicitly, as it is already one of the options under the "Fuel } \\
\text { Transfer Options" gap and is being considered as one of the means to address closure of } \\
\text { gaps through an engineering-scale demonstration program. }\end{array}$} \\
\hline
\end{tabular}




\section{Drying Issues}

\begin{tabular}{|c|c|c|c|c|c|c|c|c|c|c|c|}
\hline $\begin{array}{l}\text { UFDC's gap } \\
\text { description }\end{array}$ & \multicolumn{11}{|c|}{$\begin{array}{l}\text { Many degradation mechanisms of the SSCs within the confinement boundary are } \\
\text { dependent on or accelerated by the presence of water. Because the cask or canister is } \\
\text { loaded in a pool, it is important to remove as much water as possible during the drying } \\
\text { process. While there is no direct evidence that the amount of water that remains in a cask } \\
\text { after a normal drying process is of concern, there is a lack of data to validate just how much } \\
\text { water remains. }\end{array}$} \\
\hline $\begin{array}{l}\text { Alternate } \\
\text { description }\end{array}$ & \multicolumn{11}{|c|}{ All analyses discussing drying issues are consistent in their description of the gap. } \\
\hline \multirow{2}{*}{ Priority } & UFDC & NWTRB & NRC & EPRI & IAEA & Germany & Hungary & Japan & ROK & Spain & $\mathrm{UK}$ \\
\hline & $\mathrm{VH}$ & $\mathrm{H}$ & H1 & & $\mathrm{X}$ & & $\mathrm{H}$ & $\mathrm{C}$ & & & $\mathrm{M}$ \\
\hline $\begin{array}{l}\text { Consistency } \\
\text { of priority }\end{array}$ & \multicolumn{11}{|c|}{$\begin{array}{l}\text { Except for Japan and the United Kingdom, this gap has been assigned a high priority by } \\
\text { those that rate it. The Japanese have a different drying method from the United States and } \\
\text { consider this issue closed. }\end{array}$} \\
\hline $\begin{array}{l}\text { UFDC } \\
\text { action }\end{array}$ & \multicolumn{11}{|c|}{ No change in the UFDC priority is recommended, based on this comparison. } \\
\hline
\end{tabular}

\section{Examine Fuel after Storage}

\begin{tabular}{|c|c|c|c|c|c|c|c|c|c|c|c|}
\hline $\begin{array}{l}\text { UFDC's gap } \\
\text { description }\end{array}$ & \multicolumn{11}{|c|}{$\begin{array}{l}\text { This item was expanded from “examine the fuel at INL” to the more general "examine fuel } \\
\text { after storage," which was identified by a number of organizations and countries. The } \\
\text { purpose of this gap was to obtain a second data point on low-burnup fuel that has been in } \\
\text { dry storage, but applies as well to high-burnup fuel after it has been in storage for some } \\
\text { period. While there is emphasis on the fuel and cladding, closing this gap includes } \\
\text { examining the entire dry cask storage system after storage, including the fuel, cladding, } \\
\text { assembly hardware, baskets, neutron poisons, canister/cask, overpack if applicable, and } \\
\text { pad. This activity will provide data used in evaluating performance models of all the SSCs. }\end{array}$} \\
\hline $\begin{array}{l}\text { Alternate } \\
\text { description }\end{array}$ & \multicolumn{11}{|c|}{$\begin{array}{l}\text { There is a universal need to examine fuel and the DCSS after a period of storage to validate } \\
\text { models. }\end{array}$} \\
\hline \multirow[t]{2}{*}{ Priority } & UFDC & NWTRB & NRC & EPRI & IAEA & Germany & Hungary & Japan & ROK & Spain & UK \\
\hline & $\mathrm{H}$ & $\mathrm{H}$ & & & $\mathrm{H}$ & & $\mathrm{H}$ & $\mathrm{H}$ & & M & M \\
\hline $\begin{array}{l}\text { Consistency } \\
\text { of priority }\end{array}$ & \multicolumn{11}{|c|}{ There is relative consensus that this is a high-priority activity. } \\
\hline $\begin{array}{l}\text { UFDC } \\
\text { action }\end{array}$ & \multicolumn{11}{|c|}{ No change in the UFDC priority is recommended, based on this comparison. } \\
\hline
\end{tabular}




\section{Fuel Classification}

\begin{tabular}{|c|c|c|c|c|c|c|c|c|c|c|c|}
\hline $\begin{array}{l}\text { UFDC's gap } \\
\text { description }\end{array}$ & \multicolumn{11}{|c|}{$\begin{array}{l}\text { Fuel classification or damage definitions are important because typically fuel cannot be put } \\
\text { into dry storage if it is "damaged,” without special treatment such as placement in a } \\
\text { damaged fuel can. } \\
\text { In the United States, fuel is classified in the NRC ISG-1 Revision } 2 \text { as “damaged,” } \\
\text { "undamaged," or "intact” (NRC 2007). UNF is determined to be damaged or undamaged } \\
\text { based on its ability to meet all fuel-specific and system-related functions. These functions } \\
\text { are those imposed on the fuel rods and assemblies by the applicant to meet a regulatory } \\
\text { requirement for storage and/or transport. Intact fuel is undamaged fuel that is also not } \\
\text { breached. }\end{array}$} \\
\hline $\begin{array}{l}\text { Alternate } \\
\text { description }\end{array}$ & \multicolumn{11}{|c|}{$\begin{array}{l}\text { The Republic of Korea, Spain, and the United Kingdom all express the need to develop the } \\
\text { means to better inspect fuel assemblies for classification purposes. In the United Kingdom, } \\
\text { this is necessary because only intact fuel is to be placed in dry storage. }\end{array}$} \\
\hline \multirow{2}{*}{ Priority } & UFDC & WTRB & $\mathrm{RC}$ & $\mathrm{RI}$ & IAEA & Germa & Hungary & pan & $\mathrm{ROK}$ & Spain & $\mathrm{UK}$ \\
\hline & & & & & & & & & $\mathrm{H}$ & $\mathrm{H}$ & $\mathrm{H}$ \\
\hline $\begin{array}{l}\text { Consistency } \\
\text { of priority }\end{array}$ & \multicolumn{11}{|c|}{$\begin{array}{l}\text { In those countries that rate fuel classification and damage definition, it is assigned a high } \\
\text { priority. }\end{array}$} \\
\hline UFDC & \multicolumn{11}{|c|}{$\begin{array}{l}\text { At present, there is no evidence that the US industry is not able to properly characterize and } \\
\text { classify fuel per the definitions of ISG-1, Revision } 2 \text { (NRC 2007). Thus this gap will not be } \\
\text { added to the UFDC Gap Analysis. }\end{array}$} \\
\hline
\end{tabular}

\section{Fuel Modeling}

\begin{tabular}{|c|c|c|c|c|c|c|c|c|c|c|c|}
\hline $\begin{array}{l}\text { UFDC's gap } \\
\text { description }\end{array}$ & \multicolumn{11}{|c|}{$\begin{array}{l}\text { The UFDC does not identify this as a gap, but considers it an activity that must be pursued } \\
\text { in order to license dry cask storage. UNF cladding modeling to evaluate condition of fuel as } \\
\text { a function of dry storage is clearly identified as one of the options to close cladding gaps } \\
\text { (UFDC 2012b, Appendix A). }\end{array}$} \\
\hline $\begin{array}{l}\text { Alternate } \\
\text { description }\end{array}$ & \multicolumn{11}{|c|}{$\begin{array}{l}\text { The United Kingdom identified the "need to develop fuel characterization technique i.e., } \\
\text { determine fuel is intact," and the "need to develop fuel modeling under dry store conditions } \\
\text { accounting for periods spent in reactor and the fuel pond” (EPRI 2012). }\end{array}$} \\
\hline \multirow{2}{*}{ Priority } & UFDC & NWTRB & NRC & EPRI & IAEA & Germany & Hungary & Japan & $\mathrm{ROK}$ & Spain & $\mathrm{UK}$ \\
\hline & & & & & & & & & & & $\mathrm{H}$ \\
\hline $\begin{array}{l}\text { Consistency } \\
\text { of priority }\end{array}$ & \multicolumn{11}{|c|}{ The United Kingdom is the only country to identify this issue as a specific gap. } \\
\hline $\begin{array}{l}\text { UFDC } \\
\text { action }\end{array}$ & \multicolumn{11}{|c|}{$\begin{array}{l}\text { The UFDC agrees that fuel modeling is an important option to closing gaps. However, this } \\
\text { gap will not be added to the UFDC Gap Analysis. }\end{array}$} \\
\hline
\end{tabular}




\section{Fuel Transfer Options}

\begin{tabular}{|c|c|c|c|c|c|c|c|c|c|c|c|}
\hline $\begin{array}{l}\text { UFDC's gap } \\
\text { description }\end{array}$ & \multicolumn{11}{|c|}{$\begin{array}{l}\text { The R\&D proposed to close the fuel transfer options gap examines the effects of wetting } \\
\text { and drying on cladding properties. Fuel samples, needed for research to close the cladding } \\
\text { gaps, would most likely need to be transported from a utility site to a research laboratory. If } \\
\text { coming from dry storage, and in the absence of a dry transfer system (see Section 3.1.4), } \\
\text { the fuel would be rewetted for unloading from the dry storage cask and loading into a } \\
\text { transportation cask, and then re-dried for transport. Both these processes have the potential } \\
\text { to change the cladding properties, thus obfuscating any data obtained from those samples. } \\
\text { The proposed research will determine if rewetting and re-drying can be done in such a way } \\
\text { as to preserve the state of the cladding from storage enough to obtain interpretable data } \\
\text { from those samples. This analysis will then help determine the pros and cons of the } \\
\text { different transfer options (wet or dry) and allow researchers to make informed decisions on } \\
\text { the preferred methods for transfer of fuel. }\end{array}$} \\
\hline $\begin{array}{l}\text { Alternate } \\
\text { description }\end{array}$ & \multicolumn{11}{|c|}{$\begin{array}{l}\text { Hungary uses the same description as UFDC, whereas the Republic of Korea is more } \\
\text { concerned about the effects of transferring fuel between reactor pools as a means of } \\
\text { maintaining pool capacity. }\end{array}$} \\
\hline \multirow{2}{*}{ Priority } & UFDC & NWTRB & NRC & EPRI & IAEA & Germany & Hungary & Japan & $\mathrm{ROK}$ & Spain & $\mathrm{UK}$ \\
\hline & $\mathrm{VH}$ & & & & & & $\mathrm{H}$ & & M & & \\
\hline $\begin{array}{l}\text { Consistency } \\
\text { of priority }\end{array}$ & \multicolumn{11}{|c|}{ This gap is rated medium or high priority by those who rate it. } \\
\hline $\begin{array}{l}\text { UFDC } \\
\text { action }\end{array}$ & \multicolumn{11}{|c|}{ No change in the UFDC priority is recommended, based on this comparison. } \\
\hline
\end{tabular}




\section{Moderator Exclusion}

\begin{tabular}{|c|c|c|c|c|c|c|c|c|c|c|c|}
\hline $\begin{array}{l}\text { UFDC's gap } \\
\text { description }\end{array}$ & \multicolumn{11}{|c|}{$\begin{array}{l}\text { If the geometry of the fuel or the baskets, including neutron poisons, cannot be } \\
\text { demonstrated for normal conditions of transport and hypothetical accident conditions, } \\
\text { moderator exclusion may be a viable way to demonstrate subcriticality. There does not } \\
\text { seem to be a general technical or a regulatory path to demonstrating subcriticality during } \\
\text { normal conditions of transport and hypothetical accident conditions after a period of } \\
\text { storage. The basis will likely be a demonstration of moderator exclusion, along with } \\
\text { structural integrity of the fuel, baskets, and neutron poisons, combined with a validated full } \\
\text { burnup credit methodology. This issue, which requires further technical R\&D as well as } \\
\text { regulatory engagement, is relevant to all UNF in dual-purpose dry storage systems. }\end{array}$} \\
\hline $\begin{array}{l}\text { Alternate } \\
\text { description }\end{array}$ & \multicolumn{11}{|c|}{ UFDC is the only organization that discussed moderator exclusion. } \\
\hline \multirow{2}{*}{ Priority } & UFDC & NWTRB & NRC & EPRI & IAEA & Germany & Hungary & Japan & ROK & Spain & UK \\
\hline & $\mathrm{H}$ & & & & & & & & & & \\
\hline $\begin{array}{l}\text { Consistency } \\
\text { of priority }\end{array}$ & \multicolumn{11}{|c|}{ UFDC is the only organization that discussed moderator exclusion. } \\
\hline $\begin{array}{l}\text { UFDC } \\
\text { action }\end{array}$ & \multicolumn{11}{|c|}{ No change in the UFDC priority is recommended, based on this comparison. } \\
\hline
\end{tabular}




\section{Monitoring}

\begin{tabular}{|c|c|c|c|c|c|c|c|c|c|c|c|}
\hline $\begin{array}{l}\text { UFDC's gap } \\
\text { description }\end{array}$ & \multicolumn{11}{|c|}{$\begin{array}{l}\text { Monitoring/Inspection can be applied for research purposes in demonstration projects, or } \\
\text { more generally at the utilities. At the utilities in the United States, monitoring of the } \\
\text { confinement boundary for bolted casks is required. This is usually done by monitoring the } \\
\text { pressure between the redundant seals. Other routine monitoring/inspection activities } \\
\text { include daily surveillance of overpack inlets and outlets for blockage, periodic radiation } \\
\text { surveys, and visual inspection of the exterior of the cask or overpack. For research } \\
\text { purposes, monitoring/inspection can provide data to provide input to and evaluation of SSC } \\
\text { degradation models. } \\
\text { The gaps in monitoring capability include the lack of field-ready sensors that are adequate } \\
\text { with respect to sensitivity, environmental compatibility, physical compatibility, and } \\
\text { longevity. Monitoring inside the cask/canister without compromising the confinement } \\
\text { barrier is particularly challenging, requiring field- ready technologies for sensor power } \\
\text { transmission/generation and data transmission. }\end{array}$} \\
\hline $\begin{array}{l}\text { Alternate } \\
\text { description }\end{array}$ & \multicolumn{11}{|c|}{$\begin{array}{l}\text { Germany recommends investigation of pressure monitoring devices that failed during } \\
\text { storage operation. }\end{array}$} \\
\hline \multirow{2}{*}{ Priority } & UFDC & NWTRB & NRC & EPRI & IAEA & Germany & Hungary & Japan & ROK & Spain & $\mathrm{UK}$ \\
\hline & $\mathrm{VH}$ & $\mathrm{H}$ & $\mathrm{H} 2$ & & $\mathrm{H}$ & & $\mathrm{H}$ & $\mathrm{H}$ & & & \\
\hline $\begin{array}{l}\text { Consistency } \\
\text { of priority }\end{array}$ & \multicolumn{11}{|c|}{ This activity has a high priority to all those that rate it. } \\
\hline $\begin{array}{l}\text { UFDC } \\
\text { action }\end{array}$ & \multicolumn{11}{|c|}{ No change in the UFDC priority is recommended, based on this comparison. } \\
\hline
\end{tabular}




\section{Stress Profiles}

\begin{tabular}{|c|c|c|c|c|c|c|c|c|c|c|c|}
\hline $\begin{array}{l}\text { UFDC's gap } \\
\text { description }\end{array}$ & \multicolumn{11}{|c|}{$\begin{array}{l}\text { The stress profiles gap is a gap in the experimental data and detailed calculations needed to } \\
\text { determine the types of stresses (e.g., magnitude, frequency, duration) imparted to various } \\
\text { SSCs under various conditions. These conditions include normal cask handling, cask drop, } \\
\text { seismic events (including up to design basis), cask tipover, and normal transportation. } \\
\text { Accurate inputs and quantification of the primary stresses (from pressure and thermal } \\
\text { loadings), secondary stresses (from residual stresses from fabrication), and external } \\
\text { loadings (from vacuum drying, handling, and vibratory loads during transportation) are } \\
\text { important for evaluating the material and structural response of an SSC subjected to } \\
\text { extended storage and transportation conditions. } \\
\text { The structural analyses performed for the license applications typically use bounding } \\
\text { approximations in order to demonstrate that the SSCs maintain their safety functions } \\
\text { through design basis storage events and normal transportation. However, these analyses do } \\
\text { not use degraded material properties, so it is difficult to determine how much degradation } \\
\text { can occur and still have the SSC meet its safety functions. R\&D to close the stress profiles } \\
\text { gap will provide this information and thus provides inputs to, and outputs from, the } \\
\text { research to close gaps on the effect of the degradation mechanisms on the structural } \\
\text { properties of SSCs. }\end{array}$} \\
\hline $\begin{array}{l}\text { Alternate } \\
\text { description }\end{array}$ & \multicolumn{11}{|c|}{ All analyses discussing stress profiles are consistent in their description of the gap. } \\
\hline \multirow{2}{*}{ Priority } & UFDC & NWTRB & NRC & EPRI & IAEA & Germany & Hungary & Japan & ROK & Spain & \\
\hline & $\mathrm{VH}$ & $\mathrm{H}$ & & & $X$ & & & $\mathrm{C}$ & & & \\
\hline $\begin{array}{l}\text { Consistency } \\
\text { of priority }\end{array}$ & \multicolumn{11}{|c|}{$\begin{array}{l}\text { There is inconsistency between the UFDC and Japan. Japan considers this gap closed as a } \\
\text { result of the testing performed by the Central Research Institute of Electric Power Industry } \\
\text { (CRIEPI) between FY } 2001 \text { and FY 2008. Demonstration tests included thermal, drop } \\
\text { impact, missile impact, and seismic tests with full-scale concrete cask and metal cask } \\
\text { systems. }\end{array}$} \\
\hline $\begin{array}{l}\text { UFDC } \\
\text { action }\end{array}$ & \multicolumn{11}{|c|}{ No change in the UFDC priority is recommended, based on this comparison. } \\
\hline
\end{tabular}




\section{Thermal Profiles}

\begin{tabular}{|c|c|c|c|c|c|c|c|c|c|c|c|}
\hline $\begin{array}{l}\text { UFDC's gap } \\
\text { description }\end{array}$ & \multicolumn{11}{|c|}{$\begin{array}{l}\text { Because nearly all degradation mechanisms are temperature-dependent, thermal profile } \\
\text { histories are needed to predict SSC performance. Therefore, temperature data are needed } \\
\text { for all SSCs from the time the fuel is loaded into the cask and dried, through the storage } \\
\text { period, and during subsequent transportation. The NRC issued guidance on temperature } \\
\text { limits based on the need to maintain the integrity of the cladding (NRC 2010b). Therefore, } \\
\text { when making approximations for modeling, most modelers have used conservative ones to } \\
\text { ensure cladding does not exceed those limits. However, because some degradation } \\
\text { processes occur only as the dry cask storage system cools below a threshold temperature, } \\
\text { more realistic thermal calculations are needed. Similarly, conservatively high temperatures } \\
\text { would over-predict various degradation rates. }\end{array}$} \\
\hline $\begin{array}{l}\text { Alternate } \\
\text { description }\end{array}$ & \multicolumn{11}{|c|}{ All analyses discussing thermal profiles are consistent in their definition. } \\
\hline \multirow{2}{*}{ Priority } & UFDC & NWTRB & NRC & EPRI & IAEA & Germany & Hungary & Japan & ROK & Spain & UK \\
\hline & $\mathrm{VH}$ & $\mathrm{H}$ & H1 & & $\mathrm{X}$ & & $\mathrm{H}$ & $\mathrm{C}$ & $\mathrm{H}$ & M & $\mathrm{H}$ \\
\hline $\begin{array}{l}\text { Consistency } \\
\text { of priority }\end{array}$ & \multicolumn{11}{|c|}{$\begin{array}{l}\text { Except for Japan, which considers the thermal profiles it currently has as adequate, there is } \\
\text { consensus that more thermal modeling is needed. Regulations in Japan limit peak cladding } \\
\text { temperature to } 275^{\circ} \mathrm{C} \text {, much lower than the } 400^{\circ} \mathrm{C} \text { peak cladding temperature limit in the } \\
\text { United States. }\end{array}$} \\
\hline $\begin{array}{l}\text { UFDC } \\
\text { action }\end{array}$ & \multicolumn{11}{|c|}{ No change in the UFDC priority is recommended, based on this comparison. } \\
\hline
\end{tabular}

